\title{
Energy metabolism in cancer patients
}

Citation for published version (APA):

Fredrix, E. W. H. M. (1990). Energy metabolism in cancer patients. [Doctoral Thesis, Maastricht University]. Maastricht University. https://doi.org/10.26481/dis.19900316ef

Document status and date:

Published: 01/01/1990

DOI:

10.26481/dis.19900316ef

Document Version:

Publisher's PDF, also known as Version of record

\section{Please check the document version of this publication:}

- A submitted manuscript is the version of the article upon submission and before peer-review. There can be important differences between the submitted version and the official published version of record.

People interested in the research are advised to contact the author for the final version of the publication, or visit the DOI to the publisher's website.

- The final author version and the galley proof are versions of the publication after peer review.

- The final published version features the final layout of the paper including the volume, issue and page numbers.

Link to publication

\footnotetext{
General rights rights.

- You may freely distribute the URL identifying the publication in the public portal. please follow below link for the End User Agreement:

www.umlib.nl/taverne-license

Take down policy

If you believe that this document breaches copyright please contact us at:

repository@maastrichtuniversity.nl

providing details and we will investigate your claim.
}

Copyright and moral rights for the publications made accessible in the public portal are retained by the authors and/or other copyright owners and it is a condition of accessing publications that users recognise and abide by the legal requirements associated with these

- Users may download and print one copy of any publication from the public portal for the purpose of private study or research.

- You may not further distribute the material or use it for any profit-making activity or commercial gain

If the publication is distributed under the terms of Article $25 \mathrm{fa}$ of the Dutch Copyright Act, indicated by the "Taverne" license above, 
Het versehijnen van dit proefschrift werd mede mogelijk gemaakt door steun van de Stichting Dr. Ir. J.H.J. van der Laar. 


\section{ENERGY METABOLISM IN CANCER PATIENTS}





\title{
ENERGY METABOLISM IN CANCER PATIENTS
}

\section{PROEFSCHRIFT}

\author{
ter verkrijging van de graad van doctor \\ aan de Rijksuniversiteit Limburg te Maastricht, \\ op gezag van de Rector Magnificus, Prof. Dr. F.I.M. Bonke, \\ volgens het besluit van het College van Dekanen, \\ in het openbaar te verdedigen op vrijdag, 16 maart 1990 om 16.00 uur \\ door \\ Elisabeth Wilhelmina Hubertina Maria Fredrix \\ geboren te Elsloo
}


Promotores:

Co-promotor:

Beoordelingscommissie:
Prof. Dr. Ir. W.H.M. Saris

Prof, Dr. P.B. Soeters

Dr. M.F. von Meyenfeldt

Prof. Dr. G.H. Blijham, voorzitter

Prof. Dr. F. ten Hoor

Prof. Dr. J M. Kinney

Prof. Dr. S. de Lange

Prof. Dr. R.I.C. Wesdorp

\section{CIP-DATA KONINKLIJKE BIBLIOTHEEK, DEN HAAG}

Fredrix, Elisabeth Wilhelmina Hubertina Maria

Energy metabolism in cancer patients/

Elisabeth Wilhelmina Hubertina Maria Fredrix.

Maastricht: Datawyse.-Ill.

Thesis Maastricht.-With ref.-With summary in Dutch.

ISBN 90-5291-019-7

SISO 605.91 UDC 616-006.6:616.3(043.3)

Subject headings: cancer and nutrition / resting energy metabolism / indirect calorimetry

(c) E.W.H.M. Fredrix

Uitgave: Datawyse, Maastricht

Druk: Krips Repro, Meppel

Financial support by Mijnhardt B.V. Bunnik NL for the publication of this thesis is gratefully acknowledged. 


\section{CONTENTS}

CHAPTER 1: Introduction

CHAPTER 2: The ventilated hood system

CHAPTER 3: Estimation of body composition by bicelectrical impedance in cancer patients

CHAPTER 4: Measurement of resting energy expenditure in a clinical setting

CHAPTER 5: Resting energy expenditure in cancer patients before and one week after gastrointestinal surgery

CHAPTER 6: Resting and sleeping energy expenditure in the elderly

CHAPTER 7: Resting energy expenditure in non-small cell lung cancer patients

CHAPTER 8: Resting energy expenditure in patients with newly detected gastric and colorectal cancer

CHAPTER 9: Resting energy expenditure in cancer patients before and one year after tumor resection

CHAPTER 10: Energy balance in relation to cancer cachexia

CHAPTER 11: General discussion and conclusions

Summary

Samenvatting

Abbreviations

Nawoord 



\section{CHAPTER 1}

INTRODUCTION

Cancer is second only to cardiovascular disease as the most frequent cause of death in Western countries (1). In the Netherlands in 1986 more than 22.000 people died from cancer. Lung cancer and breast cancer are the most common tumor types in men and women respectively. For both sexes colon cancer is second in incidence.

Progressive weight loss is the most obvious clinical manifestation of cancer cachexia. The term cachexia is derived from the Greek word $x \alpha \chi \varepsilon \xi \xi \alpha$ meaning "bad condition or health". Patients with cancer cachexia are characterized by the presence of anorexia, early satiety, severe weight loss, weakness, anaemia and edema (2). Although some types of cancer are not accompanied by significant cachexia, most cancer patients with advanced malignancies develop cachexia as a result of increased tumor burden or cancer treatment.

Already in 1932 Warren reported that death in $22 \%$ of a group of 500 cancer patients can be ascribed to extreme cachexia (3). In a study of 3047 patients with different tumor types the median survival proved to be significantly shorter in patients that have lost weight (4). It was also shown that weight loss varies greatly with tumor type. For instance, severe weight loss ( $>10 \%$ of usual body weight) is present in $4-10 \%$ of patients suffering from breast cancer or non-Hodgkin's lymphoma compared to $26-38 \%$ of patients suffering from gastric or pancreatic cancer.

Thus, the importance of cachexia as a major factor contributing to the mortality of cancer patients is clearly established. Therefore, a greater understanding of the mechanisms of cachexia and weight loss may result in a more specific and more effective intervention leading to an improvement of the quality of life. Loss of body weight in chronic disease must be predominantly due to an imbalance between energy intake (EI) and energy expenditure (EE).

Anorexia is a traditional clinical observation in cancer patients. However, anorexia is difficult to study and relatively few attempts have been made to measure food intake accurately in cancer patients. Most studies have been carried out in patients with advanced disease and revealed markedly reduced food intakes (5-8). Some studies showed a similar food intake in weight-losing cancer patients as in weightlosing controls (9-10) or weight-stable patients (11). In hypermetabolic cancer patients an apparently normal $\mathrm{EI}$ is rellatively low with respect to $\mathrm{EE}(12,13)$. Only a few studies have been performed in patients in the early phase of weight loss. In cancer patients admitted for surgical treatment anorexia was found more frequently in patients with gastric cancer than with colorectal cancer and a $50 \%$ reduction in EI 
was found in anorectic patients in both malignancies (14). Althought anorexia certainly contributes to the observed weight loss, it does not fully explain the problem of cancer cachexia. Patients with cancer may lose weight even with an apparently adequate EI.

An increased $E E$ has been observed in tumor-bearing animals almost immediately after tumor transplantation $(15,16)$. However, it is questionable whether the results obtained in these controlled animal studies may apply to the clinical situation where many variables cannot be controlled.

Pettenkofer and Voit in 1869 were the first to document abnormally high oxygen consumption and carbon dioxide production in a patient with leukemia (17). Wallersteiner in 1914 was the first investigator who studied systematically EE in a group of afebrile patients with advanced cancer (18). In 1954 Fenninger and Mider listed in a review a number of studies that demonstrated an increased metabolic rate in patients with carcinoma of the stomach, leukemia and various other malignancies (17). In 1977, Young reviewed these and other studies and concluded that because of limited information in many papers and because of multiple factors that affect energy metabolism it is not certain that resting energy expenditure (REE) is consistently increased in patients with cancer (19).

A resurgence of interest in the measurement of $E E$ by indirect calorimetry occurred in the 1970 s (20). The renewed interest in energy metabolism resulted from the increased use of totall parenteral nutrition (TPN) and the introduction of equipment allowing measurement of $\mathrm{EE}$ at the bedside. As a consequence $\mathrm{EE}$ has been studied in cancer patients. The results of these studies yield conflicting answers, however, to the question whether an increased EE contributes to weight loss of cancer patients $(9,12,13,21-27)$. Different techniques of measurement may account for differences between several studies. Furthermore, small numbers of patients with different tumor types and unspecified stages in their disease are studied. Many patients had already undergone some form of therapy. Another reason for the conflicting results may be that many studies are poorly controlled, data from patients are compared with data from inadequate control subjects (25) or no control data are offered at all (21).

Knox et al measured a heterogeneous group of malnourished cancer patients and found that $60 \%$ had an abnormal REE with no uniform trend to hypermetabolism (28). Dempsey et al presented one year later the results in a relatively homogeneous group of malnourished gastrointestinal cancer patients (29). They compared measured REE with predicted EE from the Harris Benedict (HB) equation (30). Fifty-eight percent of the patients had an abnormal REE, $36 \%$ were hypometabolic 
and $22 \%$ hypermetabolic. In recent years, however, the number of papers with criticism on the use of the HB formula in elderly patients is growing (31-34).

In recent studies REE of cancer patients was compared with REE of control groups of healthy subjects and patients with nonmalignant diseases $(10,35,36)$. These studies suggest that REE is generally not increased $(10,36)$. However, there are still data indicating a small but significant increase of REE in a considerable number of cancer patients (35). An additional problem in this respect is the measurement of body composition in order to normalize REE for fat free mass (FFM). Most methods are less suitable in patients (37).

In addition to comparing REE with a standard (like the HBB equation) or with specified control groups, the influence of the presence of a malignant tumor on energy metabolism of the host may be measured by performing REE measurements in cancer patients before and after surgical resection of the tumor. Although in only a few studies tumor mediated thermogenesis was investigated in this manner, results from these studies consistently show a fall in REE after curative treatment $(12,21,27)$.

It has been suggested that different tumor types influence REE differently. Dempsey et al found that not all gastrointestinal tumors affect host metabolism in the same way (29). Patients with pancreatic and hepatobiliary tumors tended to be hypometabolic, while patients with stomach cancer tended to develop hypermetabolism. Hansell et al found lung cancer patients to have a higher REE than gastric and colorectal cancer patients, but only when REE is expressed relative to body weight (38). Nixon et al found that REE of women with lung cancer was significantly higher than REE of anorexia nervosa patients (36).

Although the results of studies addressing $\mathrm{EE}$ in cancer patients vary from no change or even a small decrease in energy metabolism to an increase of up to $30 \%$, it is an important observation that weight-losing patients show no adaptation to semi-starvation, whereas the normal adaptive response to a reduced EI and weight loss is a decrease in EE (39). Therefore, even when normal values for REE are found they may be considered inappropriately high in weight-losing cancer patients.

While reviewing the literature it appears that the cause of a negative energy balance in cancer patients could be partly the result of increased EE and of failure to adapt to semi- starvation. However, more clinical studies are needed for several reasons.

- It is still unclear whether the weight loss of cancer patients is primarily due to reduced food intake, increased $\mathrm{EE}$, or a combination of the two.

- It is generally accepted that REE has to be referred to FFM. An easy and reliable method for measuring body composition in patients is needed. 
- Because the measurement of total EE is difficult, in most studies REE is measured which is the major determinant of total $\mathrm{EE}$ in hospitalized patients. The standardized conditions that are necessary to measure REE in a clinical setting, however, are still not completely elucidated.

- The use of standards (like the HB equation) for interpreting REE in cancer patients is questionable. It seems preferable to compare REE of cancer patients with REE of non-cancer controls. In additon, tumor mediated thermogenesis has to be studied by performing REE measurements in cancer patients before and after surgical resection of the tumor.

- The question whether tumor type is an important determinant of EE deserves more attention.

- Little is known about aberrations in energy metabolism in cancer patients in the early phase of disease.

- It is suggested that cancer patients with an apparently normal EE have to be considered relatively hypermetabolic, because they fail to adapt to a reduced EI and weight loss by reduction in REE. This phenomenon also needs to be examined in more detail.

\section{Qutline of this thesis}

First a description of the ventilated hood system is given (chapter 2). This system is constructed for measuring REE in patients in a clinical setting. Body compositon is measured by bioelectrical impedance. This new technique is validated in cancer patients using deuterium dilution as a reference method (chapter 3). REE is measured in the morning under standardized conditions, i.e. the patient remaining in his bed, in the postabsorptive state. However, normal hospital routine does not allow such a rigid schedule for measurement of REE. Therefore, additional information on the influence of food intake, physical activity and moment of the day on REE measurement is needed. The influence of these factors and of TPN on EE is studied in chapter 4. Special attention is given to the impact of surgical trauma on energy metabolism (chapter 5). The following chapters are devoted to the main question whether an elevated REE contributes to the development of cancer cachexia. Patients with a recent diagnosis of gastric and colorectal cancer and non-small cell lung cancer were studied. None of these patients had been treated previously. REE of these cancer patients is compared with REE of a group of apparently healthy elderly controls. Chapter 6,7 and 8 present the results of the REE measurements in healthy controls, lung and gastric and colorectal cancer patients, respectively. In chapter 9 the hypothesis of tumor mediated thermogenesis is studied by repeating the REE measurement approximately one year after tumor resection in cancer patients that survived. Finally, in a small group of patients the contribution of a reduced $\mathbf{E l}$ to the development of cancer cachexia is investigated (chapter 10). 


\section{REFERENCES}

1. CBS. Statistisch zakboek 1988. "s-Gravenhage: Staatsuitgeverij 1988.

2. Calman KC. Cancer cachexia. Br J Hosp Med 1982;26:28-34.

3. Warren $\mathrm{S}$. The immediate causes of death in cancer. Am J Med Sci 1932;184:610-615.

4. DeWys WD, Begg C, Lavin PT et al. Prognostic effect of weight loss prior to chemotherapy in cancer patients. Am J Med 1980;69:491-497.

5. Theologides A, Ehlert J, Kennedy BJ. The calorie intake of patients with adtvanced cancer. Minn Med 1976;59:526-529.

6. Costa $G$, Lyles $K$, Ullrich $L$. Effects of human and experimental cancer on the conwersion of ${ }^{14} \mathrm{C}$ tripalmitin to ${ }^{14} \mathrm{CO}_{2}$. Cancer 1976;38:1259-1265.

7. Cohn SH, Gartenhaus W, Vartsky D et al. Body composition and dietary intake in neoplastic disease. Am J Clin Nutr 1981;34:1997-2004.

8. Walsh TD, Bowman KB, Jackson GP. Dietary intake of advanced cancer patients. Hum Nutr:Appl Nutr 1983;37A:41 45 .

9. Burke M, Bryson EI, Kark AE. Dietary intakes, resting metabolic rates, and body composition in benign and malignant gastrointestinal disease. Br Med J 1980;1:21 1-215.

10. Hansell DT, Davies JWL, Burns HJG. The relationship between resting energy expenditure and weight loss in benign and malignant disease. Ann Surg 1986;203:240-245.

11. Costa G, Bewley P, Aragon M, Siebold J. Anorexia and weight loss in cancer patients. Cancer Treat Rep 1981;65 (suppl);3-7.

12. Warnold I, Lundholm K, Schersten T. Energy balance and body composition in cancer patients. Cancer Res 1978;38:1801-1807.

13. Russell DMcR, Shike M, Marliss EB et al. Effects of total parenteral nutrition and chemotherapy on the metabolic derangements in small cell lung cancer. Cancer Res 1984; 44:1706-1711.

14. Meyenfeldt MF von, Visser G, Buil-Maassen R, Soeters PB, Wesdorp RIC. Food intake and nutritional status in patients with newly detected gastric or colorectal cancer. Clin Nutr $1988 ; 7: 85-91$

15. Pratt AW, Pumey FK. Observations on the energy metabolism of rats receiving Walker 256 transplants. J Nat Cancer Inst 1958;20:173-187.

16. Theologides A. Pathogenesis of cachexia in cancer. A review and a hypothesils. Cancer $1972 ; 29: 484-487$.

17. Fenninger $L D$, Mider GB. Energy and nitrogen metabolism in cancer. Adv Cancer Res 1954;2:229-252.

18. Wallersteiner E. Untersuchungen über das Verhalten von Gesamistoffwechsel und Eiweissumsatz bei Carcinomatösen. Disch Arch Klin Med 1914;116:145-187.

19. Young VR. Energy metabolism and requirements in the cancer patient. Cancer Res 1977;37:2336-2347.

20. Kinney JM. Food as fuel: The development of concepts. Ini: ME Shils, Young VR, eds. Modern nutrition in health and disease. Philladelphia: Lea\& Febiger 1988.

21. Bozzeti F, Pagnoni AM, Del Vecchio M. Excessive caloric expenditure as a cause of malnutrition in patients with cancer. Surg Gymecol Obstet 1980;150:229-234. 


\section{chapter I}

22. Edstron 5, Bennegard $K$, Eden $E$, Lundholm $K$. Energy and tissue metabolism in patients with cancer during nutritional support. Arch Otolaryngol 1982;108:697-699.

23. Heber D, Byerley LO, Chi $J$ el al. Pathophysiology of malnutrition in the adult cancer patient. Cancer 1986;58:1867-1873.

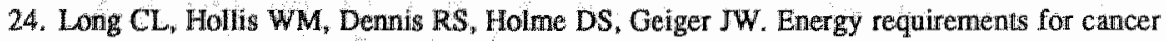
patients. Cancer Bull 1982,34:155-162.

25. Macfie I, Burkinshaw L, Oxby C, Holmfield JHM, Hill GL. The effect of gastrointestinal malignancy on resting metabolic expenditure. Br I Surg 1982;69:443-446.

26. Axelrod L, Halter JB, Cooper DS, Aoki TT, Roussell AM, Bagshaw SL. Hormone levels and fuel flow in patients with welght loss and lung cancer. Evidence for excessive metabolic expendinure and for an adaptive response mediated by a reduced level of $3,5,3^{\prime}$-triiodothyronine. Metabolism 1983;32:924-937.

27. Arbeit MM, Lees DE, Corsey $R$, Brennan MF. Resting energy expenditure in controls and cancer patients with localized and diffuse disease. Ann Surg 1984;199:292-298.

28. Knox L.s. Crosby LO, Feurer ID et al. Energy expenditure in malnourished cancer patients. Ann Surg 1983;197:152-162.

29. Dempsey DT, Feurer ID, Knox LS, Crosby LO, Buzby GP, Mullen JL. Energy expenditure in malnourished gastrointestinal cancer patients. Cancer 1984:53:1265-1273.

30. Harris JA, Benedict FG. A biometric study of basal metabolism in man. Publication no 279. Washington DC: Carmegie Institute of Washington 1919.

31. Roza AM, Shizgal HM. The Harris Benedict equation reevaluated: resting energy requirements and the body cell mass. Am J Clin Nutr 1984;40:168-182.

32. Feurer ID, Crosby LO, Mullen JL. Measured and predicted resting energy expenditure in clinically stable patients. Clin Nutr 1984,3:27-34.

33. Daly JM, Heymsfield SB, Head A, et al. Human energy requirements: overestimation by widely used prediction equation. Am J Clin Nutr 1985;42: 1170-1174.

34. Owen $\mathrm{OE}$, Holup $\mathrm{LL}_{\text {. }} \mathrm{D}^{\prime}$ Alessio DA, et all. A reappraisal of the caloric requirements of men. Am J Clin Nutr 1987;46:875-885.

35. Lindmark L, Bennegard $K$, Edén $E$ et al. Resting energy expenditure in malnourished patients with and without cancer. Gastroenterology 1984;87:402-408.

36. Nixon DW, Kutner M, Heymsfield $\mathrm{S}$ et al. Resting energy expenditure in lung and colon cancer. Metabolism 1988;37:1059-1064.

37. Lukaski HC. Methods for the assessment of human body composition: traditional and new. Arn J Clin Nutr 1987;46:537-556.

38. Hansell DT, Davies JWL, Burns HJG. The effects on resting energy expenditure of different tumor types. Cancer 1986;58:1739-1744.

39. Bremnan MF. Uncomplicated starvation versus cancer cachexia. Cancer Res 1977;37:23592364. 


\section{CHAPTER 2}

\section{THE VENTLLATED HOOD SYSTEM}

EWHM Fredrix, PFM Schoffelen, JJ Wouters, WHM Saris

From the Department of Human Biology, University of Limburg, PO Box 616 , 6200 MD Maastricht, The Netherlands

Techniques for measurement of energy expenditure $(\mathbb{E E})$ are necessary in clinical studies of metabolism. Determination of $\mathrm{EE}$ by using the principles of indirect calorimetry has been facilitated by the availability of a number of gas exchange measurement devices. In this study a computerized open-circuit ventilated hood system is described, constructed for assessing resting energy expenditure (REE) in patients in a clinical situation. The principle of a ventilated hood system is, that a stream of air is forced to pass across the face of a subject and mixes with the expired air, which is collected by a transparent plexiglas hood placed over the subject's head. The rate of $\mathrm{EE}$ can be calculated by determining the amount of air flowing through the hood and by measuring the oxygen $\left(\mathrm{O}_{2}\right)$ and the carbon dioxide $\left(\mathrm{CO}_{2}\right)$ concentrations in the incoming and outcoming air. Figure 1 gives a schematic representation of the system used in the University Hospital of Maastricht.

The canopy has a volume of $30 \mathrm{~L}$ and is made up of two parts: a square open box with three edges and a clear plexiglas globe. The patient lies with the head on the pillow in the box and the globe fits over the patient's head on top of the box. A piece of soft material is placed around the patient's neck and a piece of thin plastic connects the globe with the neck piece. This connecting piece is secured with velcro strips.

Through the hood with an air inlet in front and an air outlet at the top of the hood room air is drawn by negative pressure created by a pump downstream (Mijnhardt, Bunnik). Airflow through the hood is measured in the outlet airstream by a dry gasmeter (G6, Meterfabriek Schlumberger, Dordrecht). The dry gasmeter used is calibrated with a Blakeslee piston pump with mercury seals (Dierfysiologie, Landbouwuniversiteit Wageningen). A humidity sensor (Rotronic Hygroskop BT, Tamson, Zoetermeer) and a temperature sensor (Mijnhardt, Bunnik using the AD590) are also incorporated; ambient pressure has to be typed in and is obtained from Airport Maastricht corrected for difference in altitude. Gas temperature is measured in the gasmeter and relative humidity after the gasmeter. Flow readings of the gasmeter are converted to STPD (standard temperature pressure dry) conditions. Downstream to the flow measurement a small quantitiy $(0.1 \mathrm{~L} / \mathrm{min})$ of air is continuously withdrawn for gas analysis. Before gas analysis the sample is 
chapter 2
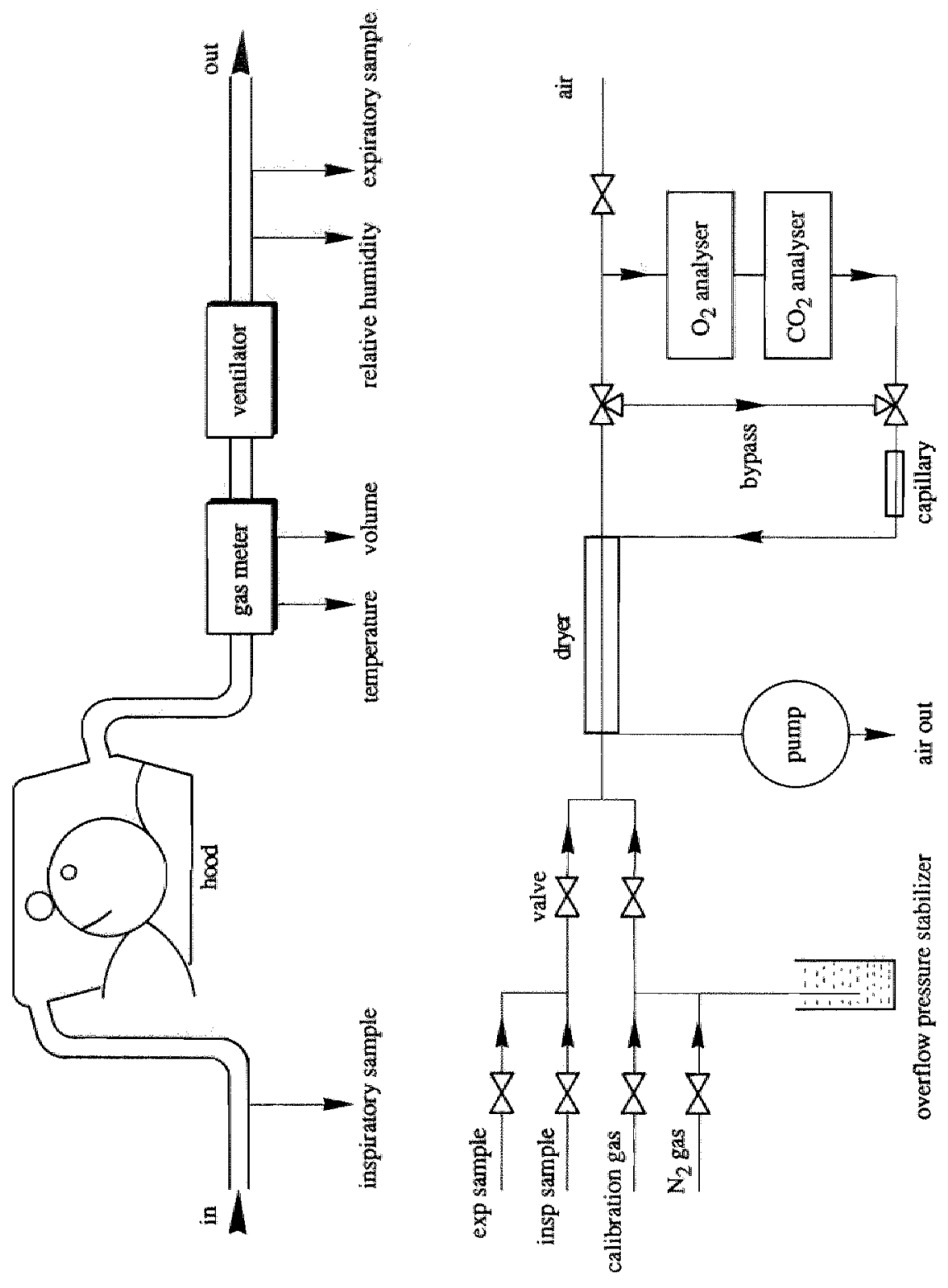

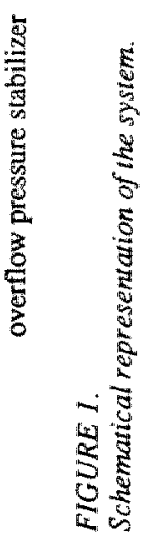


dried (Perma pure mini dryer MD, Inacom instruments $\mathrm{BV}$, Veenendaal) and sample pressure is stabilized for analysis. Through a system of computer-driven solenoid valves (Kühnke, West-Germany) sample gas is obtained from either the ventilated hood, calibration gases or room air upstream of the canopy. The $\mathrm{O}_{2}$ analyser (Mijnhardt module, Bunnik) is placed at the outlet of the $\mathrm{CO}_{2}$ analyser (modified UG51, Mijnhardt, Bunnik). Every minute one type of gas is measured. Only the last $10 \mathrm{~s}$ of data are valid due to time constants in analysers and sample system. Gas analysis is performed with, respectivelly, a paramagnetic $\mathrm{O}_{2}$ anallyser with full-scale range of 100 percent and an infrared $\mathrm{CO}_{2}$ analyser with a full-scale range of 2 percent. The $\mathrm{O}_{2}$ - and $\mathrm{CO}_{2}$ analysers are accurate to 0.05 and 1 percent of full-scale, respectively. Accuracy is improved by linearizing the $\mathrm{CO}_{2}$ analyser data and by averaging data in the computer. Analysers are calibrated using two dry calibration gases. Zero settings are performed by passing 100 percent nitrogen through the analysers $(0.1 \mathrm{~L} / \mathrm{min})$. The span of the $\mathrm{O}_{2}$ and $\mathrm{CO}_{2}$ analysers is set by passing a special gas mixture $\left(0.8 \pm 0.01 \% \mathrm{CO}_{2}\right.$ and $19.0 \pm 0.01 \% \mathrm{O}_{2}$ in $\left.\mathrm{N}_{2}\right)$ through the analyser. This calibration gas is also analysed chemically using the modified Sonden technique. The equipment is calibrated with both calibration gases at the start and end of every experiment and every half hour during long experiments. Canopy gassampling is every two minutes, with measurement of $\mathrm{O}_{2}$ and $\mathrm{CO}_{2}$ concentrations of the outlet air every even minute and gas concentrations of the inlet air every odd minute.

In adult patients, flow rates between $25-50 \mathrm{~L} / \mathrm{min}$, depending on body size are used. The flow through the canopy is adjusted to keep $\mathrm{CO}_{2}$ readings in the range of 0.50 to 0.80 percent. In the canopy a mixing process takes place. The $\mathrm{CO}_{2}$ concentration increases during exhaling and is mixed with the air in the canopy. The flow is directed over the face of the patient to remove exhaled $\mathrm{CO}_{2}$ immediately. Flow adjustments are made before the experiment is started. The flow is kept constant during the experiment. REE is measured at rest in the supine position during half an hour.

Central part of the whole system is an Apple//e microcomputer, which controls the system and performs the calculations. Output voltage signals of the $\mathrm{O}_{2}$ and $\mathrm{CO}_{2}$ analysers, the humidity and temperature sensors are measured and digitized by a data-acquisition interface (Mijnhardt, Bunnik using a 12-bit AD converter). The gasmeter pulse output is digitally counted in the computer giving a continuous flow measurement. Gas concentration measurements are taken during $10 \mathrm{~s}$ of every minute. The computer calculates and prints the values of $\mathrm{O}_{2}$ consumed, $\mathrm{CO}_{2}$ produced, the respiratory quotient and the rate of EE over the whole experimental period. EE is calculated using the abbreviated Weir formula (1), which is used because of the difficulty of obtaining routine accurate 24 -h urine collections from every patient. This formula deletes the factor necessary to adjust for incomplete protein oxidation. This results in a $2 \%$ error in the final calculation of EE in normal 


\section{chapter 2}

individuals (2). For a limited number of patients in the present thesis 24-h urine collections were obtained. Calculation of EE with the abbreviated Weir formula here also resulted in a measurement error of less than $2 \%$, because 24 -h urine $N$ values were within the normal range.

Weir formula: $\mathrm{EE}(\mathrm{kcal})=3.9 * \mathrm{~L} \mathrm{O}_{2}$ consumed $+1.1 * \mathrm{~L} \mathrm{CO}_{2}$ produced

A first ventilated hood system was built in 1984. After some improvements the above-described system was used for all studies in this thesis.

The whole system was tested by injecting a small quantitiy of $100 \% \mathrm{CO}_{2}$ into the canopy while measuring the weight reduction of the $\mathrm{CO}_{2}$ gas bottle, thus giving the exact amount of gas injected. In 25 experiments (duration $\leq 3 \mathrm{~h}) \mathrm{CO}_{2}$ was overestimated with $2.0 \pm 2.9 \%$. Furthermore, the ventilated hood system was tested in humans in an indirect calorimeter (size $14 \mathrm{~m}^{3}$ ) that had both chemical and physical gas analysis. In six experiments (duration $\geq$ two hours) $\mathrm{CO}_{2}$ production was overestimated by $3.6 \pm 1.4 \%, \mathrm{O}_{2}$ consumption was underestimated by $0.6 \pm 6.6 \%$, and consequently EE was overestimated by $0.1 \pm 5.5 \%$.

\section{REFERENCES}

1. Weir $\mathrm{SB}$. New methods for calculating metabolic rate with special reference to protein metabolism. I Physiol 1949;109:1-9.

2. Wilmore JH, Davies JA, Norton AC. An automated system for assessing metabolic respiratory function during exercise. I Appl Physiol 1976;40:619-624. 


\section{CHAPTER 3}

ESTIMATION OF BODY COMPOSITION BY BIOELECTRICAL IMPEDANCE IN CANCER PATIENTS

EWHM Fredrix; WHM Saris; PB Soeters; ADM Kester; MF von Meyenfeldt; EFM Wouters; KR Westerterp

From the Department of Human Biology, Surgery, Pulmonary Diseases and Medical Informatics and Statistics, University of Limburg, PO Box 616 , 6200 MD Maastricht, The Netherlands

submitted for publication

\section{SUMMARY}

Measurement of body composition is itiportant in the assessment of nutritional status in cancer patients. The purpose of this study was to validate the bioelectrical impedance (BI) method for body composition estimation in 33 elderly cancer patients using the deuterium dilution technique $\left({ }^{2} \mathrm{H}_{2} \mathrm{O}\right)$ as the reference method. Height $2 /$ resistance $\left(\mathrm{H}^{2} / \mathrm{R}\right)$ correlated significantly with total body water computed from ${ }^{2} \mathrm{H}_{2} \mathrm{O}(\mathrm{r}=0.89, \mathrm{p}<0.001 ; \mathrm{SE}$ of estimate $=2.4 \mathrm{l})$. The prediction equation for fat free mass ( $F F M$ ) improved significantly $\left(\mathrm{p}<0.001\right.$ ) by addition of $H^{2} / \mathrm{R}$ to the predictor variables weight, height, age and sex. We conclude that $\mathrm{BI}$ seems a useful measure for the assessment of FFM in cancer patients.

\section{INTRODUCTION}

Body composition is an important measure in the assessment of nutritional status in both normal individuals and patients. There are many methods available to estimate body composition (1). However, only a few can be used in clinical situations. One of them is the relatively new bioelectrical impedance (BI) method. The principle of this method is based upon the conductance of an electrical current through body fluids. Conductivity is far greater in the fat free mass (FFM) which contains virtually all the water and conducting electrolytes than in the fat mass. Hoffer et al defined a relationship between total body water (TBW) or FFM and height ${ }^{2} /$ resistance $\left(\mathrm{H}^{2} / \mathrm{R}\right)(2)$. Several recent studies demonstrated good correlations between $\mathrm{H}^{2} / \mathrm{R}$ and $\mathrm{TBW}$ measured by isotope dilution or densitometrically determined FFM (3-8). However, these validation studies are usually based on measurements in young healthy volunteers. Therefore, this technique needs validation in patients who sometimes show rapid changes in body composition. 
In this study we evaluated the use of the BI method in cancer patients with the deuterium dilution technique $\left(\mathrm{H}_{2} \mathrm{O}\right)$ as the reference method.

\section{METHODS}

Thirty-three patients with histologically proven gastrointestinal cancer or lung cancer participated in the study. All patients were ambulatory and recently admitted to the Department of Surgery, Internal Medicine or the Department of Pulmonary Diseases of the University Hospital of Limburg, Maastricht. All patients had newly detected cancer, so that no patient had received previous chemotherapy or radiation therapy. The patients were informed about the nature and purpose of the study and all gave their consent.

Body composition was measured by $\mathrm{BI}$ and by ${ }^{2} \mathrm{H}_{2} \mathrm{O}$. BI was measured with a

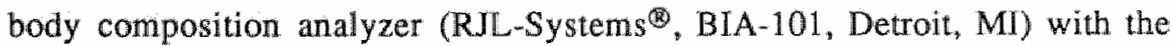
patient in the supine position as described by Lukaski et al (3). TBW was determined as follows: a standard dose of $5 \mathrm{~g}^{2} \mathrm{H}_{2} \mathrm{O} 00.84$ atom percentage excess weighted to $0.01 \mathrm{~g}$ in $\approx 50 \mathrm{~mL}$ water was administered orally and the container was rinsed once with $\approx 50 \mathrm{~mL}$ tap water which was also drunk. Isotope enrichment of the urine was measured using an isotope ratio mass spectrometer (type Aqua Sira, $V G$ Isogas). Urine was collected before and during 3-5 h after oral ${ }^{2} \mathrm{H}_{2} \mathrm{O}$ administration. Most subjects voided their bladders at least once between administration of the ${ }^{2} \mathrm{H}_{2} \mathrm{O}$ and the postdose urine sample. TBW was calculated as the isotope dilution space divided by 1.04, correcting for exchange of the deuterium label with nonaqueous hydrogen of body solids (9). The water content of the FFM was assumed to be $73 \%$.

After an overnight fast patients came to our metabolic ward where measurement of BI and TBW were both performed on the same morning. Percentage ideal body weight (PIBW) was computed from body height $(\mathrm{cm})$, body weight ( $\mathrm{kg})$ and wrist circumference $(\mathrm{cm})(10)$. Weight loss was calculated as the difference between reported pre-illness body weight minus actual body weight.

Statistical evaluation of the results was performed using Pearson correlation and multiple regression analysis. Results are presented as mean $\pm S D$ and $p$-values $<$ 0.05 are regarded as statistically significant.

\section{RESULTS}

Twenty-six men and sewen women were included in the study (Table 1). Eighteen patients had gastrointestinal cancer (two gastric and 16 colorectal), and 15 had non-small cell lung cancer. Mean PIBW was $101 \%$ and mean weight loss amounted to $4.9 \%$. 
TABLE 1.

Patient characteristics.

\section{age (y)}

body weight $(\mathrm{kg})$

PIBW (\%)

weight loss (\%)

sex (male/female)

tumor localisation (G//L)
$66 \pm 9$

$69.1 \pm 10.7$

$101 \pm 12$

$4.9 \pm 5.1$

$26 / 7$

$18 / 15$

Mean values tSD

PIBW=percentage ideal body weight; $\mathrm{Gl}=\mathrm{g}$ astrointestinal; $\mathrm{L}=$ non-small cell lung

A significant correlation was found between TBW and $\mathrm{H}^{2} / \mathrm{R}(\mathrm{r}=0.89 ; \mathrm{p}<0.001)$ (Figure 1). The slopes and intercepts of the regression lines for TBW and $\mathrm{H}^{2} / \mathrm{R}$ for men and women were statistically not different. Both men and women showed a significant correlation between TBW and $\mathrm{H}^{2} / \mathrm{R}$ (males: $\mathrm{r}=0.84, \mathrm{p}<0.001$; females: $r=0.80, p<0.05)$. The best single predictor of FFM was $\mathrm{H}^{2} / \mathrm{R}(\mathrm{r}=0.89)$, followed by resistance $(r=-0.70)$, height $(r=0.69)$, body weight $(r=0.64)$ and sex $(r=0.62)$. All these correlations were statistically significant $(p<0.001)$.

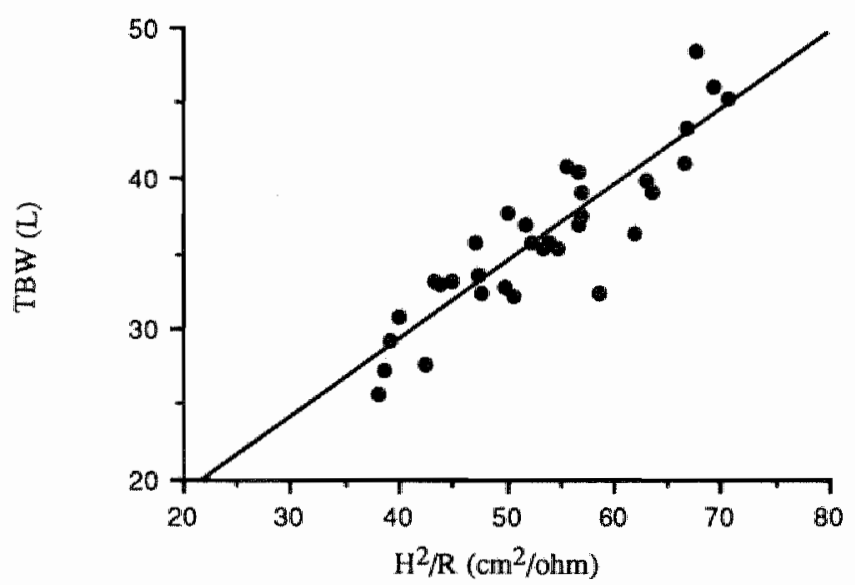

FIGURE I.

Correlation between tolal body water (TBW) and height ${ }^{2}$ resistance $\left(H^{2} / R\right)$ in cancer patients $(r=0.89, p<0.001 ; S E$ of estimate $=2.4 \mathrm{~L})$. 
The addition of $\mathrm{H}^{2} / \mathrm{R}$ to a set of possible predictor variables for FFM (weight, height, age and sex) improved the explained variance $\left(R^{2}\right)$ significantly $(p<0.001)$ (Table 2). The prediction equation for FFM in which weight, height, age and sex were not included was only borderline significantly different from the prediction equation including all variables $(\mathrm{p}=0.06)$.

TABLE 2.

Possible prediction variables for estimation of fat free mass in cancer patients.

\begin{tabular}{|c|c|c|c|c|c|}
\hline prediction variables & multiple $\mathrm{R}^{2}$ & RMS & $d f$ & F-ratio & $p$-value \\
\hline A. $H^{2} / \mathrm{H}$ & 0.79 & 11.1 & 31 & vs C: 2.6 & 0.06 \\
\hline \multicolumn{6}{|l|}{ B. weight, height, } \\
\hline age, sex & 0.76 & 12.9 & 28 & vs C: 12.6 & $<0.001$ \\
\hline C. weight, helght, & $O P 2$ & 01 & 27 & & \\
\hline
\end{tabular}

$\mathrm{A}^{2}$ wexplained varianco; $\mathrm{PMS}=$ residual mean square; df=degrees of freedom $\mathrm{H}^{2} / \mathrm{R}=$ hivight ${ }^{2}$ /resistance

\section{DISCUSSION}

The BI method seems to be an appropriate method to estimate body composition of healthy individuals. However, the validity of the method in patients requires further investigation (11).

Katch et al found that the BI method was not valid for estimating the body composition in cardiac and pulmonary patients (12). The correlation coefficient between percent fat from densitometry and percent fat from BI was 0.39 with a SE of estimate of 5.6 percent fat. Kushner and Schoeller measured body composition in patients with inflammatory bowel disease and diabetes and found no significant difference between TBW calculated from BI or measured from isotope dilution; the correlation coefficient was in the range 0.93-0.97 (5).

In the current study a good correlation between $\mathrm{H}^{2} / \mathrm{R}$ and TBW measured by $2 \mathrm{H}_{2} \mathrm{O}$ was found in patients, which agrees with the results of others in healthy individuals $(3-5,7) . \mathrm{H}^{2} / \mathrm{R}$ was the best single predictor of FFM, which also agreed with other studies (3-6). However, Segal et al found that $R$ and $H^{2}$, individually, were better predictors of FFM than $H^{2} / R(8)$. It has been suggested that predictive equations must be more influenced by the $\mathrm{H}^{2} / \mathrm{R}$ term than by the anthropometric terms to proof the value of the BI method (5). Recent studies have questioned the advantage of the BI method over simple anthropometric measurements and have suggested that the high correlations reported between BI and body composition 
parameters is due to the inclusion of height, weight or other subject characteristics (sex, age) in the prediction equation $(13,14)$. In the current study, however, it was demonstrated that the prediction equation for FFM improved significantly when $\mathrm{H}^{2} / \mathrm{R}$ was added as a predictor variable. Furthermore, when the predictor variables weight, height, age and sex were omitted, the explained variance decreased by only $4 \%$.

It should be emphasized that the development of a new method for the assessment of body composition in humans is hampered by the lack of an accurate in vivo reference method. An important limitation of ${ }^{2} \mathrm{H}_{2} \mathrm{O}$ is the need to accept a value for the water content of FFM, which is generally assumed to be $73 \%$. However, in a population of cancer patients exhibiting weight loss the hydration coefficient may be increased (15). For some patients with a significant weight loss FFM may, therefore, be overestimated. Moore et al have shown that the coefficient of hydration can be more precisely defined if the ratio of TBW and extracellular fluid is known (16). In the current study, however, the amount of intra-cellular and extra-cellular water was not measured.

The results suggest that in comparison with anthropometric measures (weight, height) and subject characteristics (age, sex) impedance measurements have a small but significant additional value in the prediction of body composition in cancer patients. Therefore, it is concluded that BI is a promising method for the assessment of FFM in clinical practice.

\section{REFERENCES}

1. Lukaski HC. Methods for the assessment of human body composition: traditional and new. Am J Clin Nutr 1987;46:537-556.

2. Hoffer EC, Meador CK, Simpson DC. Correlation of whole-body impedance with total body water volume. J Appl Physiol 1969:27:531-534.

3. Lukaski HC, Johnson PE, Bolonchuk WW, Lykken GI. Assessment of fat-free mass using bicelectrical impedance measurements of the human body. Am J Clin Nutr 1985;41:810-817.

4. Segal KR, Gutin B, Presta E, Wang J, Van Itallie TB. Estimation of human body composition by electrical impedance methods: a comparative study. J Appl Physitol $1985 ; 58: 1565-1571$.

5. Kushner RF, Schoeller DA. Estimation of total body water by bioelectrical impedance analysis. Am IClin Nutr 1986;44:417-424.

6. Lukaski HC, Bolonchuk WW, Hall CB, Siders WA. Validation of tetrapolar bioelectrical impedance method to assess human body composition. J Appl Physiol 1986:60:1327-1332.

7. Van Loan M, Mayclin P. Bioelectrical impedance analysis: Is it a reliable estimator of lean body mass and total body water? Human Biology 1987;59:299-309. 
8. Segal KR, Van Loan M, Fitzgerald PI, Hodgdon JA, Van Itallie TB. Lean body mass estimation by bioelectrical impedance analysis: four-site cross-validation study. Am J Clin Nutr 1988:4777-14.

9. Schoeller DA, Santen E van, Peterson DW, Dietz W, Jaspan J, Klein PD. Total body water measurement in humans with ${ }^{18} \mathrm{O}$ and ${ }^{2} \mathrm{H}$ labeled water. Am J Clin Nutr 1980;33:2686 2693.

10. Metropolitan Life Insurance Company Desirable weights for men: desirable weights for women. Stat. Bul. no. 23 and 24. New York: Life Extension Institute 1943.

11. Cohn SH. How valid are bioelectrical impedance measurements in body composition studies? Am J Clin Nutr 1985;42:889-890.

12. Katch FI, Solomon RT, Shayevits $M$, Shayevitz B. Validity of bioelectrical impedance to estimate body composition in cardiac and pulmonary patients. Am J Clin Nutr 1986;43:972 978.

13. Diaz EO. Villar J, Immink M, Gonzales T. Bioimpedance or anthropometry? Eur J Clin Nutr $1989 ; 43: 129-137$.

14. Deurenberg P, Kooy K van der. Bioelectrical impedance or anthropometry? Eur J Clin Nutr $1989 ; 43: 503-504$.

15. Cohn SH, Ellis KJ, Vartsky A, Gartenhaus W, Yasumura S, Vaswani AN. Comparison of methods of estimating body fat in normal subjects and cancer patients. Am J Clin Nutr $1981 ; 34: 2839-2847$.

16. Moore FD, Oleson KH, McMurrey JD, Parker HV, Ball MR, Boyden CM. The body cell mass and its supporting environment. Philadelphia, London: WB Saunders\&Company 1980. 


\title{
CHAPTER 4
}

\section{MEASUREMENT OF RESTING ENERGY EXPENDITURE IN A CLINICAL SETTING}

\author{
EWHM Fredrix; PB Soeters; MF von Meyenfeldt; WHM Saris
}

From the Department of Human Biology and Surgery, University of Limburg, PO Box 616,6200 MD Maastricht, The Netherlands

\section{accepted in Clinical Nurrition}

\section{SUMMARY}

In this study indirect calorimetry for the measurement of a patient's resting energy expenditure (REE) was assessed in clinical practice. REE measured early in the morning after an overnight fast was highly reproducible. REE measured in the afternoon, when patients had consumed their meals, was $15 \%$ higher than REE measured in the morning. REE measured at mid-morning was not different from that measured early in the moming, except for patients who had breakfast between the two measurements. Therefore, to avoid the effect of diet-induced thermogenesis in the measurement a patient must be measured in the morning in the postabsorptive state. Variations because of limited physical activities may be neglected, including a short travel from home to the hospital, which implies that REE may be measured on an outpatient basis. The effect of total parenteral nutrition on energy expenditure was a $12 \%$ increase. The respiratory quotient (RQ) rose to almost 1.0 . Nine days of enteral nutritional support showed only a $3 \%$ increase in REE, while RQ increased from 0.78 to 0.87 , indicating restored glycogen stores.

\section{INTRODUCTION}

Many hospitalized patients receive nutritional support. Therefore, the estimation of energy needs is a fundamental concern of the clinician. The delivery of too few or too many calories may result in adverse clinical effects (1-3). In the past energy requirements were mostly based on a prediction of resting energy expenditure (REE) with formulas like the Harris Benedict (HB) equation (4). Nowadays, there is a growing trend to estimate energy requirement by indirect calorimetry.

Although metabolic rate is generally assumed to be relatively constant, few data exist with regard to the within-patient variability of REE in a clinical setting. Several factors are involved which may influence metabolic rate, such as clinical condition, nutritional status, food intake and physical activity. Most of them are of importance in the daily clinical routine. In this study we therefore addressed the following questions: 
1. Is the REE measurement reproducible in stable hospitalized patients? If, indeed, the measurement would be reproducible, it would imply that one measurement would be adequate to calculate a patient's energy requirements.

2. What is the influence of hospital meals and routine physical activity on the REE measurement?

If REE would still be increased a few hours after a meal or after routine physical activities, it would imply that REE may not be measured at any time of the day and that measurements require standardized postabsorptive conditions.

3. How is energy expenditure (EE) changed in patients receiving total parenteral nutrition (TPN)?

When TPN is administered to patients it is necessary to know the magnitude of TPN-induced thermogenesis in order to estimate energy requirements.

4. Is energy metabolism changed after enteral nutritional support?

In interpreting REE values and respiratory quotient (RQ) values it may be of importance to know whether a malnourished patient or a patient who has received nutritional support during a week has been measured.

\section{METHODS}

REE was measured in different patient groups under different conditions dependent on the question to be answered (Table 1).

TABLE 1.

Patient characteristics.

\begin{tabular}{lccccc}
\hline & group I & group II & group III & group IV & group V \\
\hline number $(\mathrm{n})$ & 15 & 17 & 30 & 14 & 16 \\
age $(\mathrm{y})$ & $40 \pm 20$ & $70 \pm 10$ & $69 \pm 7$ & $72 \pm 5$ & $69 \pm 10$ \\
sex (male/female) & $9 / 6$ & $15 / 2$ & $11 / 19$ & $5 / 9$ & $5 / 11$ \\
weight $(\mathrm{kg})$ & $74 \pm 12$ & $70 \pm 10$ & $70 \pm 10$ & $63 \pm 8$ & $59 \pm 9$ \\
PlBW $(\%)$ & $108 \pm 13$ & $100 \pm 13$ & $105 \pm 11$ & $97 \pm 12$ & $94 \pm 11$ \\
\hline
\end{tabular}

group lestable hospitalized patients; group Il=lung and colorectal cancer patients; group ||$l \mid$ mapparently healthy adutts; group $\mid V=$ gastric and colorectal cancer patients; group $V=g$ astric and colorectal cancer patients: $\mathrm{PIBW}=$ percentage ideal body weight; Mean values $\pm S D$ 
1. Within-patient variability of REE measured in a hospital situation.

Fourteen stable hospitalized patients (predominantly patients with fractures) underwent two REE measurements in the morning with a 24 -h interval. Measurements were performed after an overnight fast.

2. Changes in metabolic rate during the day. The effect of food intake (breakfast. lunch) and routine physical activities on REE.

In 15 stable hospitalized patients (the same population as above) REE was measured early in the morning and once again in the mid-afternoon three hours after lunch.

Seventeen hospitalized patients suffering from lung or colorectal cancer were measured early in the morning and a few hours later (mid-morning). All patients measured early in the morning had fasted for at least 10 hours. After the first REE measurement no instructions were given with respect to having breakfast.. Some of these patients had taken breakfast $(n=5)$, while others did not $(n=12)$. Energy intake was not measured. All patients were ambulant during the hours between the two measurements, but most of them limited their activities to washing, dressing and reading the newspaper or underwent diagnostic procedures like chest X-ray.

REE was measured twice in 30 apparently healthy adults. On the first occasion they visited the hospital at 9.00 AM. They had fasted for at least 10 hours and had limited their physical activity. REE measurements were carried out after at least 30 min of bed rest. On the second accasion they spent the night in the hospital and REE was measured early in the morning under the usual standard overnight conditions. Potential effects of activities like washing, dressing and travelling were thus controlled for.

\section{The effect of the continuous administration of TPN on EE.}

Fourteen hospitalized gastric and colorectal cancer patients were measured before and on the ninth day of TPN. The non-protein (np) energy requirement was calculated for each patient as 1.5 times their REE estimated according to the HB formula. Non-protein energy was supplied as glucose (ca. 90\%) and lipids (ca.10\%). It depended on the patient's energy requirement whether lipids were administered daily or two times a week. Nitrogen was given in an amount of 7.0 $\mathrm{mg} \mathrm{N} / \mathrm{np} \mathrm{kcal}$. In both cases EE was measured in the morning under similar conditions, except that the second measurement was performed during TPN administration.

\section{Effect of 9-days enterall nutritional support on energy metabolism.}

Sixteen hospitalized gastric and colorectal cancer patients were measured before and after 9 days of enteral feeding (EF). It must be emphasized that this enteral nutritional support was not administered continuously. The np energy requirement was calculated in the same way as above. Non-protein energy was supplied as 
glucose (ca. 70\%) and lipids (ca. 30\%). Nitrogen was given in an amount of 11.7 mg N/ripkcal. Both REE measurements were performed in the morning under the usual standard postabsorptive conditions.

REE was measured by indirect calorimetry using a ventilated hood system. The system consisted of a blower, a dry gasmeter " a paramagnetic oxygen anallyser (Mijnhardt module, Bunnik) and an infrared carbon dioxide analyser (modified UG 51, Mijnhardt, Bunnik). The gas analysers were calibrated at the start and at the end of every experiment. Dry gases were measured and the results converted to standard temperature and pressure. System control and calculations were performed on a microcomputer. The hood which consisted of clear plexiglas had a volume of $30 \mathrm{~L}$. REE was calculated using the abbreviated Weir formula (5) and given as kcal/day. REE was measured for half an hour at complete rest.

Statistical analysis was performed using Student's paired t-test. The MannWhitney $U$ test and the Wilcoxon matched-pairs signed-ranks test were used for the statistical analyses of non-parametric data. Further statistical procedures included Pearson correlation.

\section{RESULTS}

The stable hospitalized patients showed no differences in REE between the two measurements in the morning (Table 2a). The test-retest reliability coefficient was high ( $r=0.98$ ) (Figure 1). The standard error of measurement of a single determination of $24-\mathrm{h}$ REE was $56 \mathrm{kcal}$ resulting in a within-patient coefficient of variation $\left(\mathrm{CV}_{\mathrm{w}}\right)$ of $3.3 \%$.

TABLE 2a.

Resting energy expenditure (REE) measured on two consecutive mornings $(n=14)$.

\begin{tabular}{llll}
\hline group I & first morning & second morning & p-value \\
\hline REE(kcal/day) & $1683 \pm 351$ & $1697 \pm 374$ & $>0.05$ \\
\hline
\end{tabular}

MarantSO

REE measured mid-afternoon three hours after lunch was significantlly higher than REE measured early in the morning (Table 2b). The mean rise in REE was 243 kcal (almost 15\%). All patients showed an increase in metabolic rate with a range from less than $5 \%$ to $25 \%$. 
TABLE 2b.

REE measured early in the morning and mid-atternoon $(n=15)$.

\begin{tabular}{llll}
\hline group I & early morning & mid-afternoon & p-value \\
\hline REE(kcallday) & $1690 \pm 339$ & $1932 \pm 389$ & $<0.001$ \\
\hline
\end{tabular}

Mean values $\pm S D$

There was no significant difference between REE measured early in the morning and mid-morning (Table $2 \mathrm{c}$ ).

TABLE 2C.

REE measured early in the morning and mid-morning $(n=17)$.

\begin{tabular}{llll}
\hline group II & early morning & mid-morning & p-value \\
\hline REE(kcal/day) & $1650 \pm 206$ & $1671 \pm 194$ & $>0.05$ \\
\hline
\end{tabular}

Mean values $\pm S D$

However, patients who had breakfast between the two measurements showed an increase in REE $(+8.8 \pm 4.9 \%)$ in contrast to patients who had not eaten who showed a modest decrease in REE (-1.6 $\pm 4.0 \%$ ) (Figure 2). However, it must be emphasized that the number of patients who had breakfast was relatively small $(\mathrm{n}=5)$.

REE measured in healthy volunteers that had spent the night in the hospital was not significantly different from REE measured in the same volunteers according to the normal routine for out-patients (Table $2 \mathrm{~d}$ ).

TABLE 2d.

REE measured in the morning whether or not coming from home $(n=30)$.

\begin{tabular}{llll}
\hline Group lll & from home & not from home & p-value \\
\hline REE(kcal/day) & $1408 \pm 202$ & $1437 \pm 215$ & $>0.05$
\end{tabular}


chapter 4

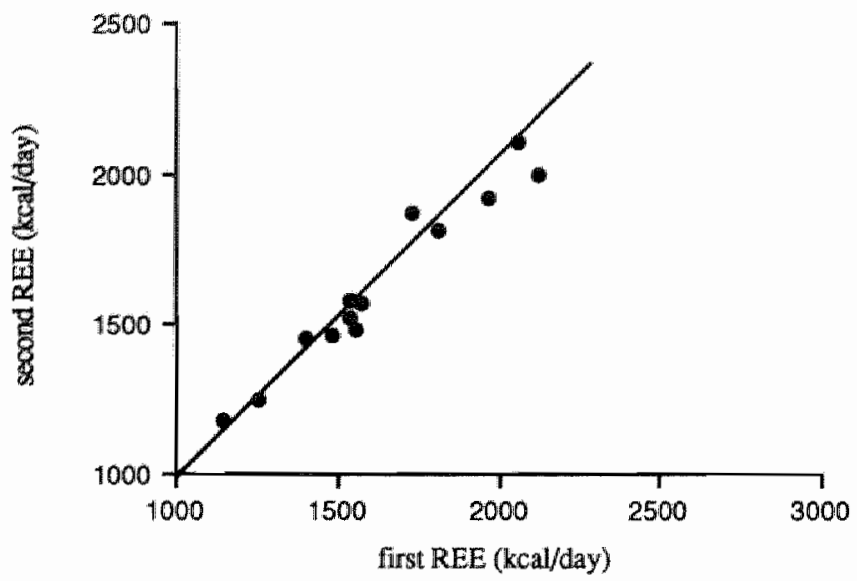

FIGURE 1.

Resting energy expenditure (REE) in stable hospitalized patients measured on first and second morning, with line of equality $(r=0.98 ; p<0.001)$. Group 1 .

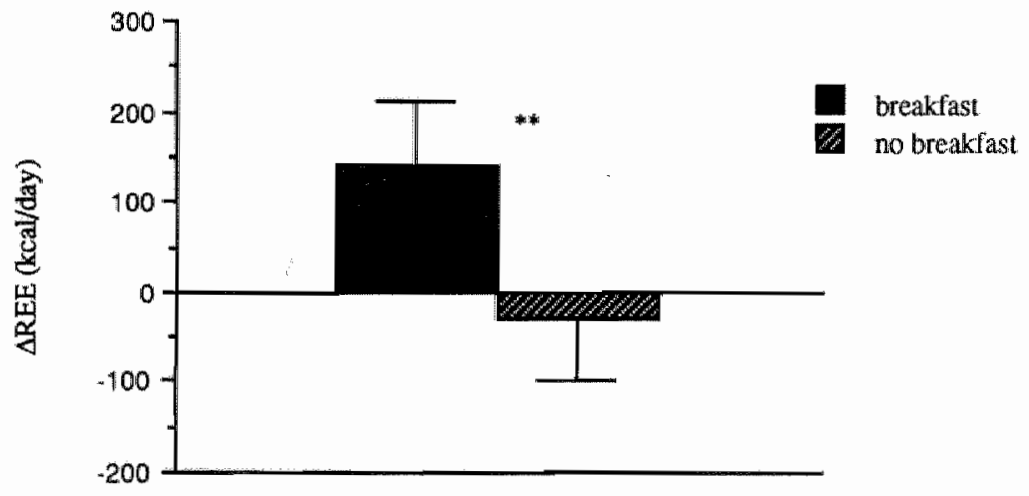

FIGURE 2.

Change in resting energy expenditure (AREE) from early in the morning to mid-morning with $(n=5)$ or without $(n=12)$ having breakfast before the second measurement. $* * 0<0.01$. Group II. Mean values $\pm S D$.

EE measured in 14 cancer patients before and after nine days of TPN increased significantly with $11.8 \%(142 \pm 132 \mathrm{kcal})$. The RQ increased from 0.77 to almost 1.0 (Figure 3).

REE measured in 16 cancer patients before and after nine days of $\mathrm{EF}$ increased also significantly, but with only $3.1 \%(37 \pm 49 \mathrm{kcal})$. However, REE expressed per $\mathrm{kg}$

$-28-$ 
body weight was not significantly higher anymore ( $\mathrm{p}=0.07)$. The RQ value increased from 0.78 to 0.87 (Figure 4 ).

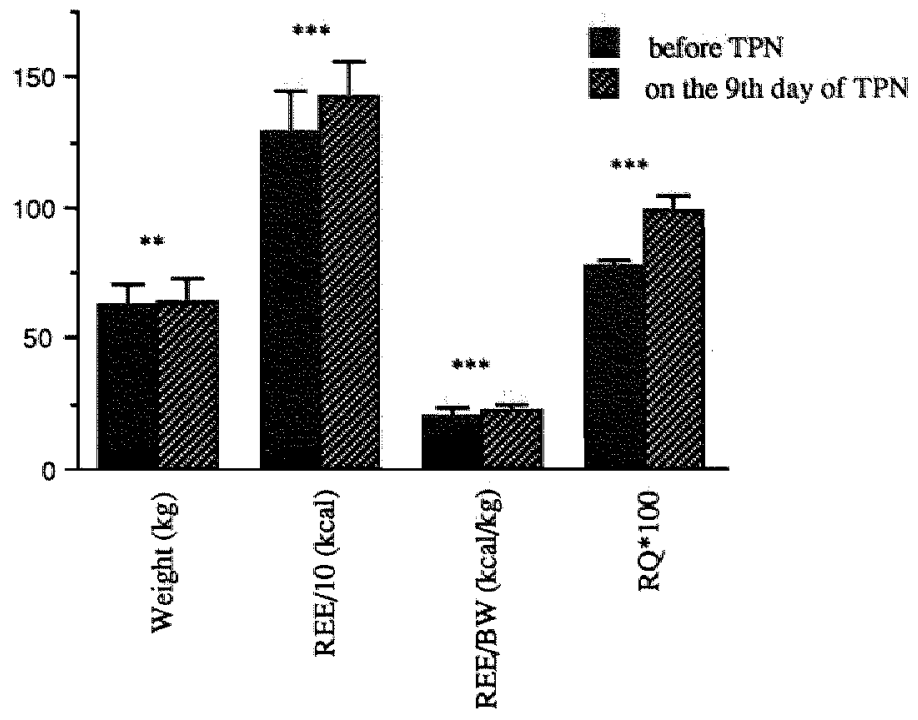

FIGURE 3.

Body weight $(B W)$, resting energy expenditure (REE), REE/BW and respiratory quotien ( $R Q)$ before and on the ninth day of total parenteral nutrition (TPN).** $p<0.01, * * * p<0.001$. Group IV. Mean values $\pm S D$.

FIGURE 4.

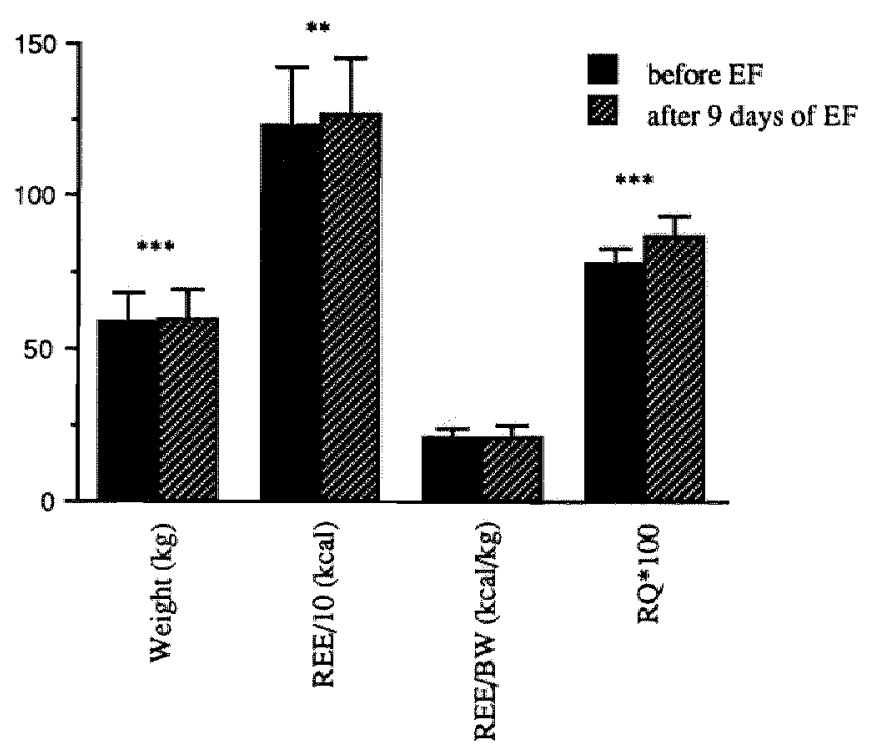

Body weight ( $B W$ ), resting energy expenditure (REE), REE/BW and respiratory quotient ( $R Q)$ before and after nine days of enteral feeding $(E F)$.** p<0.01, *** p<0.001. Group V. Mean values $\pm S D$. 


\section{DISCUSSION}

In the last few years REE has been often measured in hospitalized patients receiving nutritional support in order to fulfill energy requirements. REE in normal healthy people is usually measured in the morning after an overnight fast. This procedure of measuring REE limits its practical application in a hospital situation. Therefore, it is important to know the reproducibility of REE measurement and the influence of confounding factors on energy metabolism in patients in clinical practice.

The results of this study show that REE under normal standardized postabsorptive clinical conditions is highly reproducible. This observation confirms earlier reports in healthy volunteers that within-subject variation in REE (even when energy intake and physical activity are uncontrolled) is small $\left(\mathrm{CV}_{w}\right.$ of $\left.\mathrm{ca} .3 \%\right)(6-8)$. The current study in stable hospitalized patients shows that within-subject variation in patients is of a same magnitude.

The results of this study show that limited physical activity in a hospital setting has no measurable effect on REE. This was indicated by the agreement of the average of REE measurements in healthy adults after they had spent the night at home and after they had spent the night in the hospital. It was furthermore confirmed by the observation that REE values did not change significantly whether obtained early in the morning or at mid-morning as long as patients had not taken breakfast. Our results seem to be in agreement with those of Pacy et al who found that the level of exercise has no measurable effect on resting metabolism over 24-hours in normal subjects (9). In contrast to the effect of physical activity on REE results of this study suggest that diet-induced thermogenesis is important even three hours after a meal: REE measured at mid-morning after breakfast increased significantly by $9 \%$ while REE measured at mid-aftemoon after lunch increased significantly by $15 \%$. Feurer et al determined EE in patients receiving TPN and reported a $9 \%$ increase from early in the morning to mid-morning and a $10 \%$ increase in EE from early in the morning to mid-afternoon (10). Zurlo et al found no significant difference between REE measured in the morning and that measured in the afternoon in healthy young subjects (11). Hill et al reported that the mean duration of the thermic effect of food after an ingested meal was 4.5 hours (12). Therefore, the current study shows a higher increase in REE measured mid-afternoon than expected. The diumal variation in EE may be responsible for this phenomenon, although the literature on this subject is controversial. According to some authors REE remains unchanged from early morning to late afternoon $(11,13)$. However, Baily et al suggest that the oxygen consumption of men and women resting comfortably in the postabsorptive state is not constant, but subject to cyclic variations superimposed on a gradually rising base line (14). Also Aschoff and Poll described rhythmic variations in energy metabolism which are, at least partly, 
independent of food intake and physical activity (15).

In this study a $12 \%$ increase in EE in patients receiving TPN was found. Other studies, in which energy intake was of the same magnitude, showed an increase in EE to a similar degree (16-19). The use of glucose as the only energy source during the time of $E E$ measurement $(n=5)$ was associated with a greater rise in EE $(+14 \%)$ than when a glucose-fat regime was administered $(n=9)(+9 \%)$. This is confirmed by Macfie et al (20). The current study confirms that TPN-induced thermogenesis is of a similar magnitude as diet-induced thermogenesis of normal oral diets.

We found a significant $3 \%$ increase in REE in patients receiving enteral nutritional support. However, when corrected for the increase in body weight, significance was lost $(p=0.07)$. Surprisingly, postabsorptive $R Q$ was 0.87 after nine days of enteral nutritional support with $30 \%$ lipids, while $\mathrm{RQ}$ was 0.78 before. Both measurements were made after an overnight fast. This finding can be explained by the fact that the patients were fasting by more than 24 hours before the start of the nutrition regimen, while after mine days of EF they were still burning glucose deriwed from not yet depleted glycogen stores. The results of our study are in agreement with those of Stock et al who measured REE after a day of complete fast and again after a day of overeating ( $4700 \mathrm{kcal}$ ) and found no significant change in REE due to the previous day"s energy intake (21). The RQ value, in both cases measured after an overnight fast, was lower after fasting (0.76) than after overeating (0.86). Our results are also in agreement with those of van Es et al, who reported the effect of overfeeding (150\% of usual intake) for 7 or 8 days with a mixed diet on 24 h $\mathrm{EE}$ in healthy subjects (22). EE increased by $6 \%$ after overfeeding and RQ increased to 0.87 . The current study shows that enteral nutritional support does not increase REE substantially. However, based on the fuel mix oxidized there is still an effect of the EF on energy metabolism after an overnight fast. This should be considered when energy metabolism is measured in patients under these conditions.

In conclusion, the results of the present study have direct implications for the clinical measurement of REE. REE measurement using a ventilated hood system is highly reproducible. Therefore, it is not necessary to repeat measurements of REE in the same patient. We also demonstrated, however, that REE can not be measured at any time of the day. It seems justified to neglect variations in physical activity, also when patients come from home, which means that REE can be measured on an outpatient basis. However, diet-induced thermogenesis has to be considered in the practice of measuring REE. To control for this effect patients have to be measured in the morning prior to breakfast. The effect of TPN (1.5 times REE) on EE was a $12 \%$ increase, while 9 days of discontinuous enteral nutritional support did not increase REE substantially. However, this enteral 
feeding may have an effect on the RQ value. A high $R Q$ may be explained by oxidizing glucose from well filled glycogen stores.

\section{REFERENCES}

1. Sheldon GF, Peterson SR, Sanders R. Hepatic dysfunction during hyperalimentation. Arch Surg 1978; $113504-507$.

2. Lowry $\$ F^{*}$, Brennan MF. Abnormal liver function during parenteral nutrition; relation to unfusion excess. J Surg Res 1979,26:300-307.

3. Askanaxil I, Rosenbaum $\mathrm{SH}$, Hyman $\mathrm{AI}$, Silverberg PA, Milic-Emili I, Kinney IM. Respiratory changes induced by the large glucose loads of total parenteral nutrition. JAMA $1980 ; 243: 1444-1447$.

4. Harris JA, Benedict FG. A biometric study of basal metabolism. Washington: Carnegie Iristitution of Washington 1919.

5. Weir JB. New methods for calculating metabolic rate with special reference to protein metabolism. J Physiol 1949;109:1-9.

6. Garby $L$, Lammert $O$. Within-subjects between-days-and-weeks variation in energy expenditure at rest. Hum Nutr: Clin Nutr 1984;38C:395-397.

7. Soares MJ. Shetty $\mathbb{P S}$. Intra-individual variations in resting metabolic rates of human subjects. Hum Nutr: Clin Nutr 1986;40C:365-369.

8. Murgatroyd PR, Davies HL, Prentice AM. Intra-individual variability and measurement noise in estimates of energy expenditure by whole body indirect calorimetry. Br I Nutr 1987;58:347-356.

9. Pacy PJ, Webster JD, Isaacs G, Hunter S, Garrow IS. The effect of aerobic exercise on subsequent 24-h resting metabolic rate in normal male subjects. Proc Nutr Soc 1987;46:4A.

10. Feurer 1 . Crosby $L$, Mullen J. Diurmal changes in resting energy expenditure in patients receiving total parenteral mutrition. Clin Res 1980;28:620A.

11. Zurlo F, Schutz Y, Frascarolo P, Enzi G, Deriaz O, Jéquier E. Variability of resting energy expenditure in healthy volunteers during fasting and continuous enteral feeding. Crit Care Med 1986: 14:535-538.

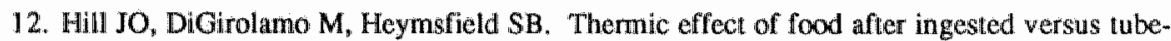
deliwered meals. Am J Physiol 1985;248:E370-E374.

13. Leff ML, Hill JO, Yates AA, Cotsonis GA, Heymsfield SB. Resting metabolic rate: measurement reliability. JPEN 1987;11:354-359.

14. Bailey D, Harry D, Johnson RE, Kupprat I. Oscillations in oxygen consumption of man at rest. J Appl Physiol 1973:34:467-470.

15. Aschoff J, Pohl H. Rhythmic variations in energy metabolism. Fed Proc 1970;29:15411552.

16. Shaw SN, Elwyn DH, Askanazi J, Iles M, Schwarz, Kinney JM. Effects of increasing nitrogen balance and energy expenditure in nutritionally depleted adult patients receiving parenteral nutrition. Am J Clin Nutr 1983;37:930-940.

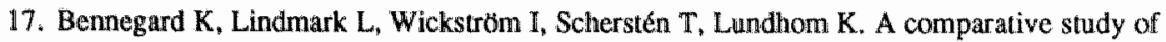
the efficiency of intragastric and parenteral nutrition in man. Am J Clin Nutr 1984;40:752757. 
18. Lindmark $L$, Edén E, Temell $M$, Bennegard $K$, Svaninger $G_{\mathrm{s}}$ Lundhoth $K$. Thermic effect and substrate oxidation in response to intravenous nutrition in cancer patients who lose weight Ann Surg 1986;204:628-636.

19. Merrick HW, Long CL, Grecos GP, Dennis RS, Blakemore WS. Energy requirements for cancer patients and the effect of total parenteral nutrition. JPEN 1988;12:8-14.

20. Macfie J, Holmfield JHM, King RFG, Hill GL. Effect of the energy source on changes in energy expenditure and respiratory quotient during total parenteral nutrition. JPEN 1983;7:1,5.

21. Stock MJ. Effects of fasting and refeeding on the metabolic response to a standard meal in man. Eur J Appl Physiol 1980;43:35-40.

22. Es AJH van, Vogt JE, Niessen $\mathrm{C}$ et al. Human energy metabolism below, near and above energy equilibrium. Br J Nutr 1984;52;429-442. 
nutritional status and degree of depletion of the patient may be responsible, or the indication for and type of surgical procedure performed. Another important factor may be the methodological differences between studies. The conditions during which REE is measured are not always standardized and sometimes poorly documented. Often a change in energy metabolism is reported based on a comparison with the Harris Benedict (HB) formula rather than on a comparison with preoperative REE measurements.

In this study REE was measured in a group of gastric and colorectal cancer patients in the preoperative as well as in the postoperative state. The impact of surgical trauma on energy metabolism was assessed one week after these patients had undergone surgery. An effort was made to control for confounding factors such as complications of surgery and total parenteral nutrition (TPN) that may influence energy metabolism.

\section{METHODS}

Patients with histologically proven gastric and colorectal cancer were included in the study. All patients were ambulatory and had recently been admitted to the Department of Surgery for surgical treatment of newly detected tumors. No patient had undergone prior chemotherapy or radiation therapy. All patients participated in a randomized prospective perioperative nutritional support trial. Malnourished patients were randomized to receive TPN or enteral nutrition during 10 days or they served as controls.

REE was calculated from measurements of oxygen uptake and carbon dioxide production. Gas exchange was measured by means of a ventilated hood system, which consisted of a dry gasmeter, a blower, a paramagnetic oxygen analyser (Mijnhardt module, Bunnik) and an infrared carbon dioxide analyser (modified UG51, Mijnhardt, Bunnik). Dry gases were measured and the results converted to standard temperature and pressure. Flow through the canopy was kept constant at a rate which was adjusted according to the body weight of the patient $\left(25^{-50 ~ L / m i n}\right)$. The hood consisted of clear plexiglas and had a volume of $30 \mathrm{~L}$. System control and calculations were performed on a microcomputer. The oxygen and the carbon dioxide analysers were calibrated with oxygen-free nitrogen and with a calibration gas (ca. $0.8 \% \mathrm{CO}_{2}$ and ca. $19.0 \% \mathrm{O}_{2}$ ), which was analysed using the modified Sonden technique. The equipment was calibrated at the start and at the end of each experiment. REE was calculated using the abbreviated Weir formula (8) which was used because of the difficulty of obtaining routine accurate $24-\mathrm{h}$ urine collections from every patient. This formula deletes the factor necessary to adjust for incomplete protein oxidation. This results in a $2 \%$ error in the final calculation of energy expenditure in normal individuals (9). The predicted energy expenditure was based on the HB formula (10). Patients with a measured REE above $115 \%$ of 
that predicted by the HB formula were considered hypermetabolic. This definition of hypermetabolism was based on Boothby's finding that $95 \%$ of normal individuals exhibit measured REE within $10 \%$ of predicted (11), and on a measurement error of $5 \%$ or less.

Measurements were performed after an overnight fast between 7:00 and 10:00 AM. REE was measured at rest in the supine position during 30 minutes.

Preoperative REE was measured in 104 patients. In 65 of these 104 patients REE was also measured after major gastrointestinal surgery on the 7 th or 8 th postoperative day under the similar conditions as preoperatively; thirty-nine patients were excluded from postoperative REE measurement. The most frequent reasons for exclusion were that these patients were inoperable $(n=8)$, suffered major complications $(n=9)$ or died $(n=8)$ or refused $(n=5)$. In nine patients technical or practical problems were encountered so that measurement could not take place. Twelve (out of 65) patients received TPN perioperatively. The remaining 53 patients were categorized in 40 who had uncomplicated surgery and 13 who developed postoperative complications (Figure 1).

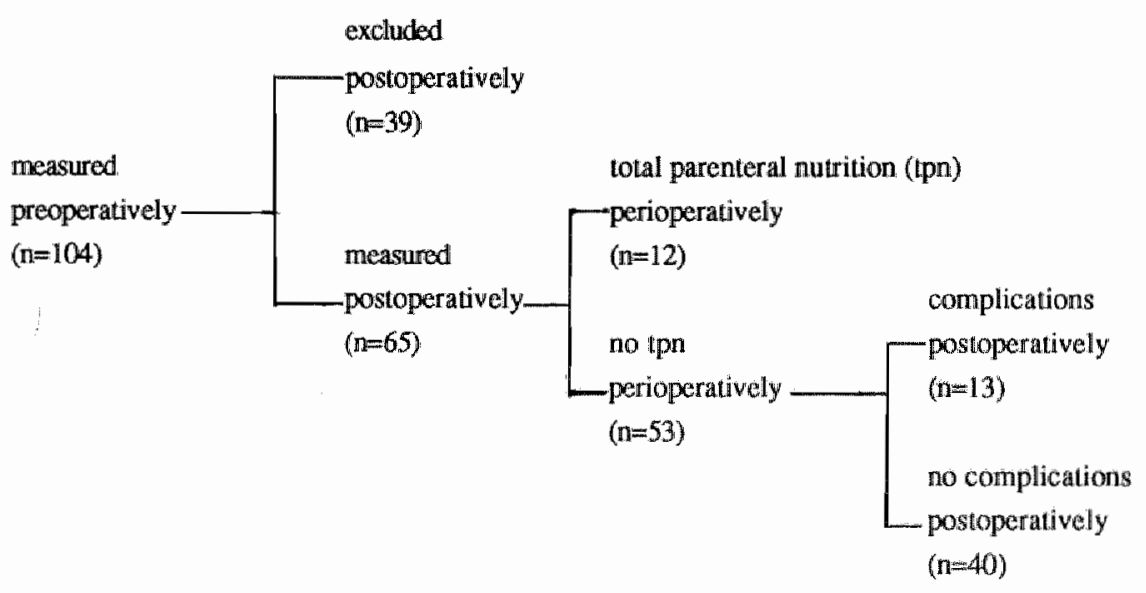

FIGURE 1 .

Ouline of different pat ient groups pre-and postoperatively.

Assessment of nutritional status included serum albumin concentration and percentage ideal body weight (PIBW) (12). Tumor stage was assessed after review of medical records, operative reports, pathology and radiology reports, according to the guidelines of the American Joint Committee on the Staging of Cancer (13). Postoperative complications were recorded and categorized as major complications (anastomotic leakage, intra-abdominal abscess, sepsis, wound dehiscence, 
formation of fistulae and mortality) and minor complications (wound infection, urinary or pulmonary tract infection).

Statistical analyses were performed using Student's paired t-tests when appropriate. The Mann-Whitney $U$ test was used for the statistical analysis of nomparametric data. Further statistical procedures included chi-square analysis and Pearson correlation. Results are presented as mean $\pm \mathrm{SD}$ and $\mathrm{p}$-values $<0.05$ were regarded as statistically significant.

\section{RESULTS}

The study group represented elderly cancer patients (mean age $70 \pm 11$ years); eighty-one suffered from colorectal cancer and 23 had gastric cancer (Table 1). Mean PIBW was $99 \%$. Twenty-five patients $(24 \%)$ had liver metastases at the time of diagnosis. There were no statistically significant differences between men and women.

TABLE 1.

Patient characteristics.

\begin{tabular}{lccc}
\hline variables & $\begin{array}{l}\text { measured pre-and } \\
\text { postoperatively } \\
(n=65)\end{array}$ & $\begin{array}{l}\text { measured only } \\
\text { preoperatively } \\
(n=39)\end{array}$ & -value \\
\hline age (y) & $67 \pm 11$ & $73 \pm 8$ & $<0.01$ \\
sex (male/female) & $35 / 30$ & $19 / 20$ & $>0.05$ \\
weight (kg) & $67.3 \pm 11.4$ & $61.8 \pm 11.2$ & $<0.01$ \\
albumin (g/L) & $34 \pm 4$ & $32 \pm 4$ & $<0.001$ \\
liver metastases (\%) & 12 & 44 & $<0.001$ \\
postoperative & 29 & 82 & $<0.001$ \\
Complications (\%) & $103 \pm 9$ & $106 \pm 11$ & $>0.05$ \\
REE (\%HB) & & &
\end{tabular}

AEE=resting energy expenditure: HB= Harris Benedict

Mean valuestso

A comparison of the 65 postoperatively measured patients with the 39 only preoperatively measured patients revealed that the not measured patients were older, had lower body weight and lower serum albumin, and had more often metastases than the measured patients. There was no significant difference in REE between the two groups.

REE after surgery was significantly higher than predicted (1471 \pm 238 vs $1325 \pm 231$

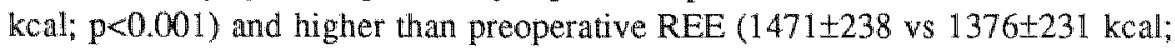


$p<0.001)$. Further analysis revealed that there were 22 hyper-metabolic patients after surgery. Part of this variation in response to surgical trauma can be explained by the administration of TPN and by an elevated body temperature. Increased body temperature was strongly correlated with the incidence of postoperative complications. Eight patients out of $11(73 \%)$ with a postoperative body temperature of $37.5^{\circ} \mathrm{C}$ or higher experienced postoperative complications.

The 40 patients that had uncomplicated surgery suffered a $2.8 \mathrm{~kg}$ body weight loss after surgery. Mean postoperative $\mathbb{R E E}$ was significantly elevated compared to mean preoperative REE. Six patients were hypermetabolic after operation compared to one before operation (Table 2).

\section{TABLE 2.}

Pre- and postoperative resting energy expenditure (REE) of patients with uncomplicated surgery $(n=40)$.

\begin{tabular}{lccc}
\hline & preoperative & postoperative & p-value \\
\hline REE $(\mathrm{kcal} / \mathrm{day})$ & $1400 \pm 258$ & $1441 \pm 262$ & $<0.01$ \\
REE $(\% \mathrm{HB})$ & $101 \pm 7$ & $106 \pm 8$ & $<0.001$ \\
REE $(\mathrm{kcal} / \mathrm{kg})$ & $20.5 \pm 1.9$ & $22.0 \pm 2.2$ & $<0.001$ \\
RQ & $0.79 \pm 0.03$ & $0.76 \pm 0.03$ & $<0.001$ \\
weight $(\mathrm{kg})$ & $68.6 \pm 12.6$ & $65.9 \pm 11.7$ & $<0.001$
\end{tabular}

$\mathrm{HB}=$ Harris Benedict; $\mathrm{AQ}=$ respiratory quotient

Mean values $\pm \mathrm{SD}$

Thirteen patients experienced complications in the postoperative period. Body weight loss in this group amounted to $1.5 \mathrm{~kg}$. Mean REE values were also significantly elevated (Table 3 ).

The increase in REE in the group with complications was significantly higher than in the group without complications ( $10.6 \%$ vs $3.2 \%$; $<<0.05$ ) (Figure 2 ).

REE measured in 12 patients before and on the ninth day of preoperative nutritional support increased significantly by $10.6 \%$ (or $125 \mathrm{kcal}$ ) (Table 4).

Postoperative REE in the TPN group in which six patients developed postoperative complications increased significantly by $19.3 \%$ (or $230 \mathrm{kcal}$ ). 


\section{TABLE 3.}

Pre- and postoperative resting energy expenditure (REE) of patients with postoperative complications $(n=13)$.

\begin{tabular}{lccc}
\hline & preoperative & postoperative & p-value \\
\hline REE (kcal/day) & $1373 \pm 188$ & $1514 \pm 210$ & $<0.01$ \\
REE $(\% \mathrm{HB})$ & $104 \pm 6$ & $115 \pm 9$ & $<0.001$ \\
REE $(\mathrm{kcal} / \mathrm{kg})$ & $20.2 \pm 1.6$ & $22.7 \pm 2.0$ & $<0.001$ \\
RQ & $0.78 \pm 0.06$ & $0.75 \pm 0.01$ & $>0.05$ \\
weight $(\mathrm{kg})$ & $68.3 \pm 8.6$ & $66.7 \pm 7.5$ & $>0.05$
\end{tabular}

$\mathrm{HB}$ Harris Benedict; $\mathrm{RQ}$-respiratory quotient

Mean valuestSD

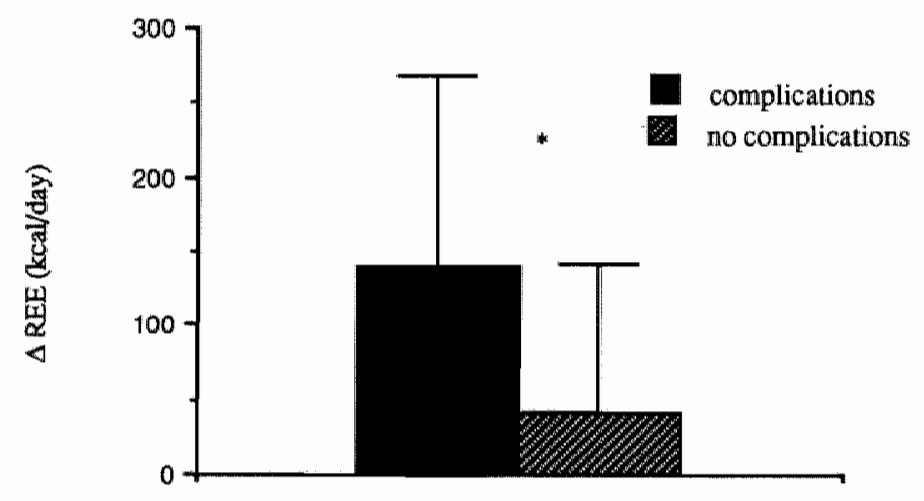

FIGURE 2.

Change in resting energy expenditure ( $\triangle R E E)$ afuer surgery for patients with $(n=13)$ and without $(n=40)$ postoperative complications Patients with total parenteral nutrition not included. * $p<0.05$. Mean valuestSD. 
TABLE 4.

Preoperative resting energy expenditure (REE) before and on the ninth day of total parenteral nutrition (TPN).

\begin{tabular}{lccc}
\hline & preoperative & 9th day of TPN & p-value \\
\hline REE (kcal/day) & $1297 \pm 165$ & $1421 \pm 153$ & $<0.05$ \\
REE $(\% \mathrm{HB})$ & $107 \pm 13$ & $117 \pm 10$ & $<0.05$ \\
$\mathrm{REE}(\mathrm{kcal} / \mathrm{kg})$ & $21.2 \pm 3.2$ & $22.8 \pm 2.8$ & $<0.05$ \\
$\mathrm{RQ}$ & $0.77 \pm 0.03$ & $1.00 \pm 0.05$ & $<0.001$ \\
energy intake (kcal/day) & $1380 \pm 640$ & $23.45 \pm 210$ & $<0.001$ \\
weight $(\mathrm{kg})$ & $61.9 \pm 8.6$ & $63.1 \pm 9.2$ & $<0.05$
\end{tabular}

$\mathrm{HE}=$ Harris Benedict ; $\mathrm{RQ}=$ respiratory quotient

Mean values $\pm S D$

\section{DISCUSSION}

Surgical trauma is generally considered to produce an increase in energy metabolism. This study reports the results of measurement of REE in patients with gastric and colorectal cancer before and one week after surgery. It may be argued that the current data were influenced by the effects of the tumor-bearing state on energy metabolism, because REE was measured pre- and post tumor resection. However, of the 65 patients measured postoperatively only $7(11 \%)$ had a preoperative REE above $115 \%$ of the predicted value. This implies that in only a limited number of patients the presence of the tumor may have been associated with an elevated REE. We therefore focussed on the impact of surgical trauma on energy metabolism.

While considering these data, it should be kept in mind that preoperative and postoperative REE were measured in 65 patients out of a total of 104 patients. These 65 patients had a better nutritional condition, had a less advanced disease stage and experienced less postoperative complications compared to the patients that were not measured postoperatively.

The use of the HB formula to predict energy requirement may be questionable. Roza and Shizgal suggested that this formula fails to predict REE accurately in many patients, particularly those with weight loss (14). Owen et al concluded that REE is slightly underestimated by the HB equation in men over 64 years of age $(15,16)$. Women were not included in their study. In the current study, therefore, most attention was given to the comparison of postoperative REE with preoperative REE. 
Over the years a number of studies have estimated the energy changes associated with elective surgery. These studies have demonstrated that surgical procedures cause only a modest increase $(10 \%)$ in REE $(1,3,4,6,7)$. In patients who received TPN or who had experienced complicated surgery REE was increased 10-30\% $(2,3)$. REE was also higher on the first postoperative days $(2,3,5,6)$, while most studies showed no change in REE anymore after the fifth postoperative day (Figure $3)$.

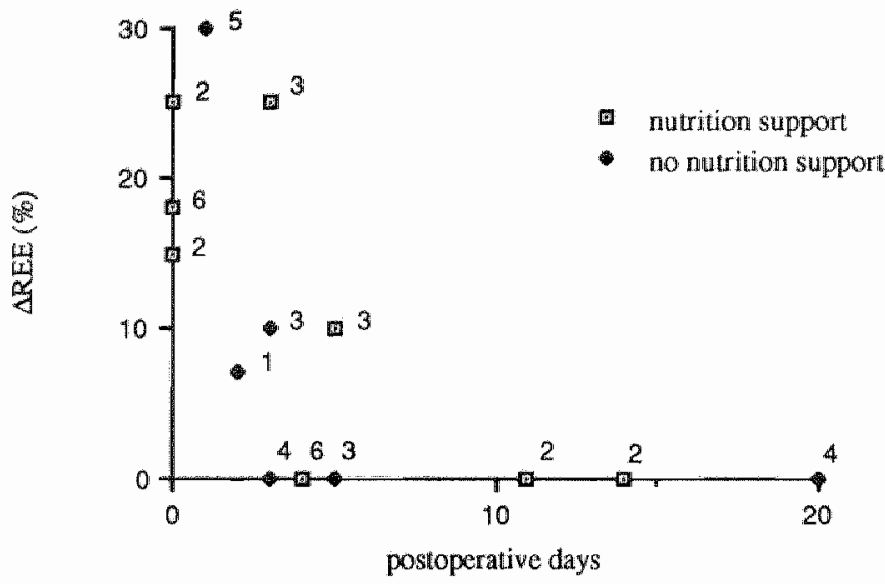

FIGURE 3.

Changes in resting energy expenditure ( $A R E E$ ) after surgery in different surgical populations. Figures refer to list of references.

Patients undergoing surgery for gastrointestinal diseases have generally an inadequate energy intake during the first postoperative week. The associated decrease in metabolic rate may therefore obscure a moderate increase in energy expenditure $(\mathbb{E E})$ after uncomplicated elective surgical treatment. In our study the group of 40 uncomplicated surgical patients had a weight loss of $2.8 \mathrm{~kg}$; their mean energy intake on the 7 th or 8 th postoperative day was $1270 \mathrm{kcal}$ with a range of 130 to $2250 \mathrm{kcal} /$ day. Levenson demonstrated a decreasing EE during starvation for seven days (17). Van Es et al reported a $2 \%$ decrease in 24 -h EE after 7 to 8 days semi-starvation ( $50 \%$ of usual intake) (18). Therefore, the increase in REE one week after uncomplicated surgical trauma may be greater than the $3 \%$ increase found in our study and probably ranges around $5 \%$.

Shaw et al measured the effect of TPN on EE in ten nutritionally depleted patients (19). Total energy intake averaged $33.0 \mathrm{kcal} / \mathrm{kg}$ corresponding to $1.31 * \mathrm{REE}$. They found an increase in REE of approximately $10 \%$, which is in agreement with the results in our study. 
Douglas and Shaw proposed numerous factors to account for the increase in energy metabolism after surgical trauma such as the increased oxygen consumption of injured tissues (20). The elevated EE may also be regarded as a physiological response to trauma and may be accompanied by raised body temperature. We, indeed, found in patients undergoing uncomplicated surgery a modest, but significant rise of $3 \%$ in REE, which was accompanied by a slight increase in body temperature after operation ( $36.6 \pm 0.5$ vs $36.9 \pm 0.3 ; \mathrm{p}<0.01$ ). However, Kinney and Roe (21) found that the presence of a modest degree of fever was not allways associated with hypermetabolism.

Patients who experienced postoperative complications showed a significantly higher increase in REE (10.6\% or $140 \mathrm{kcal})$ than patients without such complications $(3.2 \%$ or $41 \mathrm{kcal})$. In addition, most of the patients suffered from minor complications, because most patients with major complications were excluded. Major postoperative complications may have caused greater increases in REE.

Patients with postoperative complications had less weight loss $(1.5 \mathrm{~kg})$ than patients with uncomplicated operation $(2.8 \mathrm{~kg})$, presumably because of a greater tendency toward extracellular fluid expansion. This means that the rise in REE expressed per $\mathrm{kg}$ body weight in patients who had experienced complicated surgery was in fact somewhat higher than calculated.

We conclude that REE in gastric and colorectal cancer patients undergoing uncomplicated surgery is only moderately increased after the first postoperative week $(3 \%)$. Patients suffering from postoperative complications experience a significantly higher REE (10\%). Therefore, this study demonstrates that energy requirements for patients undergoing major elective surgical stress are lower than generally presumed. This is of clinical importance in the management of artificial nutrition.

\section{REFERENCES}

1. Brandi Ls, Oleggini $M$, Lachi $S$ et al. Energy metabolism of surgicall patients in the early postoperatiwe period: A reappraisal. Crit Care Med 1988;16:18-22.

2. Paaww JD, McCamish MA, Dean RE et al. Assessment of caloric needs in stressed patients. J Am Coll Nutr 1984;3:51-59.

3. Tweedle D, Johnston IDA. Factors affecting the melabolic expenditure of surgical patients. Br J Surg 1971;58:771-774.

4. Duke JH, Jorgensen $S B$, Broell JR el al. Contribution of protein to caloric expenditure following injury. Surgery 1970;68:168-174.

5. Carli $F$, Aber WR. Thermogenesis after major clective surgical procedures. Br I Surg $1987 ; 74: 1041-1045$. 
6. Novick WM, Nusbaum M, Stein TP. The energy costs of surgery as measured by the doubly labeled water method. Surgery 1988;103:99-106.

7. Kinney $\mathrm{M}$, Duke $\mathrm{JH}$, Long $\mathrm{CL}$. Tissue fuel and weight loss after injury. I Clin Path 1970;23 (Suppl 4):65-72.

8 Weir, IB. New methods for calculating metabolic rate with special reference to protein metabolism. J Physiol 1949;109:1-9.

9. Wilmore JH, Davis JA, Norton AC. An automated system for assessing metabolic respiratory function during exercise. J Appl Physiol 1976;40:619-624.

10. Harris $\mathrm{IA}$, Benedict $\mathrm{FG}$ : A biometric study of basal metabolism. Washington: Carnegie Institution of Washington 1919.

11. Boothby WM, Berkson J, Dunn HL. Studies on the energy of metabolism of normal individuals: A standard for basal metabolism with a nomogram for clinical application. Am J Physiol 1936;3:468-483.

12. Metropolitan Life Insurance Company. Desirable weights for men: desirable weights for women. Stat. Bul. no. 13. New York: Life Extension Institute of New York City 1943.

13. American Joint Committee on Cancer: Manual for Staging of Cancer. Philadelphia: Lippincott Company 1983.

14. Roza AM, Shizgal HM. The Harris Benedict equation reevaluated: resting energy requirements and the body cell mass. Am J Clin Nutr 1984;40:168-182.

15. Owen $\mathrm{OE}$, Kavle $\mathrm{E}$, Owen RS et al. A reappraisal of caloric requirements in healthy women. Am J Clin Nutr 1986:44:1 19.

16. Owen $\mathrm{OE}$, Holup JL, D'Alessio DA et al. A reappraisal of the caloric requirements of men. Am J Clin Nutr 1987;46:875-885.

17. Levenson SM, Barbul A, Seifter E: Some biochemical, endocrinologic, and immunologic changes and adaptations following starvation. In: Nutritional aspect of care of critically ill. Richards, JR, Kinney, JM (Eds). London: Churchill Livingstone 1977.

18. Es AJH van, Vogt JE, Niessen C et al. Human energy metabolism below, near and above energy equilibrium. Br J Nutr 1984:52:429-442.

19. Shaw SN, Elwyn DH, Askanazi $J$ et al. Effects of increasing nitrogen intake on nitrogen balance and energy expenditure in nutritionally depleted adult patients receiving parenteral nutrition. Am J Clin Nutr 1983;37:930-940.

20. Douglas RG, Shaw JHF. Metabolic response to sepsis and trauma. Br J Surg 1989;76:115-122.

21. Kinney JM, Roe CF. Caloric equivalent of fever: I. Patterns of postoperative response. Ann Surg 1962;156:610-622. 


\section{CHAPTER 6}

RESTING AND SLEEPING ENERGY EXPENDITURE IN THE ELDERLY

EWHM Fredrix; PB Soeters; IM Deerenberg; ADM Kester; MF von Meyenfeldt; WHM Saris

From the Department of Human Biology, Surgery and Medical linformatics and Statistics, University of Limburg, PO Box 616,6200 MD Maastricht, The Netherlands

accepted in European Journal of Clinical Nutrition

\section{SUMMARY}

An estimate of a patient's energy needs is usually derived from equations, that predict energy expenditure by considering sex, age and body weight. Due to the increasing number of elderly people in a hospital population, more data on energy requirements in this age-group are needed. In this study resting energy expenditure (REE) of 40 healthy men and women, aged 51-82 years, was measured using a ventilated hood system. The results show that some commonly used prediction equations underestimate REE by approximately $6 \%$. REE was highly correlated with fat free mass $(r=0.88 ; p<0.001)$ and body weight $(r=0.85 ; p<0.001)$. A stepwise multiple regression analysis showed that the combination of body weight, sex and age resulted in the best prediction for REE: REE (kcal) $=1641+$ $10.7 *$ weight $(\mathrm{kg})-9.0 *$ age $(\mathrm{y})-203 * \mathrm{sex}(1=$ male, $2=$ female $)(\mathrm{r}=0.92)$. However, REE of an individual may be over or underestimated by $\pm 225 \mathrm{kcal}$ (10$20 \%$ ) due to large between-subject variations. We suggest therefore that the energy requirements of elderly people should be measured rather than predicted. Due to small within-subject variations (including measurement error) a single REE measurement would suffice. Sleeping energy expenditure was $7 \%$ lower than REE.

\section{INTRODUCTION}

There is a growing clinical interest in accurately predicting energy requirements of individual patients. One reason for this interest is to fulfill energy needs of critically ill hospitalized patients avoiding at the same time the adverse clinical consequences of overfeeding (1-3). Artificial nutrition is often planned for hospital patients on the basis of estimated daily energy expenditure (EE) which is seldom measured. The most common approach is to apply an equation such as that of Harris and Benedict (HB) (4), to estimate the normal resting energy expenditure (REE) for an individual from the patient's age, size and sex, and then add an arbitrary factor such as $10 \%$ for the thermic effect of a mixed diet and perhaps $20-40 \%$ for the presumed energy needs of physical activity and disease. 
There are indications that the $\mathrm{HB}$ equation is not the best reference as a standard in an elderly population of patients. Roza and Shizgal suggested that this formula underestimates REE in patients with weight loss (5). In contrast, Daly et al found that the HB equation overestimates REE in healthy men and women (6). Feurer et al found that the HB prediction over-or underestimates REE by $10 \%$ or more in $20 \%$ of healthy control subjects (7). Owen et al recently have published data concerning REE in healthy men and women $(8,9)$. They concluded that the classic prediction equations including the $H B$ formula overestimate REE in men and women under the age of 64 . REE is slightly underestimated in men over 64 years of age. Women over 64 years of age were not included in their study.

The original $H B$ equation is based on REE measurements in volunteers in the age group 18-65 years. However, the number of studies in young and middle-aged people has exceeded those in the elderly. An extensive analysis of all available data in the literature by Schofield resulted in two linear equations for the elderly relating REE to body weight, based on 50 measurements in men and 38 measurements in women $(10)$. Now that a larger proportion of the total population and especially the hospital population is composed of people over sixty years and older, it is even more desirable to quantitate their energy requirements accurately.

In the current study the energy requirements of 40 apparently healthy men and women (50 years and older) were measured at rest. Measured REE values were compared with three predicted values. Furthermore, the relationship between sleeping energy expenditure (SEE) and REE was examined.

\section{METHODS}

Forty healthy men and women between the age of 51 and 82 years living in Maastricht and surroundings participated in the study (Table 1). All volunteers had normal dietary habits, had stable weights for at least 6 months before the study and had no evidence of physical or mental disease. Their physical activities were approximately comparable from day to day. All subjects had normal blood pressures, pulse rates and body temperatures. They underwent a medical examination to exclude disorders which might have affected their metabolic rate such as high blood pressure, thyroid dysfunction, heart failure, infectious disease, chronic obstructive pulmonary disease and anaemia.

REE was measured once or several times. The first time all subjects came to the hospital in the morning after a 10 -h overnight fast. They were asked to travel by car, bus or train in order to reduce physical activity. REE was measured after a period of at least 30-min bed rest. Measurements were performed with a ventilated hood system during a half hour. Gas analyses were performed using a paramagnetic oxygen analyser (Mijnhardt module, Bunnik) and an infrared carbon 
TABLE 1.

Subject characteristics.

\begin{tabular}{llll}
\hline & males $(\mathrm{n}=18)$ & temales $(\mathrm{n}=22)$ & total $(\mathrm{n}=40)$ \\
\hline age $(\mathrm{y})$ & $63 \pm 8$ & $66 \pm 7$ & $\begin{array}{l}65 \pm 8 \\
(\text { range } 51-82)\end{array}$ \\
weight $(\mathrm{kg})$ & $81.1 \pm 11.0$ & $64.8 \pm 7.1$ & $\begin{array}{l}72.1 \pm 12.1 \\
(\text { range } 54.112)\end{array}$ \\
BMI $(\mathrm{kg.m}-2)$ & $26.4 \pm 2.4$ & $25.5 \pm 2.6$ & $25.9 \pm 2.5$ \\
& & & $($ range 21.31$)$ \\
FFM $(\mathrm{kg})$ & $60.1 \pm 6.8$ & $44.1 \pm 4.0$ & $51.3 \pm 9.7$ \\
& & & $($ range 39.77$)$ \\
\hline
\end{tabular}

Mean valuest $\mathrm{SD}_{i}$

BMl=body mass index; FFM=fat tree mass

dioxide analyser (modified UG51, Mijnhardt, Bunnik). Dry gases were measured and the results converted to standard temperature and pressure. Flow through the canopy was kept constant during measurements and was adjusted to the body weight of the patient $(25-50 \mathrm{~L} / \mathrm{min})$. System control and calculations were performed on a microcomputer. The equipment was calibrated at the start and at the end of every experiment. The hood consisted of clear plexiglas and had a volume of $30 \mathrm{~L}$. REE was calculated using the abbreviated Weir formula (11). The measured REE was extrapolated to $24-\mathrm{h}$ and was then compared to the corresponding values predicted by the $\mathrm{HB}$, the Schofield and the Owen equations.

Body composition was determined by measurement of the bioelectrical impedance using the formulae of Segal (12) to predict fat free mass (FFM).

To assess reproducibility of the results a second REE measurement was performed with an interval of about five months under the same conditions in subjects with the highest $\mathrm{REE}(\mathrm{n}=11)$ and in subjects with the lowest REE $(\mathrm{n}=11)$ axpressed as a percentage of the $\mathrm{HB}$ value.

SEE and subsequently REE were measured in 30 subjects (out of 40 ). For the measurement of SEE each subject stayed for $12 \mathrm{~h}(20.00-08.00)$ in a computerized open-circuit indirect calorimeter $\left(14 \mathrm{~m}^{3}\right)$, equipped with a bed, toilet, television and chair. The volume of air drawn through the chambers was measured by a dry gas meter (Dort, The Netherlands) and continuously analysed by a paramagnetic $\mathrm{O}_{2}$ analyser (Serwomex Taylor, England) and an infrared $\mathrm{CO}_{2}$-analyser (Harmann and Braun, West Germany). From the air flow rate, and the $\mathrm{O}_{2}$ and $\mathrm{CO}_{2}$ concentration 
of the in- and outflowing air $\mathrm{O}_{2}$ consumption and $\mathrm{CO}_{2}$ production were computed on line through an automatic acquisition system interfaced with a computer (13). SEE was calculated during the period of sleeping from 03.00-06.00 AM. The next morning the subjects left the room after waking up and REE was measured under the usual conditions using the ventilated hood system .

REE was expressed in absolute terms (REE), per kg body weight (REE/BW), per $\mathrm{kg}$ FFM (REE/FFM) or as a percentage of the $\mathrm{HB}$, Schofield and Owen equations, respectively (REE/HB, REE/SCHO, $\mathrm{REE} / \mathrm{OWEN}$ ). The relationship between REE and several independent variables was assessed using Pearson's coefficient of correlation. Stepwise multiple regression was used to determine the best predictors of REE of these subjects. Further statistical procedures included Student's paired ttest. Results are presented as mean $\pm \mathrm{SD}$ and $\mathrm{p}$-values $<0.05$ were regarded as statistically significant.

\section{RESULTS}

Mean REE of the 40 healthy volunteers was $1512 \pm 269 \mathrm{kcal}$ (Table 2). REE/BW and REE/FFM were in the same range for men and women. Measured REE was higher than predicted REE no matter what prediction equation was used (Table 3). The HB, Schofield and Owen equations underpredicted the measured value by $7 \%$, $6 \%$ and $4 \%$, respectively.

\section{TABLE 2.}

Resting energy expenditure (REE) in the elderly.

\begin{tabular}{llll}
\hline & males $(n=18)$ & females $(n=22)$ & total $(n=40)$ \\
\hline REE (kcal) & $1733 \pm 205$ & $1330 \pm 155$ & $\begin{array}{l}1512 \pm 269 \\
\text { (range 1106-2145) }\end{array}$ \\
REE (kcal/kgBW) & $21.4 \pm 1.5$ & $20.6 \pm 2.0$ & $21.0 \pm 2.0$ \\
& & & (range 17.5-26.0) \\
REE (kcal/kgFFM) & $28.9 \pm 2.0$ & $30.2 \pm 3.3$ & $29.6 \pm 2.9$ \\
& & & (range 25.1-36.5) \\
\hline
\end{tabular}

Mean values.tSD

BW body weight; FFMefat free mass

Significant correlations existed between REE and FFM ( $\mathrm{r}=0.88)$, body weight $(r=0.85)$, sex $(r=0.75)$ and age $(r=0.54)$. A stepwise multiple regression analysis revealed that the combination of body weight, sex and age gave the best prediction for REE ( $\mathrm{r}=0.92$ and SE of estimate $=111$; REE $(\mathrm{kcal})=1641+10.7^{*}$ weight $(\mathrm{kg})$ $9.0 *$ age $(y)-203 * \operatorname{sex}(1=$ male, $2=$ female) $)$. When $B W$ and age were used as 
TABLE 3.

Measured and predicted resting energy expenditure (REE).

\begin{tabular}{lllll}
\hline & measured & $\begin{array}{l}\text { predicted } \\
H B\end{array}$ & $\begin{array}{l}\text { predicted } \\
\text { SCHO }\end{array}$ & $\begin{array}{l}\text { predicted } \\
\text { OWEN }\end{array}$ \\
\hline REE (kcal) & $1512 \pm 269$ & $1420 \pm 244^{* * *}$ & $1427 \pm 244^{* * *}$ & $1461 \pm 240^{*}$ \\
\hline
\end{tabular}

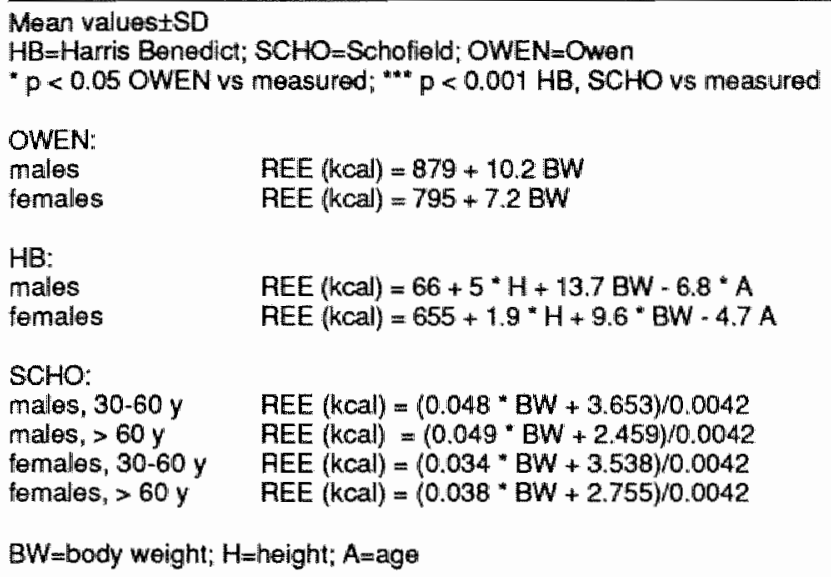

the variables to predict REE of men and women, the slopes of the regression lines were statistically indistinguishable. Therefore, no seperate lines for men and women were developed. By taking weight, sex and age into account $84 \%$ of the variance in REE could be explained. The $95 \%$-prediction limits calculated as two times the SE of estimate were wide ( $\pm 225 \mathrm{kcal})$, reflecting the heterogeneous nature of the REE for healthy people over 50 years of age. This was also demonstrated by the wide range for REE/BW $(17.5$ to $26.0 \mathrm{kcal} / \mathrm{kg})$ and for REE/FFM (25.1 to $36.5 \mathrm{kcal} / \mathrm{kg})$.

The 22 subjects (mean age $64 \pm 8$ years) who were measured twice showed no significant differences in REE between the two measurements (Table 4). There were also no significant differences in body weight and body composition. The test-retest correlation coefficient was high $(\mathrm{r}=0.96)$ (Figure 1). The standard error of measurement of a single determination of $24-\mathrm{h}$ REE was $53 \mathrm{kcal}$ resulting in a within-subject coefficient of variation $\left(\mathrm{CV}_{w}\right)$ of $3.5 \%$. The same results were found when the data of the subjects with either a high or a low REE were analysed separately. 


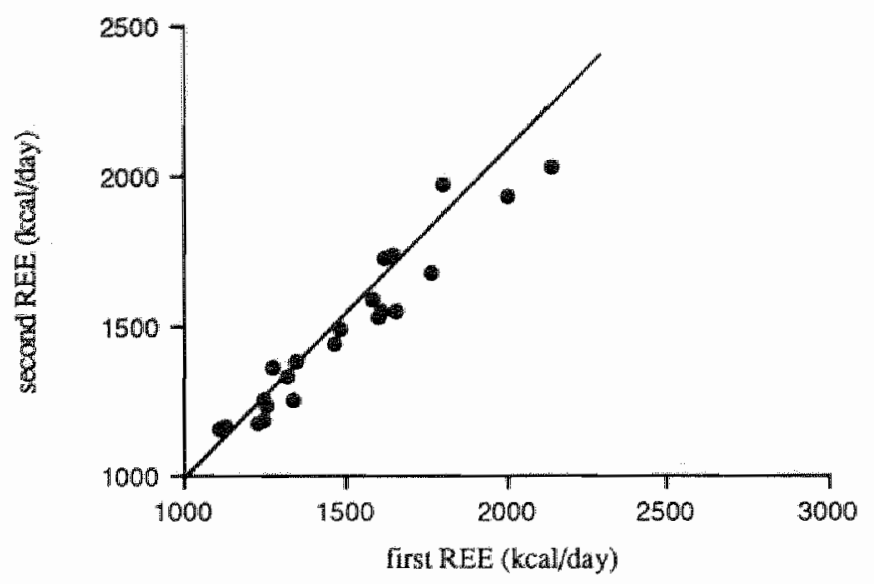

FIGURE 1.

Resting energy expenditure (REE) measured on first and second morning, with line of equality $(r=0.96 ; * * 0.001)$.

\section{TABLE 4.}

Reproducibility of resting energy expenditure (REE) in subjects with either high ( $\mathrm{n}=11$ ) or low ( $n=11$ ) REE during the first measurement.

\begin{tabular}{llll}
\hline & 10 measurement & $2^{e}$ measurement & \\
\hline low REE & $1392 \pm 309$ & $1376 \pm 270$ & 0.98 \\
high REE & $1598 \pm 207$ & $1599 \pm 228$ & 0.93 \\
total & $1495 \pm 277$ & $1488 \pm 269$ & 0.96 \\
& & & \\
\hline
\end{tabular}

rocorrelation coefficient:

Mean valuestSD

In the subgroup of 30 patients (mean age $69 \pm 7$ years) in which SEE as well as REE were determined, SEE was significantly lower than REE $(p<0.001)$. The mean ratio of SEE:REE was $0.93 \pm 0.08$.

\section{DISCUSSION}

An accurate prediction of REE is particularly important when calculating energy requirements. The energy costs for physical activity, for diet-induced thermogenesis and for disease or injury are usually determined by multiplying the REE by an empirical factor. Thus, the estimation of energy needs is usually based on the predicted REE. Few data on REE in the elderly are published. 
This study shows that measured REE for healthy elderly people is higher than the predicted REE based on results from the most commonly used prediction equation of HB. This seems to be in agreement with the observation of Owen and coworkers that the HB equation slightly underestimates REE in men over 64 years of age (9). It is therefore necessary to study many more elderly people to evaluate properly the influence of age on REE. Although the original HB equations developed in 1919 are based on REE measurements in healthy people in the age group 18-65 years, two further studies published by Benedict in 1928 and 1935 included subjects with a wider age range $(14,15)$. A reevaluation of these data by Roza and Shizgal showed that the regression equations derived using the original 1919 data are virtually identical to the equations obtained with the data from the larger number of subjects (5). The $\mathrm{HB}$ equation seems therefore equally valid for both younger and older individuals.

Measured REE in the current study was also higher than predicted by the new equations published by Owen. This can be explained by the fact that REE in the study of Owen was measured mainly in younger people (males:38t16 years; females:35 12 years). Quite unexpected was the finding that the Schofield equations underpredicted measured REE by $6 \%$, because these equations were based on all data on REE in the elderly that are availabe in the literature. Our results indicate that the currently available equations underestimate the REE of older healthy men and women. The impact of underestimation of on average six percent may not be neglected. Energy requirements are based on the predicted REE which in itself accounts for about $65-70 \%$ of total EE. Besides, for individuals the predicted REE may over or underestimate by $10-20 \%$ actual REE. Therefore, it seems important to employ the most appropriate prediction equation when calculating daily energy requirements.

The differences between our results and the results of other studies may be ascribed to both technical and biological differences. It cannot be excluded that today's adults (over 50 years of age) have a different REE compared to their ancestors, as the result of climatic factors, level of physical activity, dietary habits and general level of health. If and to what extent these factors may contribute to the observed differences is unknown.

We developed a new prediction equation for the REE of heal thy men and women of 50 years and older. It should be emphasized that, due to the large variations in measured REE, predicted REE may over or underestimate actual REE by $10-20 \%$, which makes the usefulness of a prediction equation questionable. The metabolic requirements of elderly people should therefore preferably be measured rather than predicted. In critically ill patients a necessity to measure EE exists even more, because daily energy requirement estimates are even less accurate. 
The best predictor for REE was FFM. A multiple regression analysis resulted however in a prediction equation without FFM, but with body weight, sex and age. This possibly casual finding can be explained by the fact that FFM was highly interrelated with weight and sex $(r>0.83)$. Body weight has the advantage of being a variable that is more easily determined than FFM. Only $16 \%$ of the total variance in REE in the healthy elderly cannot be explained by these three variables.

The results of this study are in agreement with earlier reports that REE measurements are highly reproducible (16-19). $\mathrm{A} \mathrm{CV}_{\mathrm{w}}$ of $3.5 \%$ indicates both reasonable methodological precision and small within-subject variability. This small within-subject variation for subjects with a high or a low REE confirms the observation that there is a wide range of REE for healthy men and women over 50 years of age.

The terms resting and sleeping EE (REE and SEE, respectively) all refer to energy exchange, measured under conditions that differ only slightly. The differences measured between SEE and REE are small. However, these differences may be of importance. The FAO/WHO/UNU recommendations for daily energy requirements are based on the assumption that SEE is equal to REE (20). Two recent studies have demonstrated SEE to be $5 \%$ lower than REE $(21,22)$. In these studies SEE was measured during a period of at least 7 hours of sleeping, while in our study SEE was measured from 03.00-06.00 AM. SEE in the current study was $7 \%$ lower than REE. Therefore, overnight EE will be overestimated with $5-7 \%$ by the use of the REE-value.

We conclude that commonly used prediction equations underestimate the REE of healthy men and women over 50 years of age. Furthermore, due to large betweensubject variation in REE it is difficult to predict individual energy requirements accurately. Therefore, we suggest that energy requirements of elderly people should preferably be measured rather than predicted. Due to small within-subject variation and methodological error in REE, only a single measurement is needed, that can be performed under strictly defined conditions on an outpatient basis. We demonstrated SEE to be 7\% lower than REE.

\section{REFERENCES}

1. Sheldon $\mathrm{GF}$, Peterson SR, Sanders R. Hepatic dysfunction during hyperal imentation. Arch Surg 1978:113:504-507.

2. Lowry $S F$, Brennan MF. Abnormal liver function during parenteral nutrition; relation to infusion excess. J Surg Res 1979;26:300-307.

3. Askanazi J, Rosenbaum SH, Hyman AI, Silverberg PA, Milic-Emili J, Kinney JM. Respiratory changes induced by the large glucose loads of total parenteral nutrition. JAMA 1980;243:1444-1447. 
4. Harris $\mathrm{JA}_{4}$ Benedict FG. A biometric study of basal metabolism in man. Washington, DC: Carnegie Institute of Washington, Publication no $279,1919$.

5. Roza AM, Shizgal HM. The Harris Benedict equation reevaluated: resting energy requirements and the body cell mass. Am J Clin Nutr 1984:40:168-182.

6. Daly $\mathrm{M}$, Heymsfield $\mathrm{SB}$, Head $\mathrm{A}_{*}$ et all. Human energy requirements: overestimation by widely used prediction equation. Am J Clin Nutr 1985;42:1170-1174.

7. Feurer ID, Crosby LO, Mullen NL. Measured and predicted resting energy expenditure in clinically stable patients. Clin Nutr 1984;3:27-34.

8. Owen $\mathrm{OE}$, Kavle E, Owen RS, et al. A reappraisal of caloric requirements in heal thy women. Am J Clin Nutr 1986;44:1-19.

9. Owen $O E_{w}$ Holup $\pi, D^{\prime}$ Alessio DA, et al. A reappraisal of the caloric requirements of men. Am J Clin Nutr 1987;:46:875-885.

10. Schofield WN. Predicting basal metabolic rate, new standards and review of previous work. Hum Nutr:Clin Nutr 1985;39C:5-41 suppl.

11. Weir JB. New methods for calculating metabolic rate with special reference to protein metabolism. J Physiol 1949;109:1-9.

12. Segal KR. Van Loan M, Fitzgerald PI, Hodgdon JA, Van Itallie TB. Lean body mass estimation by bioelectrical impedance analysis: a four-site cross-validation study. Am J Clin Nutr 1988;47:7-14.

13. Schoffelen P, Saris WHM, Westerterp $K R_{n}$ Hoor $F$ ten. Evaluation of an automatic indirect calorimeter for measurement of energy balance in man. In: Human energy metabolism: Physical activity and energy expenditure measurement in epidemiological research based upon direct and indirect calorimetry. Ed: AJH van Es. Euro Nut report 5, 1985: p 51-54.

14. Benedict FG. Basal metabolism data on normal men and women (series II) with some considerations on the use of prediction standards. Am J Physiol $₫ 928 ; 85: 607-620$.

15. Benedict FG. Old age and basal metabolism. N Engl J Med 1935;212:1111-1122.

16. Garby L, Lammert $O$. Withim-subjects between-days-and-weeks variation in energy expenditure at rest. Hum Nutr:Clin Nutr 1984;38C:395-397.

17. Murgatroyd $P R$, Davies $H L$, Prentice AM. Intra-individual variability and measurement noise in estimates of energy expenditure by whole body indirect calorimetry. Br I Nutr 1987:58:347-356.

18. Soares MJ, Shetty PS. Intra-individual variations in resting metabolic rates of human subjects. Hum Nutr:Clin Nutr 1986:40C:365-369.

19. Soares MJ, Piers LS, Kraai L, Shetty PS. Day-10-day variations in basal metabolic rates and energy intakes of human subjects. Eur J Clin Nutr 1989;43:465-472.

20. FAO/WHO/UNU. Energy and protein requirements. Report of a joint Expert Consultation. WHO Tech. Rep. Series No. 724. Geneva: WHO, 1985.

21. Goldberg GR, Prentice AM, Davies HL, Murgatroyd PR. Overnight and basal metabolic rates in men and women. Eur J Clin Nutr 1988;42:137-144.

22. Garby $L$, Kurzer MS, Lammert $O$. Nielsen E. Energy expenditure during sleep in men and women: evaporative and sensible heat losses. Hum Nutr:Clin Nutr 1987;41C:225-233. 



\section{CHAPTER 7}

\section{RESTING ENERGY EXPENDITURE IN NON-SMALL CELL LUNG CANCER PATIENTS}

EWHM Fredrix; EFM Wouters; PB Soeters; ACJM van der Aalst; ADM Kester; MF von Meyenfeldt; WHM Saris

From the Department of Human Biology, Surgery, Pulmonary Diseases and Medical Informatics and Statistics, University of Limburg, PO Box 616 , 6200 MD Maastricht, The Netherlands

submitted for publication

\section{SLMMARY}

Resting energy expenditure (REE) was determined in 30 patients with newly detected non-small cell lung cancer. Measured values were compared with the values predicted by the Harris Benedict formula. Mean REE was $20 \%$ higher than predicted. Eighteen patients $(60 \%)$ had an elevated REE ( $\geq 115 \%)$ compared to this formula. The prevalence of hypermetabolism in a group of gastric and colorectal (GCR) cancer patients was only $13 \%$ (13 out of 104). When corrected for fat free mass REE was still significantly higher $(p<0.001)$ in the lung cancer group compared to the GCR cancer group. Whereas weight loss in healthy men leads to an adaptational decrease in energy expenditure, weight loss in the lung cancer patients was accompanied by an increase in REE. Tumor stage, tumor localisation, pulmonary function or smoking behaviour could not explain the observed increase in REE in lung cancer patients. Therefore, these metabolic alterations appear to be tumor mediated.

\section{INTRODUCTION}

Weight loss is a well known phenomenon in cancer patients. Weight loss is caused by a negative energy balance, resulting from decreased energy intake (Eli) or increased energy expenditure (EE), or both. Several authors have suggested that cancer patients have an increased energy metabolism that significantly contributes to the development of cancer cachexia (1-5).

It is a common clinical finding that weight loss and cachexia occur frequently in lung cancer patients. Hansell et al compared resting energy expenditure (REE) of 11 non-small cell lung cancer patients with values of gastric and colorectal cancer patients and found a significantly higher REE in the lung cancer patients. When corrected for fat free mass (FFM) this difference lost significance (6). Otherwise, Russell et al studied energy metabolism in 31 patients with small cell cancer and demonstrated measured REE to be $31 \%$ higher than predicted REE (7). 
The present study was designed to further elucidate the contribution of hypermetabolism to the development of cachexia in non-small cell lung cancer patients.

\section{METHODS}

Thirty newly detected non-small cell lung cancer patients were included in the study. All patients had histologically documented tumor, and none had been treated previously with chemotherapy or radiotherapy.

REE was measured by indirect calorimetry using a ventilated hood system. Gas analyses were performed using a paramagnetic oxygen analyser (Mijnhardt module, Bunnik) and an infrared carbon dioxide analyser (modified UG51, Mijnhardt, Bunnik). Dry gases were measured and the results converted to standard temperature and pressure. Flow through the canopy was kept constant during measurements and was adjusted to the body weight of the patient (25-50 $\mathrm{L} / \mathrm{min}$ ). System control and calculations were performed on a microcomputer. The equipment was calibrated at the start and at the end of every experiment. The hood consisted of clear plexiglas and had a volume of $30 \mathrm{~L}$. REE was calculated using the abbreviated Weir formula (8). After an overnight fast, and while at complete rest, a measurement was made over a 30-min period.

Measured REE was compared with predicted REE calculated by the HB formula (9). Patients with a measured REE above $115 \%$ of that predicted by the $\mathrm{HB}$ formula were considered hypermetabolic. This definition of hypermetabolism was based on Boothby's finding that $95 \%$ of normal individuals exhibit measured REE within $10 \%$ of predicted $(10)$, and on a measurement error of $5 \%$ or less. REE in these lung cancer patients was compared with REE in a group of 104 newly detected gastric and colorectal (GCR) cancer patients measured according to the same procedure.

FFM was estimated with the bioelectrical impedance method (RJL-Systems ${ }^{\text {, }}$, BIA-101, Detroit) and was calculated using the formulae of Segal (11) The percentage weight change from reported pre-illness stable weight was used to divide patients into weight stable ( $<5 \%$ weight loss) or weight losing groups ( $\geq 5 \%$ weight loss). Actual body weight was also presented as a percentage of ideal body weight (PIBW) (12). Tumor stage was assessed according to the classification of the International Union against Cancer (13). Spirometric tests included measurement of forced expiratory volume in $1 \mathrm{~s}\left(\mathrm{FEV}_{1}\right)$, which was expressed as a percentage of the reference value (14).

REE was expressed in absolute terms (REE), per kg body weight (REE/BW), per $\mathrm{kg}$ FFM (REE/FFM) and as a percentage of the HB value (REE/HB). The Mann- 
Whitney $U$ test and the chi-square test were used for nonparametric statistical analyses. Further statistical procedures included Pearson correlation. Results are presented as mean $\pm \mathrm{SD}$. P-values $<0.05$ were regarded as statistically significant.

\section{RESULTS}

Twenty-seven men and three women with lung cancer were included in the study (Table 1). Their mean PIBW was $92 \%$ and their mean FEV 1 was $85 \%$ of the reference value. One hundred and four patients with GCR cancer were included in the study. Percentage weight loss was the same for both groups. Compared to the GCR cancer group males were relatively overrepresented in the lung cancer group. Lung cancer patients were younger and had a lower PIBW.

TABLE 1.

Patient characteristics.

\begin{tabular}{lccc}
\hline & $\begin{array}{l}\text { lung cancer } \\
\text { patients } \\
(\mathrm{n}=30)\end{array}$ & $\begin{array}{l}\text { GCR cancer } \\
\text { patients } \\
(\mathrm{n}=104)\end{array}$ & p-value \\
\hline age $(\mathrm{y})$ & $65 \pm 8$ & $70 \pm 11$ & $<0.05$ \\
sex (male/female) & $27 / 3$ & $54 / 50$ & $<0.001$ \\
weight $(\mathrm{kg})$ & $64.6 \pm 11.6$ & $65.2 \pm 11.6$ & $>0.05$ \\
fat free mass $(\mathrm{kg})$ & $49.0 \pm 8.2$ & $45.5 \pm 8.8$ & $>0.05$ \\
weight loss $(\%)$ & $6.4 \pm 6.8$ & $7.1 \pm 6.4$ & $>0.05$ \\
PIBW $(\%)$ & $92 \pm 11$ & $99 \pm 13$ & $<0.01$ \\
FEV & $85 \pm 20$ & - & \\
\hline
\end{tabular}

Mean values $\pm S D$

PIBW=percentage ideal body weight; $F E V_{1}=$ forced expired volume in $1 \mathrm{~s}$;

$\mathrm{GCR}=$ gastric and colorectal

$\mathrm{REE} / \mathrm{HB}$ revealed a significant elevation of $20 \%$ in $\|$ ung cancer patients (Table 2). Sixty percent (18/30) of the lung cancer patients were hypermetabolic and only $40 \%$ $(12 / 30)$ had a REE within the range $85-115 \%$ of predicted.

REE in lung cancer patients even when corrected for FFM was significantly increased when compared with GCR cancer patients. Significantly more lung cancer patients than GCR cancer patients proved to be hypermetabolic ( $\mathrm{p}<0.001$ ) (Table 2). Males were relatively overrepresented in the $\mathrm{L}$ cancer group compared to the GCR cancer group. However, REE/FFM in male $L$ cancer patients was also significantly elevated when compared to male GCR cancer patients ( $\mathrm{p}<0.001)$. 
chapter 7

TABLE2.

Resting energy expenditure (REE) in patients with lung cancer and gastric and colorectal (GCA) cancer.

\begin{tabular}{lccc}
\hline & $\begin{array}{l}\text { lung cancer } \\
\text { patients } \\
(\mathrm{n}=30)\end{array}$ & $\begin{array}{l}\text { GCR cancer } \\
\text { patients } \\
(\mathrm{n}=104)\end{array}$ & p-value \\
\hline REE (kcal/day) & $1615 \pm 246$ & $1352 \pm 231$ & $<0.001$ \\
REE $(\% \mathrm{HB})$ & $120 \pm 13$ & $104 \pm 10$ & $<0.001$ \\
REE (kcal/kgBW) & $25.4 \pm 3.7$ & $20.9 \pm 2.7$ & $<0.001$ \\
REE (kcal/kgFFM) & $33.7 \pm 4.1$ & $29.8 \pm 4.3$ & $<0.001$ \\
hypermetabolism $(\%)$ & 60 & 13 & $<0.001$ \\
RQ & $0.79 \pm 0.03$ & $0.78 \pm 0.04$ & $>0.05$
\end{tabular}

Mean values $\pm \mathrm{SD}$

$\mathrm{HB}=$ Harris Benedict; $\mathrm{AO}=$ respiratory quotient; $F F M=$ fat tree mass; $\mathrm{BW}=$ body weight

A significant correlation existed between REE/FFM and percent weight loss $(\mathrm{r}=0.61 ; \mathrm{p}<0.001$ ) (Figure 1). REE/BW as well as REE/FFM were significantly higher in the weight losing patients compared to the weight stable patients $(\mathrm{p}<0.01)$. Both weight stable and weight losing groups had an elevated REE/HB (Figure 2).

A comparison between the hypermetabolic and the normometabolic patients showed no significant differences with respect to body temperature, pulmonary function, smoking behaviour, tumor localisation and tumor stage (Table 3).

However, significant correlations existed between REE/BW and body temperature $(\mathrm{r}=0.61 ; \mathrm{p}<0.01), \mathrm{FEV}_{1}(\mathrm{r}=-0.37 ; \mathrm{p}<0.05)$ and smoking $(\mathrm{r}=0.36 ; \mathrm{p}<0.05)$. The correlation coefficients for REE/BW and tumor localisation and tumor stage were not significant. An elevated REE/BW was found for patients with a $F E V_{1}$ below $75 \%$ of the reference value, for patients with a body temperature of $37.5^{\circ} \mathrm{C}$ or higher and for smokers (Table 4). However, for REE/FFM these differences were not or less significant. 


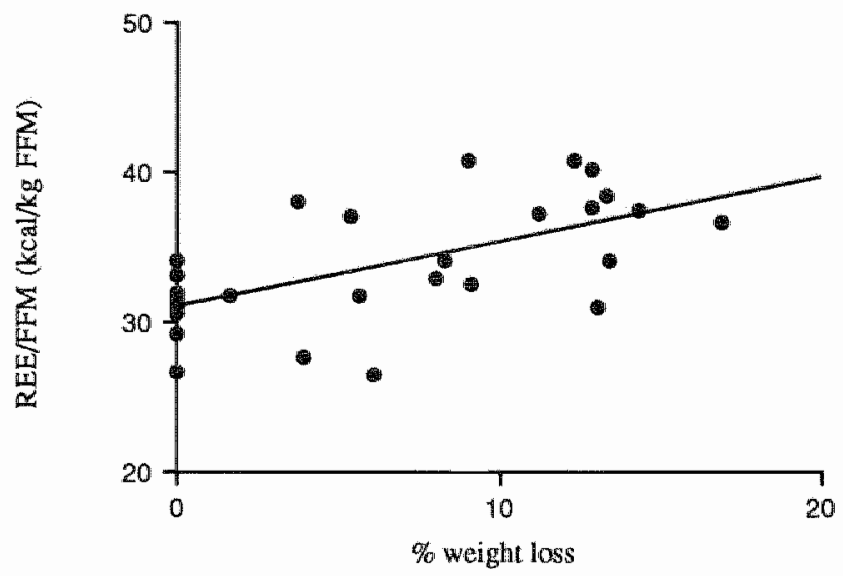

FIGURE I.

Correlation between resting energy expenditure per $\mathrm{kg}$ fat free mass (REEIFFM) and to we ight loss $(r=0.61 ; p<0.001)$.

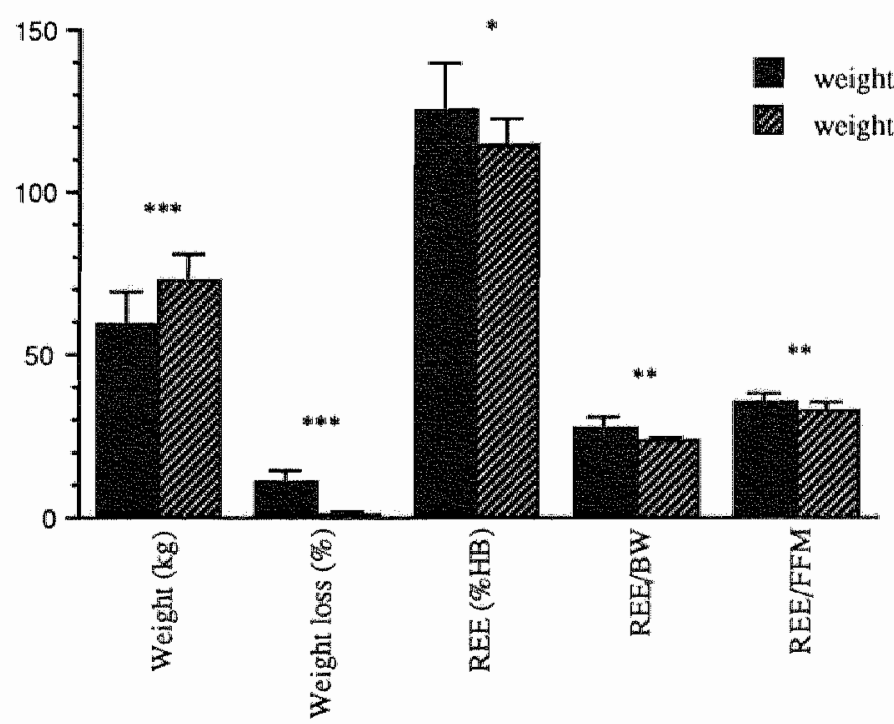

FIGURE 2 .

Body weight, weight loss, resting energy expenditure as of of the Harris Benedict walue (REE (FHB)), expressed per $\mathrm{kg}$ body weight (REEIBW) or per $\mathrm{kg}$ fat free mass (REEIFFM) of weight losing $(n=17)$ and weight stable $(n=13)$ lung cancer patients. $* p<0.05$, ** $p<0.01$. $* * 0<001$. Mean values $\pm S D$. 
Table 3.

Characteristics of hypermetabolic and normometabolic lung cancer patients.

\begin{tabular}{lccc}
\hline & $\begin{array}{l}\text { hypermetabolic }) \\
\text { patients } \\
(\mathrm{n}=18)\end{array}$ & $\begin{array}{l}\text { normometabolic } \\
\text { patients } \\
(n=12)\end{array}$ & p-value \\
\hline REE (\%HB) & $128 \pm 11$ & $109 \pm 5$ & \\
weight (kg) & $62.3 \pm 11.6$ & $67.9 \pm 11.2$ & $>0.05$ \\
lat free mass (kg) & $47.4 \pm 8.2$ & $51.4 \pm 7.8$ & $>0.05$ \\
FEV $(\%)$ & $83 \pm 22$ & $90 \pm 17$ & $>0.05$ \\
body temperature $\left({ }^{\circ} \mathrm{C}\right)$ & $37.1 \pm 0.7$ & $36.9 \pm 0.3$ & $>0.05$ \\
smoking (yes/no) & $16 / 2$ & $8 / 4$ & $>0.05$ \\
tumor localisation & & $9 / 3$ & $>0.05$ \\
(peripheral/central) & $10 / 8$ & $7 / 5$ & $>0.05$ \\
tumor stage & $11 / 7$ & & \\
$(1-2 / 3-4)$ & & & \\
\hline
\end{tabular}

Mean values $\pm S D$; 1) REE/HB $\geq 115 \%$

REE = resting energy expenditure; $H B=$ Harris Benedict

$\mathrm{FEV} \mathrm{V}_{1}=$ forced explied volume in $1 \mathrm{~s}_{\|}^{\circ} \mathrm{C} C=$ degree Celcius

\section{DISCUSSION}

Weight loss is a well known phenomenon in cancer patients, and particularly in lung cancer patients. Weight loss is the result of a disbalance between $\mathrm{EI}$ and $\mathrm{EE}$. Especially in lung cancer patients an elevated $E E$ is of interest, because apart from the possible tumor mediated thermogenesis the deterioration of pulmonary function may influence energy metabolism (15). Furthermore, most lung cancer patients are heavy smokers, which in itself is associated with an increased EE (16). Therefore, these and several other aspects were taken into account in order to estimate their relative contribution leading to an increased $\mathrm{EE}$.

In the present study REE measurements in patients with newly detected non-small cell lung cancer indicated that $60 \%$ had an elevated REE compared to the HB formula as a reference. The validity of the $\mathrm{HB}$ formula to predict REE accurately in patients is under debate, particularly in patients with weight loss (17). However, in the current study REE of lung cancer patients was also compared with REE of GCR cancer patients. The prevalence of hypermetabolism in the GCR cancer patients was only $13 \%$. Both groups of cancer patients had the same percentage of weight loss. Therefore, these results suggest that cancer cachexia in GCR cancer patients is most likely the result of a decreased food intake, while in lung cancer patients also an elevated REE has to be considered. 
TABLE 4.

Resting energy expenditure per $\mathrm{kg}$ body weight (REE/BW) and per $\mathrm{kg}$ fat free mass (REE/FFM) in lung cancer patients in relation to body temperature, pulmonary function, smoking behaviour, tumor localisation and tumor stage.

\begin{tabular}{|c|c|c|c|c|}
\hline & REE/BW & $p$-value & REE/FFM & $p$-value \\
\hline pulmonary function & & $<0.05$ & & 0.07 \\
\hline $\mathrm{FEV}_{1}<75 \%(\mathrm{n}=9)$ & $27.4 \pm 3.6$ & & $35.6 \pm 3.9$ & \\
\hline$F E V_{1} \geq 75 \%(n=21)$ & $24.5 \pm 3.5$ & & $32.8 \pm 3.9$ & \\
\hline body temperature & & $<0.01$ & & $<0.01$ \\
\hline$\geq 37.5^{\circ} \mathrm{C}(n=5)$ & $30.2+1.9$ & & $38.2 \pm 1.6$ & \\
\hline$<37.5^{\circ} \mathrm{C}(\mathrm{n}=25)$ & $24.4 \pm 3.2$ & & $32.8 \pm 3.8$ & \\
\hline smoking behaviour & & $<0.05$ & & 0.09 \\
\hline smokers $(n=24)$ & $26.0 \pm 3.8$ & & $34.2 \pm 4.3$ & \\
\hline non-smokers $(n=6)$ & $22.8 \pm 1.3$ & & $31.3 \pm 1.3$ & \\
\hline tumor localisation & & $>0.1$ & & $>0.1$ \\
\hline central tumor $(n=11)$ & $26.4 \pm 3.8$ & & $34.7 \pm 3.9$ & \\
\hline peripheral tumor $(n=19)$ & $24.8 \pm 2.6$ & & $33.1 \pm 4.2$ & \\
\hline turnor stage & & $>0.1$ & & $>0.1$ \\
\hline stage $1-2(n=18)$ & $25.2 \pm 4.0$ & & $33.3 \pm 4.4$ & \\
\hline stage $3-4(n=12)$ & $25.7 \pm 3.2$ & & $34.5 \pm 3.5$ & \\
\hline
\end{tabular}

Mean values $\pm \mathrm{SD}$

$F E V_{1}=$ forced expiratory volume in 4 secand

Over the years a number of studies have estimated the changes in energy metabolism associated with lung cancer. Some of these studies have found no change in REE (18-20), others have demonstrated an increase of 10 to $30 \%$ $(6,7,21)$. The observation in the current study that REE was significantly increased, no matter how it was expressed, is in contrast to Hansell's study where REE/FFM was not significantly different between the lung cancer and gastric and colorectal cancer group (6). However, the number of $\mathbb{L}$ cancer patients that was measured in their study was small $(n=11)$.

REE was higher in weight-losing lung cancer patients compared to weight-stable lung cancer patients. This is in contrast with the decrease in EE which normally occurs during starvation and weight loss in healthy men and women (22). The 
positive correlation found between REE/FFM and percent weight loss therefore suggests that increased REE leads to weight loss.

Mean body temperature nor mean FEV1 were significantly different in the hypermetabolic group compared to the normometabolic group. Furthermore no significant differences in smoking behaviour, tumor stage or tumor localisation could be established between both groups. However, some findings seem to be of interest.

The hypermetabolic group included five patients with a body temperature of $37.5^{\circ} \mathrm{C}$ or higher and three of these patients had an obstructive infiltrate as the result of a central tumor.

REE was not significantly different between tumor stages. Only two patients with distant metastases were measured. Therefore, it could not be established whether patients with metastatic disease have a higher REE compared with patients who have a localized malignancy.

Schols et al (23) found in a group of patients with chronic obstructive pulmonary disease (COPD) $\left(\mathrm{FEV}_{1}=35 \%\right)$ that $51 \%$ exhibited an increased REE. In the hypermetabolic patients mean $\mathrm{FEV}_{1}$ was significantly lower than in the normometabolic patients with COPD ( 29 vs $42 \% ; \mathrm{p}<0.001$ ). In the current study however, mean $\mathrm{FEV}_{1}$ was normal for the lung cancer patients. Therefore, an increased work of breathing secondary to an airway obstruction does not seem to have had an important influence on energy metabolism in this study group.

Although the difference in smoking behaviour between hypermetabolic and normometabolic patients was not statistically significant, it would reach statistical significance when approximately 90 patients were included in the study.

Six patients stopped smoking at least six months before study entry and four of them were not hypermetabolic. It is suggested in the literature that cigarette smoking influences EE by stimulation of the sympathetic nervous system (16). Therefore, it is likely that smoking is of importance to explain the observed increase in REE. However, the magnitude of the effect has to be studied in more detail.

An additional statistical analysis was performed to test whether REE was also elevated for non-smoking patients with a normal body temperature $\left(36.7^{\circ} \mathrm{C}\right)$. For this purpose a multiple regression model was used with REE/HB as dependent variable and body temperature and smoking behaviour as independent variables. However, the estimated REE/HB for the above-mentioned patients was 
$113.7 \% \pm 4.8 \%$ (SEM), thus also significantly higher than $100 \%(\mathrm{p}=0.01)$.

In this study the observed increase in REE in lung cancer patients cannot be fully explained by tumor stage, tumor localisation, pulmonary function, smoking behaviour or body temperature. It therefore appears that elevated REE is induced by the tumor itself. To test this hypothesis it is necessary to measure REE in patients pre- and post tumor resection.

We conclude that a considerable number of patients $(60 \%)$ with newly detected primary lung cancer are hypermetabolic. Although the pathogenesis most likely is multifactorial, the tumor itself appears to mediate these metabolic alterations to a significant degree.

\section{REFERENCES}

1. Arbeit JM, Lees, DE,Brennan MF. Resting energy expenditure in controls and cancer patients with localized and diffuse disease. Ann Surg 1984;199:292-298.

2. Bozzetti F Pagnoni AM. Del Vecchio M. Excessive caloric expenditure as a cause of malnutrition in patients with cancer. Surg Gynecol Obstet 1980;150:229-234.

3. Macfie $\mathrm{J}$, Burkinshaw $\mathrm{L}$, Oxby $\mathrm{C}$ et al. The effect of gastrointestinal malignancy on resting metabolic expenditure. Br J Surg 1982;69:443-446.

4. Warnold I, Lundholm $\mathbb{K}_{n}$ Schersten $T$. Energy balance and body composition in cancer patients. Cancer Res 1978;38:1801-1807.

5. Lindmark L, Bennegard $\mathrm{K}$, Eden $\mathrm{E}$ et al. Resting energy expenditure in malnourished patients with and without cancer. Gastroenterology 1984;87:402-408.

6. Hansell DT, Davies JWL, Burns HJG. The effects on resting energy expenditure of different tumor types. Cancer 1986;58:1739-1744.

7. Russell DMcR, Shike M, Marliss EB et al. Effects of total parenteral nutrition and chemotherapy on the metabolic derangements in small cell lung cancer. Cancer Res 1984:44:1706-1711.

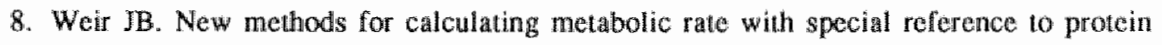
metabolism. J Physiol 1949:109:1-12.

9. Harris JA, Benedict FG. A biometric study of basal metabolism in man, publication no. 279. Washington DC: Carnegie Institute of Washington 1919.

10. Boothby WM, Berkson J, Dunn HL. Studies on the energy of metabolism of normal individuals: A standard for basal metabolism with a nomogram for clinical application. Am $J$ Physiol 1936;3:468-483.

11. Segal KR, Van Loan M, Fitsgerald PI., Hodgdon JA, Van Itallie TB. Lean body mass estimation by bioclectrical impedance analysis: a four-site cross-validation study. Am J Clin Nutr $1988 ; 47: 7-14$.

12. Metropolitan Lile Insurance Company. Desirable weights for men: desirable weights for women, Stat. Bul. no. 23 and 24. New York: Life Extension Institute of New York City 1943. 
13. viCC. Lung tumour. In: Hemanek, Sobin LH. eds., TNM classification of malignant tumowrs. Berlin Heidelberg New York London Paris Tokyo.: Springer-Verlag 1987.

14. Quanjer PH ed. Standardized lung function testing. Clin Resp Physioll 1983;19:7-44.

15. Edelman $\mathrm{NH}$, Rucker RB, Peavy $\mathrm{HH}$. Nutrition and the respiratory system: Chronic Obstructiwe Pulmonary Disease (COPD). Am Rev Respir Dis 1986;134:347-352.

16. Hofstetter A, Schutz $\Psi$, Jequier E et all. Increased 24 hour energy expenditure in cigaretee smokers. N Engl J Med 1986;314:79.82,

17. Roza $\mathrm{AM}_{*}$ shizgal HM. The Harris Benedict equation reevaluated: resting energy requirements and the body cell mass. Am J Clin Nutu 1984;40:168-182.

18. Heber D, Chlebowsiki RT, Ishibashi DE, Herrold JN, Block JB. Abnormalities in glucose and protein metabolism in noncachectic lung cancer patients. Cancer Res 1982;42:4815-4819.

19. Fearon KCH, Hansell DT, Preston T et al. Influence of whole body protein turnover rate on resting energy expenditure in patients with cancer. Cancer Res 1988;48:2590-2595.

20. Nixon DW, Kutner $M$, Heymsfield $S$ et al. Resting energy expenditure in lung and colon cancer. Metabolism 1988;37:1059-1064.

21. Axelrod L, Halter JB, Cooper DS, Aoki TT, Roussell AM, Bagshaw SL. Hormone levels and fuel flow in patients with weight loss and lung cancer. Evidence for excessive metabolic expenditure and for an adaptive response mediated by a reduced lewel of 3,5,3:-triiodothyronine. Metabolism 1983;32:924-937.

22. Brennan MF. Uncomplicated starwation versus cancer cachexia. Cancer Res 1977;37:2359364.

23. Schols AMWJ, Mostert R, Soeters PB, Greve LH, Wouters EFM. Resting energy expenditure in COPD. (Abstr) Eur Respir J 1989;2:359S. 


\section{CHAPTER 8}

\section{RESTING ENERGY EXPENDITURE IN PATIENTS WITH NEWLY DETECTED GASTRIC AND COLORECTAL CANCER}

EWHM Fredrix; PB Soeters; MMJ Rouflart; MF von Meyenfeldt; WHM Saris

From the Department of Human Biology, Surgery and the Nutritional Support

Team, University of Limburg, PO Box 616,6200 MD, Maastrich, The Netherlands

\section{submitted for publication}

\section{SUMMARY}

It has been suggested that an increase in resting energy expenditure (REE) contributes to weight loss in cancer patients. In the current study, REE was measured in 104 patients with newly detected gastric and colorectal cancer (GCR) and compared with two groups of controls without cancer: healthy subjects and patients with nonmalignant diseases of the gastrointestinal (GI) tract. REE in GCR cancer patients was not significantly different from REE in GI patients or healthy controls. Comparing measured REE with prediction equations may erroneously suggest that increased REE is a contributing factor in the development of weight loss No significant differences in REE were found when patients with liver metastases were compared with patients without metastases. There were no differences in REE between gastric and colorectal cancer patients. The decrease in energy expenditure which normally occurs during starvation and weight loss in healthy men and women could not be demonstrated in weight losing GCR cancer patients. Therefore, some GCR cancer patients may be considered as relatively hypermetabolic. It is concluded that elevation of REE contributes litule to the pathogenesis of cancer cachexia in GCR cancer patients.

\section{INTRODUCTION}

Cachexia is a common feature in patients with cancer. Moreover, abnormal parameters of nutritional status are also frequently observed in cancer patients. Both increased energy expenditure (EE) and decreased dietary intake have been incriminated as the causative factor for the observed weight loss and poor nutritional status.

Several authors demonstrated that patients with malignant disease have an slevated resting energy expenditure (REE) (1-5). Others, however, have found no change: (6-10). According to Dempsey et al (11) $22 \%$ of patients with gastrointestinal cancer have a measured REE that is higher than predicted, whereas $36 \%$ have an 
abnormally low REE. In most studies the finding of an elevated REE was based on a comparison with the Harris Benedict (HB) formula (12). This formula is universally employed in hospitals to predict REE. However, recent studies demonstrated that the $\mathrm{HB}$ equation may not be the best reference in healthy men and women (13-15) or in patients (16).

The aim of the current study was to investigate the presence of aberrations in REE in patients with newly detected gastric and colorectal (GCR) cancer. These patients were compared with two groups of controls without cancer: apparently healthy subjects and patients with nonmalignant diseases of the gastrointestinal (GI) tract.

\section{METHODS}

One-hundred and four cancer patients and 72 controls without cancer were studied over a period of two years.

One hundred and four patients with histologically proven GCR cancer were included in the study. All patients were ambulatory and recently admitted to the Department of Surgery or Internal Medicine of the University Hospital of Limburg, Maastricht. All patients had newly detected cancer, so that no patient had received chemotherapy or radiation therapy previously.

Controls were patients with nonmalignant GI diseases and healthy normal subjects. Thirty-two patients with nonneoplastic GI disorders were included in the study (Table 1). Some of them were measured on an outpatient basis, others were admitted to the Department of Surgery or Internal Medicine. Fourty apparently healthy men and women participated in the study. Their REE was measured on an outpatient basis. These healthy controls underwent a medical examination to exclude disorders which might affect their metabolic rate, such as anaemia, high blood pressure, thyroid dysfunction, heart failure, infectious disease and chronic obstructive pulmonary disease (COPD).

\section{TABLE 1.}

Pathology of patients with benign gastrointestinal diseases.

\begin{tabular}{ll}
\hline pathology & number \\
\hline peptic ulceration & 8 \\
duodenal ulceration. & 11 \\
Mallory-Weiss & 1 \\
ulcerative collitis & 6 \\
diverticulitis & 4 \\
villous adenoma & 2 \\
\hline
\end{tabular}


The GCR cancer patients were retrospectively examined for the same disorders using the medical reports. Twenty-nine GCR cancer patients had to be excluded because of the above-mentioned diseases. Because limited medical information was available in some of the GI patients, it was impossible to completely rulle out the possibility that they might have suffered from disorders which may have influenced energy metabolism.

REE was calculated from measurements of oxygen uptake and carbon dioxide production. Gas exchange was measured by means of a ventilated hood system, which consisted of a dry gas meter, a blower, a paramagnetic oxygen analyser (Mijnhardt module, Bunnik), and an infrared carbon dioxide analyser (modified UG51, Mijnhardt, Bunnik). Dry gases were measured and the results converted to standard temperature and pressure. Flow through the canopy was kept constant and was adjusted to the body weight of the subject $(25-50 \mathrm{~L} / \mathrm{min})$. System control and calculations were performed on a microcomputer. The hood consisted of clear plexiglas and had a volume of $30 \mathrm{~L}$. REE was calculated using the abbreviated Weir formula (17).

GCR cancer patients and some of the GI patients were measured cluring their hospital stay between 7.00 and 10.00 AM after an overnight fast. The other GI patients and the healthy controls were measured on an outpatient basis. They came to the hospital in the moming after a 10-h ovemight fast. They travelled by car, bus or train in order to reduce their physical activity. REE was measured after a period of at least 30-min bed rest. Measurements were performed, while at complete rest, in the supine position, during a period of $30 \mathrm{~min}$. In a recent study we showed that REE in 30 healthy volunteers measured after they had spent the night in the hospital was not significantly different from REE measured after they had come from home as in this study (18).

Measured REE was compared with predicted REE calculated by the HB formula. Patients and subjects with a measured REE above $115 \%$ of that predicted by the HB formula were considered hypermetabolic. This definition of hypermetabolism was based on Boothby's finding that $95 \%$ of normal individuals exhibit measured REE within $10 \%$ of predicted (19), and on a measurement error of $5 \%$ or less.

Fat free mass (FFM) was estimated with the bioelectrical impedance (BI) method and was calculated using the formulae of Segal (20). BI was measured in only half of the gastric and colorectal cancer patients, because at the start of the study no device was available to measure body composition. The percentage weight change from reported pre-illness stable weight was used to divide patients in weight stable (less than 5\% weight loss) or weight losing groups (more than $5 \%$ weight loss). Assessment of nutritional status included also serum albumin, total iron binding 
capacity (TTBC) and percentage ideal body weight (PIBW) (21). Tumor staging was performed after review of medical reports, operative reports, and pathology and radiology reports. Tumor stage was assessed according to the guidelines of the American Joint Committee on the Staging of Cancer (22).

REE was expressed in absolute terms (REE), per kg body weight (REE/BW), per $\mathrm{kg}$ FFM (REE/FFM) or as percentage of the HB equation (REE/HB). Statistical analysis was performed using the Tukey pairwise multiple comparison procedure. The Mann-Whitney $U$ test was used where appropriate. Frequency data were compared using the Chi-square test. Results are presented as mean \pm SD and $p$ values $<0.05$ were regarded as statistically significant.

\section{RESULTS}

GCR cancer patients were older than healthy controls and GI patients (Table 2). There was no significant difference in sex between the groups. Body weight and PIBW were lower in the GCR cancer patients compared to healthy controls. Albumin and TIBC were also significantly lower in GCR cancer patients and in GI patients. GCR cancer patients showed more weight loss than Gl patients ( $7.1 \%$ vs $4.0 \%, \mathrm{p}<0.01)$.

TABLE 2.

Patient characteristics.

\begin{tabular}{|c|c|c|c|}
\hline & $\begin{array}{l}\text { GCF cancer patients } \\
(n=104)\end{array}$ & $\begin{array}{l}\text { Gl patients } \\
(n=32)\end{array}$ & $\begin{array}{l}\text { healthy controls } \\
(n=40)\end{array}$ \\
\hline age $(y)$ & $70 \pm 111^{* * *} ;$ & $64 \pm 14$ & $65 \pm 8$ \\
\hline body weight (kg) & $65.2 \pm 11.6 *$ & $67.4 \pm 12.7$ & $72.1 \pm 12.1$ \\
\hline PIBW $(\%)$ & $99 \pm 13^{* *}$ & $99 \pm 12^{\$}$ & $105 \pm 11$ \\
\hline weight loss $(\%)$ & $7.1 \pm 6.4^{\#}$ & $4.0 \pm 4.9$ & 1) \\
\hline albumin (g/L) & $34 \pm 4^{* * * *}$ & $35 \pm 4 \$ \$$ & $40 \pm 3$ \\
\hline TIBC ( $\mu$ mollL) & $50.1 \pm 11.6^{* * * *}$ & $49.2 \pm 8.8^{\$ \$ \$}$ & $55.9 \pm 7.4$ \\
\hline sex (male/female) & $54, \sqrt[50]{ }$ & $20 / 12$ & $18 / 22$ \\
\hline
\end{tabular}

Meain valuestSD; 1) weight stable

PIBW=percentage ideal body weight; $T I B C=$ =tolal iron binding capacity

GCA $=$ gastric and colorectal; Gl=benign gastrointestinal disease

* $p<0.01 \mathrm{GCR}$ ws contrals; *" $p<0.001 \mathrm{GCR}$ vs controls

$\# p<0.05$ GCR ws Gl; $p<0.01$ GCA ws Gil

$\$ p<0.05$ Gl vs controls; $\$ \$ p<0.001$ GI vs controls

REE in absolute terms was significantly higher in the healthy controls compared to the GCR cancer patients (Table 3). However, no significant differences existed between the three groups for REE/BW, REE/FFM and REE/HB. Thirteen percent 
(13 out of 104) of the GCR cancer patients were hypermetabolic compared to $13 \%$ (4 out of 32) and 20\% (8 out of 40) in GI patients and healthy controls. respectively. This prevalence of hypermetabolism was not significantly different between the groups.

TABLE 3.

Resting energy expenditure (REE) in gastric and colorectal (GCR) cancer patients, compared to patients with benign gastrointestinal (GI) diseases and healthy controls.

\begin{tabular}{lcccc}
\hline & \multicolumn{2}{c}{ GCR cancer patients } \\
$(n=104)$ & $(n=75)^{1)}$ & $\begin{array}{l}\text { Gi patients } \\
(n=32)\end{array}$ & $\begin{array}{l}\text { healthy controls } \\
(n=40)\end{array}$ \\
\hline REE (kcal/day) & $1352 \pm 231^{* *}$ & $1364 \pm 243^{* \star}$ & $1.420 \pm 194$ & $1512 \pm 269$ \\
FEE (kcal/kgBW) & $20.9 \pm 2.7$ & $20.6 \pm 2.5$ & $21.5 \pm 3.0$ & $21.0 \pm 2.0$ \\
REE $(\mathrm{kcal} / \mathrm{kgFFM})$ & $29.8 \pm 4.3$ & $28.5 \pm 2.7$ & $29.0 \pm 2.8$ & $29.6 \pm 2.9$ \\
REE $(\% \mathrm{HB})$ & $104 \pm 10$ & $103 \pm 9$ & $103 \pm 9$ & $107 \pm 8$ \\
hyper $(\%)$ & 13 & 9 & 13 & 20 \\
\hline
\end{tabular}

Mean valuest $\mathrm{SD}_{\text {; }}^{-1}$ excluded those with disorders which might affect REE

BW=body weight; FFM=fat free mass

$\mathrm{HB}=$ Harris Benedict; , hyper=hypermetabolic

*** $p<0.01$ GCR vs controls

A comparison between the 29 excluded GCR cancer patients and the 75 notexcluded patients revealed that the excluded patients were older, had lower PIBW and lower serum albumin and had more weight loss. Tumor stage or the presence of distant metastases were not significantly different between both groups. REE tended to be higher in the excluded patients (REE/HB: $p<0.05$; REE/BW: $\mathrm{p}=0.07$ and REE/FFM: $p=0.10$ ). Nine percent (7 out of 75) of the not-excluded patients were hypermetabolic (Table 3). A comparison between the not-excluded GCR cancer patients with the GI patients or the healthy controls revealed no significant differences for REE/BW, REE/FFM and REE/HB.

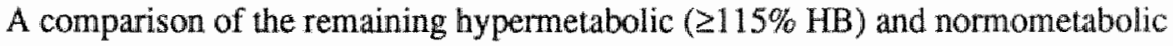
GCR cancer patients showed no differences with respect to age, tumor site and tumor stage, serum albumin and TIBC (Table 4). Weight loss was $14.2 \%$ for the hypermetabolic patients, in contrast to a $5.6 \%$ weight loss for the normometabolic patients. The hypermetabolic group comprised more smokers than the normometabolic group. It must be emphasized that the number of hypermetabolic patients was relatively small $(n=7)$. 
chapter 8

TABLE 4.

Comparison beween hypermetabolic and normometabolic gastric and colorectal (GCR) cancer patients.

\begin{tabular}{|c|c|c|c|}
\hline & $\begin{array}{l}\text { hypermetabolic } 1) \\
\text { patients }(n=7)\end{array}$ & $\begin{array}{l}\text { normometabolic } \\
\text { patients }(n=68)\end{array}$ & p-value \\
\hline REE $(\% H B)$ & $124 \pm 8$ & $100 \pm 6$ & \\
\hline age $(y)$ & $70 \pm 5$ & $68 \pm 11$ & $>0.1$ \\
\hline body weight (kg) & $59.8 \pm 6.6$ & $67.4 \pm 11.9$ & $<0.05$ \\
\hline PIBW $(\%)$ & $87 \pm 10$ & $102 \pm 12$ & $<0.01$ \\
\hline weight loss (\%) & $14.2 \pm 9.9$ & $5.6 \pm 5.2$ & $<0.01$ \\
\hline albumin (g/L) & $32+3$ & $35 \pm 4$ & 0.07 \\
\hline TIBC (umol/L) & $45.1 \pm 12.2$ & $48.8 \pm 11.2$ & $>0.1$ \\
\hline sex (male/female) & $6 / 1$ & $33 / 35$ & $>0.1$ \\
\hline tumor site $(\mathrm{G} / \mathrm{CA})$ & $3 / 4$ & $13 / 55$ & $>0.1$ \\
\hline liver metastases $(\%)$ & 43 & 21 & $>0.1$ \\
\hline smoking (yes/no) & $5 / 2$ & $19 / 49$ & $<0.05$ \\
\hline
\end{tabular}

Mean valuestSD, ") REE/HB2115\%

PIBW=percentage ideal body weight; TIBC=total iron binding capacity; $H B=H a r r i s$ Benedict

Twenty percent (11 of 54) of the male GCR cancer patients were hypermetabolic compared to only $4 \%$ ( 2 of 50 ) in fermale GCR cancer patients. This difference was significant. There were no significant differences between gastric and colorectal cancer patients, except that significantly more gastric cancer patients were smokers. No significant differences in REE were found when patients with liver metastases were compared to patients without metastases (Table 5).

TABLE 5.

Resting energy expenditure (AEE) in gastric and colorectal cancer patients with and without liver metastases.

\begin{tabular}{lccc}
\hline & $\begin{array}{l}\text { liver metastases } \\
(\mathrm{n}=25)\end{array}$ & $\begin{array}{l}\text { no liver metastases } \\
(\mathrm{n}=79)\end{array}$ & p-value \\
\hline REE (kcal/day) & $1339 \pm 244$ & $1356 \pm 228$ & $>0.05$ \\
REE (kcal/kgBW) & $21.7 \pm 3.2$ & $20.7 \pm 2.5$ & $>0.05$ \\
REE (kcal/kg FFM) & $29.7 \pm 3.2$ & $29.1 \pm 4.6$ & $>0.05$ \\
REE (\%HB) & $108 \pm 11$ & $103 \pm 9$ & $>0.05$ \\
hypermetabolism $(\%)$ & 20 & 10 & $>0.05$
\end{tabular}

Mean walues $t S D$; $B W=b o d y$ weight; $F F M=$ fat free mass; $H B=$ Harris Benedict 
The correlation between REE/BW or REE/FFM and percent weight loss was significant for the GCR cancer patients $(r=0.40 ; p<0.001$ and $t=0.30 ; p<0.05$ respectively), but not for the GI patients. No significant differences in REE were found when weight losing GCR cancer patients were compared with weight losing GI patients (Table 6). REE/BW, REE/FFM and REE/HB of weight losing GCR cancer patients were not different from that of weight stable GCR cancer patients or healthy controls.

TABLE 6.

Resting energy expenditure (REE) in weight losing and weight stable patients.

\begin{tabular}{|c|c|c|c|c|c|}
\hline & \multicolumn{2}{|c|}{ GCA cancer patients } & \multicolumn{2}{|c|}{ Gi patients } & \multirow[t]{2}{*}{ controis } \\
\hline & $\begin{array}{l}\text { weight losing } \\
(n=58)\end{array}$ & $\begin{array}{l}\text { weight stable } \\
(n=46)\end{array}$ & $\begin{array}{l}\text { weight losing } \\
(n=12)\end{array}$ & $\begin{array}{l}\text { weight stable } \\
(n=20)\end{array}$ & \\
\hline REE (kcal/day) & $1302 \pm 210^{\text {wat }}$ & $1416+242$ & $1371+236$ & $1449 \pm 164$ & $1512 \pm 269$ \\
\hline REE (kcal/kgBW) & $21.5 \pm 3.1$ & $20.2 \pm 1.9$ & $21.6 \pm 3.9$ & $21.4 \pm 2.5$ & $21,0 \pm 2,0$ \\
\hline REE (kcal/kgFFM) & $29.3 \pm 4.9$ & $29.2+2.5$ & $29.7 \pm 3.1$ & $28.5+2.6$ & $29.6 \pm 2.9$ \\
\hline REE $(\% \mathrm{HB})$ & $105 \pm 1$ & $102+8$ & $101 \pm 9$ & $105 \pm 9$ & $107 \pm 8$ \\
\hline hyper (\%) & 17 & 7 & 8 & 15 & 20 \\
\hline
\end{tabular}

Mean valueS $\pm S D$

$B W=$ body weight; FFM=fat free mass: $\mathrm{HB}=$ Harris Benedict; hyper=hypermetabolic $\mathrm{GCR}=$ gastric and colorectal; $\mathrm{Gl}=$ benign gastrointestinall disease

$* * *<<0.001$ GCA weight losing vs Gi weight stable and vs controls

\section{DISCUSSION}

Increased REE may contribute to the development of cancer cachexia. In most studies aberrations in REE in patients with cancer were established using the $\mathrm{HB}$ formula as a reference. This formula is a multiple linear regression equation derived from indirect calorimetry data on 239 healthy volunteers measured after an overnight fast, resting 30 minutes in bed after arrival at the study center. Boothby et al demonstrated that $95 \%$ of normal individuals exhibit measured REE within $10 \%$ of predicted $(19)$, while Dempsey et al reported that $95 \%$ of normal volunteers exhibit measured REE within $15 \%$ of predicted (11). In the current study $13 \%$ of GCR cancer patients proved to be hypermetabolic, defined as a measured REE above $115 \%$ of that predicted by the HB formula. Twenty-six percent of patients had a measured REE above $110 \%$ of that predicted by the HB formula. These percentages are higher than expected. Thus, a considerable number of GCR cancer patients is found to be hypermetabolic when measured REE is compared with the $\mathrm{HB}$ equation. 
However, the validity of the $\mathrm{HB}$ formula as a reference to establish hypermetabolism in cancer patients may be questionable. Roza and Shizgal suggested that this formula fails to predict REE accurately in many patients, particularly those with weight loss (16). As a consequence the number of hypermetabolic patients is probably overestimated. In contrast, Daly et al found that the HB equation overestimates REE in healthy men and women (15). Feurer et al found that in $20 \%$ of healthy control subjects measured REE is over or underestimated by the $\mathrm{HB}$ prediction (23). Owen et al concluded recently that the HB equation overestimates REE in healthy men and women under the age of 64 $(13,14)$. It seems more appropriate to compare REE to measured values in healthy controls of the same age. The current study revealed that $20 \%$ of the healthy controls were hypermetabolic ( $\geq 115 \% \mathrm{HB}$ ), which was not significantly different from the prevalence of hypermetabolism in GCR cancer patients. Comparison with GI patients (weight stable and weight losing) also revealed no significant difference in the prevalence of hypermetabolism. Therefore, the suggestion in many studies that an increased REE is an important contributing factor in the development of weight loss may be false, because the current study suggests that this is the result of selection of inappropriate control subjects.

Hypermetabolism ( $\geq 115 \% \mathrm{HB}$ ) coincides to a considerable extent with disorders potentially influencing energy metabolism. Six (out of 13) hypermetabolic patients had to be excluded because of diseases like hypertension, anaemia, COPD, thyroid state and severe heart failure. A comparison between the remaining hypermetabolic and normometabolic GCR cancer patients showed differences with respect to smoking behaviour, body weight and weight loss. It is suggested in the literature that cigarette smoking influences $\mathrm{EE} \mathrm{(24).} \mathrm{Therefore,} \mathrm{it} \mathrm{is} \mathrm{likely} \mathrm{that} \mathrm{smoking} \mathrm{is} \mathrm{of}$ more importance to explain the observed prevalence of hypermetabolism in GCR cancer patients than the tumor-bearing state. The sex difference in hypermetabolism is probably also due to a difference in smoking behaviour. A chi-square analysis showed a significant association between sex and smoking $\left(x^{2}=6.3, p<0.05\right)$, with significantly more males than females being smokers.

GCR cancer patients had a weight loss of almost $5 \mathrm{~kg}$ (or $7.1 \%$ ). REE of the weight losing GCR cancer patients was not significantly different compared to REE of the non-weight-losing GCR cancer patients. This is in contrast with the decrease in $\mathrm{EE}$ which normally occurs during starvation and weight loss in healthy men and women (25). Therefore, some of the GCR cancer patients that showed weight loss and that had an apparently normal REE should be considered as relatively hypermetabolic. In these patients normal adaptational mechanisms to a negative energy balance therefore appear to be disturbed. The fact that both GCR cancer and GI patients fail to adapt to starvation implies that this is not a cancerspecific phenomenon. The influence of the weight losing state on energy 
metabolism in cancer patients needs to be studied in more detail. Nixon et al measured REE several times in ten cancer patients who lost weight during the study and concluded that the change in REE with weight loss varied unpredictibly from patient to patient (9). Nevertheless, seven (out of 10) patients in their study who had a mean weight loss of $10 \%$ showed an increase in REE.

Some of the previous studies have suggested that advanced disease is associated with an increased REE $(1,4)$, but this observation has not been confirmed in the present study. Patients with metastatic disease did not have a higher REE compared with patients who had a localized malignancy. These results are in agreement with those of Hansell et al that there is no evidence that the presence of liver metastases alters REE significantly (7).

We conclude that this study demonstrates that REE is not elevated in patients. with newly detected GCR cancer. There is no evidence that tumor type (gastric or colorectal) or tumor stage is important in relation to an increase in REE in cancer patients. The disturbance of mechanisms that regulate the balance between energy intake and $\mathrm{EE}$ rather than an elevation of REE contributes to the development of weight loss in GCR cancer patients. Therefore, the suggestion that anorexia could account for the observed weight loss needs to be examined in more detail.

\section{REFERENCES}

1. Arbeit JM, Lees DE, Brennan MF. Resting energy expenditure in controls and cancer petterits with localized and diffuse disease. Ann Surg 1984;199:292-298.

2. Bozzettil F, Pagnoni AM, Del Vecchio M. Excessive caloric expenditure as a cause of malnutrition in patients with cancer. Surg Gynecol Obstet 1980;150:229-234.

3. Lindmark L, Bennegard $\mathrm{K}$, Eden E et al. Resting enetgy expenditure in malnourished patients with and without cancer. Gastroenterology 1984;87:402-408.

4. Macfie J, Burkinshaw $L$, Oxby C. Holmfield JHM, Hill GL. The effect of gastroinucatinal malignancy on resting metabolic cxpenditure. Br J Surg $1982 ; 69 ; 443-446$.

5. Wamold I, Lundholm $K$, Schersten T. Energy balance and body composition in cancer patients. Cancer Res 1978:38:1801-1807.

6. Burke M, Bryson EI, Kark AE. Dietary intakes, resting metabolic rates, and body composition in benign and malignant gastrountestinal disease. $\mathrm{Br}$ Med $\mathrm{J} 1980$; $1: 211-215$.

7. Hansell DT, Davies JWL, Burns HJG. The relationship beween rasting energy expenditure and weight loss in benign and malignant disease. Ann Surg 1986;203,240-245.

8. Hansell DT, Davies JWL, Burns HUG. The effects on resting energy expenditure of different tumor lypes. Cancer 1986;58:1739-1744.

9. Nixon DW, Kutner M, Heymsfield S et al. Resting energy expenditure in lung and colon cancer. Metabolism 1988;37:1059-1064.

10. Fearon KCH, Hansell DT, Preston T ef al. Influence of whole body protein turnover rate on resting energy expendiure in patients with cancer. Cancer Res 1988;48:2590-2595. 
11. Dempsey DT; Feurer ID, Knox LS et al. Energy expenditure in malnowrished gastrointestinal cancer patients. Cancer 1984;53:1265-1273.

12. Harris $\mathrm{JA}$, Benedict $\mathrm{FG}$. A biometric study of basal metabolism. Publication no 279. Camegie Institution, Washington 1919.

13. Owen $O E$, Kavle $\mathbb{E}_{;}$Owen $R S$ et al. A reappratsal of caloric requirements in healthy women. Am J Clin Nutr 1986:44:1-19.

14. Owen OE, Holup $\mathrm{JL}$, D'Alessio DA et all. A reappraisal of the caloric requirements of men. Am J Clin Nutr 1987;46:875-885.

15. Daly $J$, Heymsfield $S$, Head $C$ et al. Human energy requirements: owerestimation by widely used prediction equation. Am J Clin Nutr 1985;42:1170-1174.

16. Roza AM, Shizgall HM. The Harris Benedict equation reevaluated: resting energy requirements and the body cell mass. Am J Clin Nutr 1984;40:168- 182.

17. Weir JB. New methods for calculating metabolic rate wih special reference to predict protein metabolism. J Physiol 1949;109:1-9.

18. Firedrix EWHM, Soeters PB, Meyenfeldt MF won, Saris WHM 1989 Resting energy expenditure in a clinical setting (this thesis chapter 4).

19. Boothby WM. Berkson J, Dunn HL. Studies on the energy of metabolism of normal individuals: A standard for basal metabolism with a nomogram for clinical application. Am J Physiol 1936;3:468-483.

20. Segall KR, Van Loan M, Fitzgerald PI. Hodgdon JA, Van Itallie TB. Lean body estimation by bioelectrical impedance analysis: a four-site cross-validation study. Am I Clin Nutr $1988: 47: 7-14$.

21. Metropolitan Life Insurance Company. Desirable weights for men: desirable weights for women. Stat, Bul. no. 23 and 24. Life Extension Institute, New York 1943.

22. American Joint Committee on Cancer. Manual for Staging of Cancer. Lippincot Company, Philadelphia 1983.

23. Feurer ID, Crosby LO, Mullen $\pi L$. Measured and predicted resting energy expenditure in clinically stable patients. Clin Nutr 1984;3:27-34.

24. Hofstenter A, Schutz $\mathrm{Y}$, Jequier $\mathrm{E}$ et al. Increased 24-hour energy expenditure in cigarette smokers. N Engl J Med 1986;314:79-82.

25. Brennan MF. Uncomplicated starvation versus cancer cachexia. Cancer Res 1977;37:23592364. 


\title{
CHAPTER 9
}

\section{RESTING ENERGY EXPENDITURE IN CANCER PATIENTS BEFORE AND ONE YEAR AFTER TUMOR RESECTION}

\author{
EWHM Fredrix; PB Soeters; EFM Wouters; IM Deerenberg; MF won Meyenfeldt; \\ WHM Saris
}

From the Department of Human Biology, Surgery and Pulmonary Diseases, University of Limburg, PO Box 616, 6200 MD Maastricht, The Netherlands

\section{submitted for publication}

\section{SUMMARY}

The purpose of this study was to investigate whether the presence of a malignant tumor influences energy metabolism of the host. Resting energy expenditure (REE) was measured in 104 gastric and colorectal (GCR) cancer patients and in 36 nonsmall cell lung cancer patients and compared with REE values in 40 apparently healthy controls. REE expressed per $\mathrm{kg}$ fat free mass (REE/FFM) in lung cancer patients was elevated in comparison to healthy controls (34.0 44.6 and $29.2 \pm 2.4$ $\mathrm{kcal}$, respectively; $\mathrm{p}<0.001$ ), in contrast to REE/FFM in GCR cancer patients that showed no difference. In 47 patients with GCR cancer and in 11 patients with lung cancer REE was also determined post tumor resection. REE in GCR cancer patients measured one-and-a-half year after tumor resection showed a small, but significant increase. No differences were observed between GCR cancer patients with or without signs of tumor recurrence. REE in lung cancer patients measured one year after tumor resection did not change. However, lung cancer patients with no signs of tumor recurrence had a significant decrease in REE (REE/FFM: $-9.3 \%$ ), while patients who had evidence of tumor recurrence showed no change in REE or even an increase. After curative surgery REE returned to a normal levell in the lung cancer patients. These results suggest that tumor type is a major determinant of an increased energy expenditure in cancer patients.

\section{INTRODUCTION}

Weight loss is a common feature in patients with cancer. Both increased energy expenditure (EE) and decreased dietary intake have been incriminated as causative factors for the observed weight loss. Several authors have found an elevated resting. energy expenditure (REE) in patients with a malignant disease (1-5). Others have found no change $(6,7)$. Some of these studies, however, have been poorly controlled, data from patients are compared with data from inadequate control subjects or no control data are offered at all. It has also been suggested that different tumor types may exert different influences on REE. Dempsey et al determined REE in gastrointestinal cancer patients and found patients with 
pancreatic or hepatobiliary tumors to be predominantly hypometabolic; gastric cancer patients tended to be hypermetabolic (8). These conclusions were reached by comparing measured REE with that predicted from the Harris Benedict (HB) formula. In only a few studies cancer patients functioned as their own controls by measurement of REE before and after surgical resection of the tumor $(1,4)$.

The current study investigates the presence of an elevated REE in patients with gastric and colorectal (GCR) cancer and in patients with non-small cell lung cancer by comparing them with healthy controls. In addition, in order to measure tumor mediated thermogenesis REE measurements in these cancer patients were performed pre (PRE) and post tumor resection (POST).

\section{METHODS}

Patients with histologically proven GCR cancer and lung cancer were included in the study. All patients had newly detected tumors and no patient had undergone prior treatment.

\section{GCR cancer patients}

PRE-REE was measured in 104 patients. In 47 of these 104 patients POST-REE was measured after one-and-a-half year ( $18 \pm 5$ months). Fifty-seven patients were excluded from the second REE measurement. The reasons for exclusion were that these patients died $(n=44)$, refused $(n=7)$, were in a bad physical condition $(n=5)$, or were not operated $(n=1)$. The remaining 47 patients were categorized into 32 patients in which tumor recurrence was not likely and 11 patients with signs of tumor recurrrence. Presence of recurrence was established by examination of medical records produced during routine follow-up on an outpatient basis. In four patients it could not be established whether they had tumor recurrence or not.

\section{Lung cancer patients}

PRE-REE was measured in 36 patients. In 11 of these 36 patients POST-REE was measured after one year (12 \pm 4 months). Twenty-five patients were excluded from the second REE measurement. The reasons for exclusion were that these patients died $(n=20)$, refused $(n=2)$, were in a bad physical condition $(n=2)$, or were not operated $(n=1)$. The remaining eleven patients were categorized in eight patients in which no tumor recurrence was detected and three patients who had evidence of tumor recurrence.

REE was measured by indirect calorimetry using a ventilated hood system. Gas analyses were performed using a paramagnetic oxygen analyser (Mijnhardt module, Bunnik) and an infrared carbon dioxide analyser (modified UG51, Mijnhardt, Bunnik). Dry gases were measured and the results converted to standard temperature and pressure. Flow through the canopy was kept constant during 
measurements and was adjusted to body weight of the patient $(25-50 \mathrm{~L} / \mathrm{min})$. System control and calculations were performed on a microcomputer. The equipment was calibrated at the start and at the end of every experiment. The hood consisted of clear plexiglas and had a volume of $30 \mathrm{~L}$. REE was calculated using the abbreviated Weir formula (9).

PRE-REE in the hospital was measured between 7.00 and $9.00 \mathrm{AM}$ after an overnight fast. POST-REE was measured on an outpatient basis. Patients visited the hospital at 9.00 AM. They had fasted for at least $10 \mathrm{~h}$ and had travelled by car, bus or train. REE measurements were carried out after at least $30 \mathrm{~min}$ of complete bed rest. On both occasions REE was measured at rest in the supine position during $30 \mathrm{~min}$. In a recent study we showed that REE in 30 healthy volunteers measured after they had spent the night in the hospital was not significantly different from REE measured after they had come from home as in this study (10).

In addition, REE in these cancer patients was compared with REE values in a group of 40 apparently healthy controls (mean age $65 \pm 8$ years) measured according to the same procedure. These healthy controls underwent a medical examination to exclude disorders which might affect their metabolic rate, such as anaemia, thyroid dysfunction, infectious disease, high blood pressure, heart failure and chronic obstructive pulmonary disease.

Fat free mass (FFM) was estimated with the bioelectrical impedance (BI) method (RJL Systems ${ }^{\circledR}$, BIA-101, Detroit) and was calculated using the formulae of Segal (11). BI was measured in only half of the GCR cancer patients, because at the start of the study no device was available to measure body composition.

Actual body weight was also expressed as percentage ideal body weight (PIBW) (12). Tumor stage was assessed after review of medical records, operative reports, pathology and radiology reports, according to the guidelines of the American Joint Committee on the Staging for Cancer for GCR cancer patients (13) and according to the guidelines of the International Union against Cancer for $\|$ ung cancer patients (14).

REE was expressed in absolute terms (REE), per kg body weight (REE/BW), per $\mathrm{kg} \mathrm{FFM} \mathrm{(REE/FFM)} \mathrm{and} \mathrm{as} \mathrm{a} \mathrm{percentage} \mathrm{of} \mathrm{the} \mathrm{HB}$ value (REE/HB). Statistical analysis was performed using the Tukey pairwise multiple comparison procedure. The Mann-Whitney $U$ test and the Wilcoxon matched-pairs signed-ranks test were used for nonparametric statistical analyses. Further statistical procedures included Student's paired t-test and chi-square analysis. Results are presented as mean $\pm \mathrm{SD}$ and $p$-values $<0.05$ were regarded as statistically significant. 


\section{RESULTS}

Fifty-four men and fifty women with GCR cancer were included in the study (Table 1). Their mean age was 70 years and their mean PIBW was $99 \%$. There were almost four times as many colorectal cancer patients as gastric cancer patients. Thirty-two men and four women with lung cancer were included in the study. Their mean age was 65 years and their mean PIBW was 92\%.PRE-REE in lung cancer patients even when corrected for FFM was increased when compared with GCR cancer patients or healthy controls.

TABLE 1 .

Patient characteristics.

\begin{tabular}{|c|c|c|c|}
\hline & $\begin{array}{l}\text { GCR cancer } \\
\text { patlents } \\
(n=104)\end{array}$ & $\begin{array}{l}\text { lung cancer } \\
\text { patients } \\
(n=36)\end{array}$ & $\begin{array}{l}\text { healthy } \\
\text { controls } \\
(n=40)\end{array}$ \\
\hline age $(y)$ & $70 \pm 11^{\prime \prime}: \$$ & $65 \pm 8$ & $65 \pm 8$ \\
\hline sex (male/female) & $54 / 50$ & $32 / 4$ & $18 / 22$ \\
\hline weight $(\mathrm{kg})$ & $65.2 \pm 11.6^{\$ \$}$ & $64.8 \pm 11.0^{\# \#}$ & $72.1 \pm 12.1$ \\
\hline $\mathrm{FFM}(\mathrm{kg})$ & $\left.45.5 \pm 8.8^{1}\right) ;$ & $49.1 \pm 7.9$ & $51.3 \pm 9.7$ \\
\hline PHBW $(\%)$ & $99+13^{* * ;} ; \$$ & $92 \pm 10^{\# \# \# ~}$ & $105 \pm 11$ \\
\hline weight loss (\%) & $7.1 \pm 6.4$ & $7.3 \pm 6.2$ & 2 \\
\hline REE (kcal/kg BW) & $20.9 \pm 2.7^{* * *}$ & $25.6 \pm 4.0 \#$ & $21.0 \pm 2.0$ \\
\hline REE (kcal/kg FFM) & $\left.29.8 \pm 4.3^{1}\right)^{* * * *}$ & 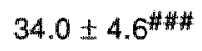 & $29.6 \pm 2.9$ \\
\hline
\end{tabular}

\footnotetext{
Mean values $\pm S D$ 1) $n=49$ patients; 2) weight stable

GCR $=$ gastric and collorectal; PIBW=percentage ideal body weight

AEE

"p<0.05 GCA vs lung; "p<0.01 GCR vs lung; *t" $p<0.001$ GCA vs lung

$\$ p<0.05$ GCA v controls; $\$$ \$ $\$ 0.01$ GCR vs controls

\#\#<0.01 lung vs controls; \#\# $p<0.001$ lung vs controls
}

The 57 GCR cancer patients who were not measured after tumor resection were older, had a lower PIBW and a more advanced tumor stage at the time of primary treatment than the 47 measured patients. PRE-REE was not significantly different between both groups. POST-REE in GCR cancer patients was significantly higher than PRE-REE, no matter how it was expressed. POST-REE was significantly increased in both the $32 \mathrm{GCR}$ cancer patients without tumor recurrence and the 11 GCR cancer patients with tumor recurrence (Table 2). This difference was less significant when expressed as REE/BW and was not significant for the GCR cancer patients with tumor recurrence when expressed as REE/FFM. POST-REE in GCR cancer patients after curative tumor resection was not different from REE values in healthy controls (Table 3 ). 
TABLE 2.

Resting energy expenditure (REE) before (PRE) and after (POST) umor resection in gastric and colorectal (GCA) cancer patients with or without signs of tumor recurrence.

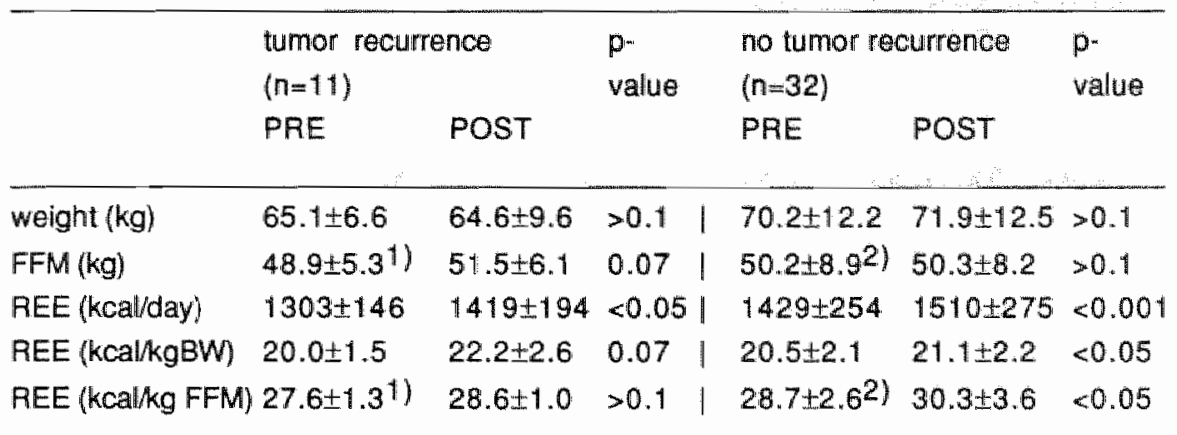

1) $n=4$ patients; 2) $n=14$ patients; Mean values $\pm S D$

FFMlMfat free mass; $B W=b o d y$ weight

TABLE 3.

Resting energy expenditure (REE) after curative tumor resection in cancer patients compared with controls.

\begin{tabular}{llll}
\hline & $\begin{array}{l}\text { GCR cancer } \\
\text { patients } \\
(n=32)\end{array}$ & $\begin{array}{l}\text { lung cancer } \\
\text { patients } \\
(n=8)\end{array}$ & $\begin{array}{l}\text { healthy } \\
\text { controls } \\
(n=40)\end{array}$ \\
\hline REE (kcal/kg BW) & $21.1 \pm 2.2$ & $22.0 \pm 2.1$ & $21.0 \pm 2.0$ \\
REE (kcal/kg FFM) & $29.8 \pm 3.41)$ & $29.9 \pm 2.2$ & $29.6 \pm 2.9$ \\
\hline
\end{tabular}

Mean values $\left.\pm \mathrm{SD}^{1}\right)_{n=27}$ patients

$\mathrm{GCR}=$ gastric colorectal; $\mathrm{BW}=$ body weight; $\mathrm{FFM}=$ fat free mass

differences are not statistically significant

A comparison between the 25 lung cancer patients that were not measured after tumor resection and the 11 measured patients showed no significant differences with respect to age, PIBW and tumor stage at the time of primary treatment. PREREE was not significantly different between both groups. POST-REE was not significantly different from PRE-REE, no matter how it was expressed. BW and FFM showed also no significant changes. However, the eight lung cancer patients with no tumor recurrence showed a significant increase in BW and a tendency in FFM after tumor resection, which resulted in a significant decrease in REE/BW and in REE/FFM (Table 4). This was in contrast with the three lung cancer patients who had tumor recurrence. These patients all showed a decrease in $\mathrm{BW}$ (mean: 6.2 
$\mathrm{kg}$ ) and in FFM (mean: $3.8 \mathrm{~kg}$ ) and this resulted in an increase in REE/BW for all three patients and in an increase in REE/FFM for two patients (Figure 1). This rise in REE/FFM in lung cancer patients with tumor recurrence was significantly different from the fall in REE/FFM in lung cancer patients with no evidence of tumor recurrence (Figure 2).

TABLE 4.

Resting energy expenditure (REE) before (PRE) and after (POST) tumor resection in non-small cell lung cancer patients with or without signs of tumor recurrence.

\begin{tabular}{lllllll}
\hline & \multicolumn{2}{l}{$\begin{array}{l}\text { tumor recurrence } \\
(n=3)\end{array}$} & & \multicolumn{2}{l}{$\begin{array}{l}\text { no tumor recurrence } \\
(n=8)\end{array}$} & $\begin{array}{l}\text { p- } \\
\text { value }\end{array}$ \\
& PRE & POST & PRE & POST & \\
\hline weight $(\mathrm{kg})$ & $73.2 \pm 8.6$ & $67.0 \pm 10.8$ & $64.3 \pm 12.7$ & $70.1 \pm 11.2$ & $<0.05$ \\
FFM $(\mathrm{kg})$ & $53.2 \pm 2.9$ & $49.4 \pm 3.2$ & $\mid$ & $48.8 \pm 8.3$ & $51.3 \pm 6.9$ & 0.07 \\
REE (kcal/day) & $1626 \pm 189$ & $1616 \pm 155$ & $1592 \pm 244$ & $1536 \pm 245$ & $>0.1$ \\
REE (kcal/kgBW) & $22.2 \pm 0.5$ & $24.3 \pm 1.5$ & $\mid$ & $25.3 \pm 4.1$ & $22.0 \pm 2.1$ & $<0.05$ \\
REE (kcal/kgFFM) & $30.5 \pm 2.0$ & $32.7 \pm 1.3$ & $\mid$ & $33.0 \pm 3.7$ & $29.9 \pm 2.2$ & $<0.05$
\end{tabular}

Meani values $\mathrm{SCD}$

FFM=fat troe mass; BW=body woight

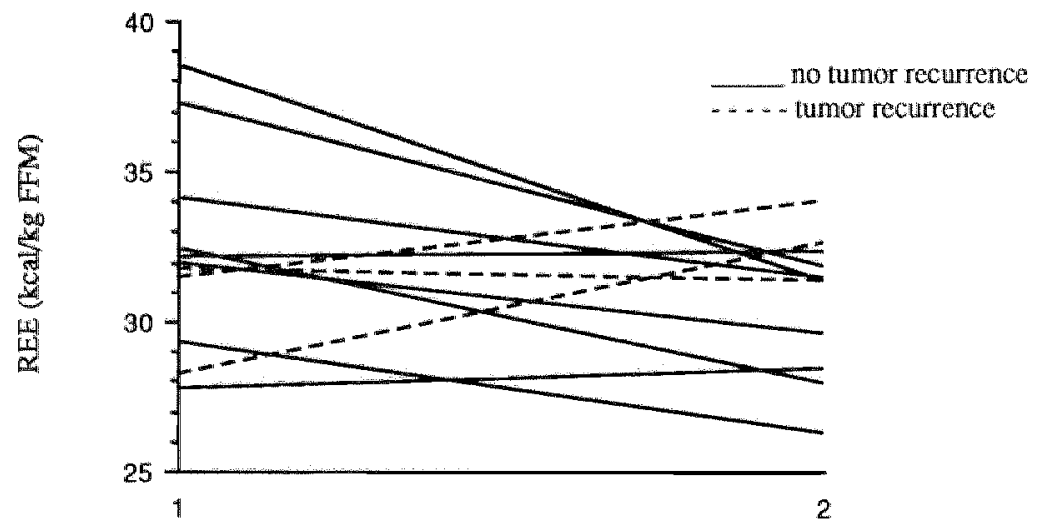

FIGURE 1 .

Resting energy expenditure per $\mathrm{kg}$ fat free mass (REE/FFM) pre ( $($ ) and post (2) tumor resection in hung cancer patients with or without inmor recurrence. 


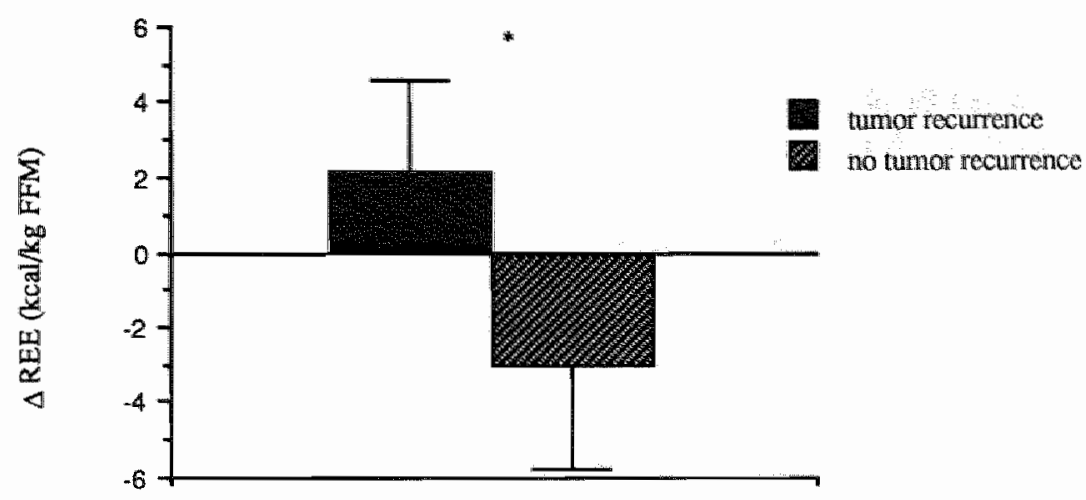

FIGURE 2 .

Change in resting energy expenditure per $\mathrm{kg}$ fal free mass ( $\triangle R E E / F F M$ ) post tumor resection in lung cancer patients with ( $n=3$ ) or wichoul ( $n=8$ ) tumor recurrence. Mean values $\pm S D .{ }^{*} p<0.05$.

The differences in REE between lung cancer patients and GCR cancer patients or healthy controls had disappeared after surgical resection of the tumor (Table 3). After curative tumor resection POST-REE in Iung cancer patients was not elevated when compared with POST-REE in GCR cancer patients or with REE in healthy controls.

\section{DISCUSSION}

It has been suggested that an increased $\mathrm{EE}$ contributes to the weight loss commonly seen in cancer patients. Macfie et al demonstrated that REE of patients with disseminated malignancy is increased when compared with younger healthy controls (4). Dempsey et al found that approximately one third of cancer patients is hypermetabolic, one third is normal, and one third hypometabolic (8). In their study measured REE was compared with values predicted by the HB formula. This formula is based on measurements of REE in normal young volunteers. Roza and Shizgal suggested that this formula underpredicts REE in malnourished patients (15).

To assess the effect of the tumor-bearing state on REE it is important to compare the results of cancer patients with control data. Therefore, in the current study REE of GCR and lung cancer patients was also compared with REE values of healthy controls in the same age group. The results show that lung cancer patients had an elevated REE compared to GCR cancer patients and to healthy controls, in contrast to GCR cancer patients who showed no change in REE. Hansell et al found that REE/FFM in lung cancer patients was not significantly higher than in GCR cancer 
patients (16). However, the number of lung cancer patients that was measured was small $(n=11)$.

Another way to investigate tumor mediated thermogenesis is to measure REE in cancer patients before and after surgical resection of the tumor. Arbeit et al studied four patients with localized disease pre and post tumor resection and found that all patients had a postoperative drop in their REE (1). Warnold et al showed that after curative surgery EE returned to a normal level in one cancer patient (4). Bozzetti et al had a similar result in two cancer patients who had a good response to chemotherapy (2). None of these patients, however, had gastric, colorectal or lung cancer. In the current study lung cancer patients with no signs of tumor recurrence showed a significant decrease in POST-REE/BW and POST-REE/FFM, in contrast to lung cancer patients with evidence of turnor recurrence who showed an increase in POST-REE/BW and POST-REE/FFM. Although the number of lung cancer patients was small, this finding is an indication that the tumor itself induced the elevated REE in lung cancer patients. This is even more supported by our observation that REE values of lung cancer patients who had no signs of tumor recurrence 12 months after resection were not different from REE values in helathy controls. Six (out of 8) of the lung cancer patients with no tumor recurrence were smokers before diagnosis of their disease. Five of them stopped smoking after tumor resection and one reported to smoke less cigarettes. The evidence concerning the effects of cigarette smoking on EE is conflicting. Hofstetter et al demonstrated that smoking increases $24-\mathrm{h} \mathrm{EE}$ by approximately 10 percent (17). They also found, however, that the thermogenic effect of smoking has ceased by the morning after a day of smoking. Therefore, we believe that the fall in REE in lung cancer patients was rather the result of succesful removal of the tumor than of cessation of smoking.

In the current study POST-REE in GCR cancer patients was increased, but still not significantly different from REE in healthy controls. This increase in POST-REE could not be explained by an increase in body weight. Furthermore, the increase in FFM in tumor recurrent patients was based on only four patients. It is possible that the GCR cancer patients were in a semi-starved state during their hospital stay and subsequently showed an adaptational decrease in REE, because EE normally decreases during starvation and weight loss (18). The observation that both patients with or without signs of tumor recurrence showed an increase in POST-REE suggests that the presence of the tumor in GCR cancer patients has no clear impact on energy metabolism, which is in agreement with the observations of Hansell et al $(7,16)$ and Burke et al $(6)$.

In the current study the period between the two measurements was 12 months and 18 months for the lung cancer and the GCR cancer patients, respectively. We, therefore assume that any influence on energy metabolism from the surgical 
procedure or subsequent radiotherapy may be ignored. As recurrent disease resulted in death of a significant number of patients, only a selection of the original study population, 47 (out of 104) GCR cancer patients and 11 (out of 36) lung cancer patients, was measured before and after operation. In addition, FFM was not measured pre and post tumor resection in all $\mathrm{GCR}$ cancer patients (18 out of 47). However, no significant differences were observed with regard to PRE-REE data and patients who did or did not undergo a POST-REE measurement, or a measurement of FFM.

In lung cancer patients a significant correlation existed between the change in REE/FFM and the incidence of tumor recurrence $(r=0.70 ; p<0.05)$. In addition, two (out of three) patients with tumor recurrence showed a rise in REE/FFM. Furthermore, six (out of eight) patients without signs of tumor recurrence showed a fall in REE/FFM. One must assurne that after an initial fall in tumor resected patients, patients with recurrent tumor showed an increased REE, in two out of three, to an even higher level than PRE values.

We conclude from this study that lung cancer patients have an elevated REE which returns to a normal level after curative surgery, while in GCR cancer patients REE is not elevated. These results suggest that tumor type is a major determinant of an increased $\mathrm{EE}$ in cancer patients.

\section{REFERENCES}

1. Arbeit $\mathrm{JM}_{n}$ Lees DE, Brennan MF. Resting energy expenditure in controls and cancer patients with localized and diffuse disease. Ann Surg 1984;199:292-298.

2. Bozzetti F, Pagnoni AM, Del Vecchio M. Excessive caloric expenditure as a cause of malnutrition in patients with cancer. Surg Gynecol Obstet 1980;150:229-234.

3. Macfie J, Burkinshaw $\mathrm{L}$, Oxby $\mathrm{C}$ et al. The effect of gastrointestinal malignancy on resting metabolic expenditure. Br I Surg 1982;69:443-446.

4. Warnold $I$, Lundholm $K$, Schersten $T$. Energy balance and body conposition in cancer patients. Cancer Res 1978;38:1801:1807.

5. Lindmark $L_{n}$ Bennegard $K$, Eden $E$ et al. Resting energy expenditure in malnourished patiens with and without cancer. Gastroenterology 1984;87:402-408.

6. Burke M, Bryson EI, Kark AE. Dietary intakes, resting metabolic rates, and body composition in benigm and malignant gastrointestinal diseases, Br Med J 1980;1:21 1-215.

7. Hansell DT, Davies JWL, Bums HJG. The relationship between resting energy expenditure and weight loss in benign and malignant diseases. Ann Surg 1986;203:240-245.

8. Dempsey DT, Feurer ID, Knox LS, Crosby LO, Buzby GP, Mullen JL. Energy expenditure in malnourished gastrointestinal cancer patients. Cancer 1984; 53:1 265-1273.

9. Weir JB. New methots for calculating metabolic rate with special veference to protcin metabolism. I Physiol 1949; 109:1-12.

10. Fredrix EWHM, Soeters PB, Meyenfeldt MF von, Saris WHM. Resing energy expenditure in a clinical setting (chapter 4 this thesis). 
11. Segal KR, Var Loan M, Fitgerald PI, Hodgdon JA, Van Itallie TB. Lean body mass estination by bioelectrical impedance analysis: a four-site cross-ralidation study. Am J Clin Nutr 1988; 47:7-14.

12 Metropolitan Life Insurance Company. Desirable weights for men: desirable weights for women, Stat. Bull. no. 23 and 24. New York: Life Extension Institute of New York City 1943.

13 American Joint Committe on Cancer: Manual for Staging of Cancer. Philadelphia: Lippincott Company 1983.

14. UICC. Lung tumour. In: P Hermanek, Sobin LH, eds., TNM classification of malignant twmours. Berlin Heidelberg New York London Paris Tokyo: Springer-Verlag 1987.

15 Roza AM, Shizal HM. The Harris Benedict equation reevaluated: resting energy requirements and the body cell mass. Am J Clin Nutr 1984;40:168-182.

16 Hansell DT, Davies JWL, Burns HJG. The effects on resting energy expenditure of different tumor types. Cancer 1986; 58:1739-1744.

17 Hofstetter A, Schutz Y, Jequier $\mathrm{E}$ et al. Increased 24-hour energy expenditure in cigarette gmokers. N Engl J Med 1986; 314:79-82.

18 Breman MF. Uncomplicated stairvation versus cancer cachexia. Cancer Research 1977; $37: 2359-2364$. 


\section{CHAPTER 10 \\ ENERGY BALANCE IN RELATION TO CANCER CACHEXIA}

EWHM Fredrix; PB Soeters; EFM Wouters; IM Deerenberg; MF von Meyenfeldr; WHM Saris

From the Department of Human Biology, Surgery and Pulmonary Diseases, University of Limburg, PO Box 616,6200 MD Maastricht, The Netherlands

submitted for publication

\section{SUMMARY}

The aim of the current study was to determine the contribution of increased resting energy expenditure (REE) and/or decreased energy intake (EI) to the development of weight loss in gastric and colorectal (GCR) and lung cancer patients. REE was measured in $22 \mathrm{GCR}$ cancer patients and 17 lung cancer patients and was compared with REE values in 40 apparently healthy controls. REE in lung cancer patients expressed per $\mathrm{kg}$ fat free mass (REE/FFM) was significantly increased when compared to healthy controls (33.5 \pm 5.4 and $29.6 \pm 2.9 \mathrm{kcal}$, respectively; $\mathrm{p}<0.01$ ). GCR cancer patients had no elevated REE compared to these healthy controls. No significant differences in EI were established between the three groups. Eight GCR cancer patients reported a decrease in food intake compared to pre-disease intake, in contrast to only one lung cancer patient. Semi-starving GCR cancer patients showed a significant weight loss $(8.7 \pm 8.1 \%)$, a low respiratory quotient $(0.76 \pm 0.04)$ and a high $\beta$-hydroxybutyrate level $(259 \pm 192 \mu \mathrm{mol} / \mathrm{L})$, but they showed no difference in REE compared to patients with a normal EI. The current study suggests that weight loss in GCR cancer patients is initiated by decreased food intake, whereas increased REE is the primary event in the initiation of weight loss in lung cancer patients.

\section{INTRODUCTION}

Clinical experience suggests that weight loss and cachexia occur frequently in cancer patients. Weight loss must be the result of a reduced energy intake (EI) and/or an increased energy expenditure (EE). Little information is available regarding the contribution of both in the development of weight loss in cancer patients.

Several authors have suggested that food intake is markedly reduced in patients with cancer cachexia (1-4). Some studies revealed a normal food intake for cancer patients compared to a control group $(5,6)$. However, studies in which EI and EE were simultaneously measured, demonstrated that food intake fails to meet energy requirements in hypermetabolic cancer patients $(7,8)$. Anorexia develops in the 
groups consisting of less than five patients or controls. Frequency data were compared using the chi-square test. Results are presented as mean $\pm S D$ and pvalues $<0.05$ were regarded as statistically significant.

\section{RESULTS}

Thirteen men and nine women with GCR cancer were included in the study (Table 1). There were five times as many colorectal cancer patients as gastric cancer patients (18 v 4). Sixteen men and one woman with lung cancer were included in the study. Their mean $\mathrm{FEV}_{1}$ was $79 \%$ of the reference value. Fourty healthy controls (18 men, 22 women) with a mean age of 65 years participated in the study. There were no significant differences in age and BW between the three groups. Patients with lung cancer had a lower PIBW than healthy controls. Weight loss was $5 \%$ in GCR cancer patients and almost $9 \%$ in lung cancer patients. This difference was not significant.

\section{TABLE 1.}

Subject characteristics.

\begin{tabular}{lccc}
\hline & $\begin{array}{l}\text { GCR cancer } \\
(\mathrm{n}=22)\end{array}$ & $\begin{array}{l}\text { lung cancer } \\
(\mathrm{n}=17)\end{array}$ & $\begin{array}{l}\text { healthy controls } \\
(\mathrm{n}=40)\end{array}$ \\
\hline age $(\mathrm{y})$ & $68 \pm 10$ & $67 \pm 9$ & $65 \pm 8$ \\
sex (malle/female) & $13 / 9$ & $16 / 1$ & $18 / 22$ \\
weight (kg) & $69.0 \pm 12.2$ & $66.6 \pm 10.1$ & $72.1 \pm 12.1$ \\
FFM (kg) & $49.0 \pm 8.9$ & $50.4 \pm 8.9$ & $51.3 \pm 9.7$ \\
PIB $N(\%)$ & $102 \pm 15$ & $95 \pm 10^{\prime}$ & $105 \pm 11$ \\
weight loss $(\%)$ & $5.0 \pm 6.2$ & $8.7 \pm 8.1$ & $1)$ \\
FEV $(\%)$ & - & $79 \pm 19$ & - \\
\hline
\end{tabular}

Mean valuest $\mathrm{SD}$; i) weight stable

FFM fat tree mass; PIBW=percentage ideal body weight

FEV 1 forced explratory volume in $1 \mathrm{~s} ; \mathrm{GCR}=$ gastric and colorectal

\# $0<0.001$ lung vs controis

There were no differences in FFM between the three groups. Nevertheless, REE/FFM in lung cancer patients was significantly increased when compared with healthy controls $(\mathrm{p}<0.01)$ (Table 2). Males were relatively overrepresented in the lung cancer group compared to the control group. However, REE/FFM in male lung cancer patients was also significantly elevated when compared to male healthy controls. GCR cancer patients had no elevated REE compared to healthy controls, no matter how it was expressed. 
TABLE 2.

Resting energy expenditure (REE) in cancer patients and controls.

\begin{tabular}{llll}
\hline & $\begin{array}{l}\text { GCR cancer } \\
(\mathrm{n}=22)\end{array}$ & $\begin{array}{l}\text { lung cancer } \\
(\mathrm{n}=17)\end{array}$ & $\begin{array}{l}\text { healthy controls } \\
(\mathrm{n}=40)\end{array}$ \\
\hline REE $(\mathrm{kcal})$ & $1504 \pm 272$ & $1661 \pm 248$ & $1512 \pm 269$ \\
REE $(\mathrm{kcal} / \mathrm{kgBW})$ & $21.9 \pm 2.5$ & $25.2 \pm 4.0 \$ \$ ;$ & $21.0 \pm 2.0$ \\
REE (kcal/kgFFM) & $30.9 \pm 3.5$ & $33.5 \pm 5.4 \$ \$$ & $29.6 \pm 2.9$ \\
RQ & $0.76 \pm 0.04$ & $0.78 \pm 0.05$ & $0.76 \pm 0.05$ \\
\hline
\end{tabular}

Mean values \pm SD

$R Q=$ respiratory quotient; $B W=$ body weight; FFM=fat free mass;

$G C R=$ gastric and colorectal

$\$ \$ p<0.001$ lung vs controls; \$ $\$$ < $<0.01$ lung vs controls; $p<0.01$ lung vs GCR

The mean ratio of EI to REE in the lung cancer group amounted to $125 \%$ and was lower than in the GCR cancer group (143\%) or in the healthy control group (141\%) (Table 3). However, these differences did not reach statistical significance. No significant differences in EI/BW and EI/FFM were established between the three groups. There were also no differences in energy percentages from protein, carbohydrate, fat and alcohol intake: $14 \%, 43 \%, 40 \%$ and $3 \%$, respectively. For both GCR and lung cancer groups, EI in weight losing patients was not significantly different from $E I$ in weight stable patients, no matter how it was expressed.

\section{TABLE 3.}

Energy intake (EI) in cancer patients and controls.

\begin{tabular}{lccl}
\hline & $\begin{array}{l}\text { GCR cancer } \\
(n=22)\end{array}$ & $\begin{array}{l}\text { lung cancer } \\
(\mathrm{n}=17)\end{array}$ & $\begin{array}{l}\text { healthy controls } \\
(\mathrm{n}=40)\end{array}$ \\
\hline El $(\mathrm{kcal})$ & $2137 \pm 683$ & $2068 \pm 502$ & $2095 \pm 614$ \\
El $(\mathrm{kcal} / \mathrm{kgBW})$ & $31.4 \pm 10.1$ & $31.4 \pm 10.1$ & $29.4 \pm 8.2$ \\
El $(\mathrm{kcal} / \mathrm{kgFFM})$ & $44.2 \pm 13.8$ & $41.5 \pm 1.2 .5$ & $40.8 \pm 11.0$ \\
El $(\%$ REE $)$ & $143 \pm 44$ & $125 \pm 37$ & $141 \pm 39$
\end{tabular}

Mean values $\pm S D_{;}$differences are not statistically significant REE=resting energy expenditure; $B W=b o d y$ weight; $F F M=f a t$ free mass $\mathrm{GCR}=$ gastric and colorectal

Mean values for all blood parameters in GCR cancer patients were within the normall range according to the Clinical Chemistry Laboratory of the University Hospital of Limburg, except for serum albumin which was moderately decreased (Table 4). 
However, mean values for free fatty acids and $\beta$-hydroxybutyrate reached the upper limit of the normal range. Furthermore, some individual patients showed a significant elevation in triglycerides, free fatty acids, glycerol and $\beta$ hydroxybutyrate.

TABLE 4.

Blood parameters in gastric and colorectal (GCA) cancer patients.

\begin{tabular}{lccc}
\hline parameter & \multicolumn{2}{c}{ GCR cancer patients $(\mathrm{n}=22)$} & \\
& mean \pm SD & range & normal range \\
\hline glucose $(\mathrm{mmol} / \mathrm{L})$ & $5.5 \pm 1.3$ & $3.9-9.0$ & $<6.9$ \\
lactate $(\mathrm{mmo} / \mathrm{L})$ & $0.67 \pm 0.25$ & $0.25-1.10$ & $0.6-2.4$ \\
triglycerides $(\mathrm{mmol} / \mathrm{L})$ & $1.39 \pm 0.46$ & $0.79-2.42$ & $0.80-1.94$ \\
free fatty acids $(\mathrm{mmol} / \mathrm{L})$ & $0.58 \pm 0.37$ & $0.06-1.69$ & $0.10-0.60$ \\
glycerol ( $\mu$ mol/L) & $130 \pm 63$ & $56-289$ & $30-180$ \\
B-hydroxybutyrate $(\mu / \mathrm{mol} / \mathrm{L})$ & $158 \pm 153$ & $21-583$ & $58-170$ \\
albumin $(\mathrm{g} / \mathrm{L})$ & $34 \pm 4$ & $25-42$ & $35-55$ \\
pre-albumin $(\mathrm{g} / \mathrm{L})$ & $0.22 \pm 0.05$ & $0.13-0.32$ & $0.10-0.40$ \\
& & & \\
\hline
\end{tabular}

Eight GCR cancer patients (including all four gastric cancer patients) reported a reduced food intake. El decreased by $30 \%$ from $2165 \pm 725 \mathrm{kcal} /$ day to $1510 \pm 629$ $\mathrm{kcal} /$ day (Table 5). REE/BW as well as REE/FFM in these semi-starving cancer patients were not significantly different compared with patients who maintained their food intake on pre-disease levels. Respiratory quotient (RQ) tended to be lower in the semi-starving patients. Weight loss was almost $9 \%$ in this group. Serum albumin and pre-albumin were significantly lower, whereas $\beta$-hydroxybutyrate was significantly increased in the semi-starving patients as compared with the nonstarving patients (Figure 1).

\section{DISCUSSION}

Weight loss is a well known phenomenon in cancer patients. In general terms, weight loss must be the result from a negative balance between energy requirement and EI.

In the current study lung cancer patients revealed a significantly increased REE compared to healthy controls, in contrast to GCR cancer patients that had a normal REE. Mean difference in REE/FFM between lung cancer patients and healthy controls was $3.9 \mathrm{kcal} / \mathrm{kg}$ FFM; mean FFM for lung cancer patients was $50.4 \mathrm{~kg}$. This implies an increase in REE of $197 \mathrm{kcal}$ per day when lung cancer patients are compared with healthy controls. Assuming that $1 \mathrm{~kg}$ of weight loss represents $50 \%$ 
TABLE 5.

Comparison between semi-starving and non-starving gastric and colorectal canceir patients.

semi-starving patients non-staring patients p-value

$(n=8) \quad(n=14)$

\begin{tabular}{lccl}
\hline El (\%REE) & $113 \pm 51$ & $159 \pm 32$ & $<0.05$ \\
REE (kcal/kgBW) & $21.6 \pm 2.1$ & $22.1 \pm 2.8$ & $>0.1$ \\
REE (kcal/kgFFM) & $30.9 \pm 2.4$ & $30.8 \pm 4.1$ & $>0.1$ \\
weight loss (\%) & $8.9 \pm 8.1$ & $2.6 \pm 3.0$ & $<0.05$ \\
RO & $0.75 \pm 0.05$ & $0.78 \pm 0.03$ & 0.07
\end{tabular}

Mean values $\pm S D$

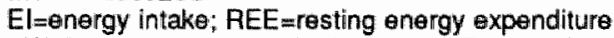

$B W$ mbody woight; $F F M=f a t$ free mass; $R Q=$ respiratory quotient

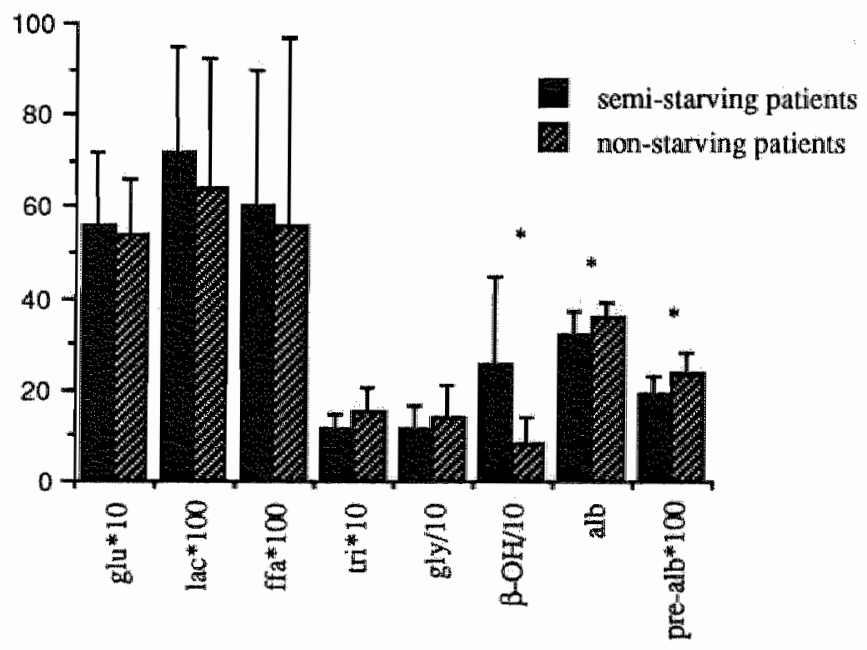

FIGURE 1 .

Blood parameters of semi-starving and non-starving GCR cancer patients.

$(G C R=$ gastric and colorectal; glu=glucose (mmoll $) ; l a c=i a c t a t e(m m o l / L) ;$ ffa $=$ free falty acids (mmollL); tri=iriglycerides (mmollL); gly $=g$ lycerol $(\mu$ mollL); $\beta-O H=\beta$-hydroxybutyrate ( $a l b=a l b u m i n e(g / L) ;$ pre-alb=pre-albumine $(g / L) ; * 0<0.05$. Mean walues $\mathbb{E} S D$. 
fat mass (with an energy equivalent of $7000 \mathrm{kcal} / \mathrm{kg}$ ) and 50\% FFM (with an energy equivalent of $1000 \mathrm{kcal} / \mathrm{kg}$ ), the energy equivalent of $1 \mathrm{~kg}$ of weight loss equals $4000 \mathrm{kcal}$. Therefore, an elevation in REE of the order found in this study can account for a weight loss of one-and-a-half $\mathrm{kg}$ per month, assuming that EI is unchanged.

No significant differences in EI between GCR cancer patients, lung cancer patients and healthy controls could be established. Unfortunately, there were only four patients (all women) with gastric cancer included in the study. A comparison between these four female gastric cancer patients and female colorectal cancer patients $(n=5)$ showed that the gastric cancer patients had a lower energy intake (23.8 $\pm 6.9 \mathrm{vs} 35.6 \pm 6.4 \mathrm{kcal} / \mathrm{kg} \mathrm{BW}$ ). All gastric cancer patients reduced their EI, in contrast to only 4 (out of 14) colorectal cancer patients. Only one (out of 17) lung cancer patient reported a diminished food intake compared to usual intake. In addition, mean $\mathrm{EI}$ in the lung cancer group exceeded mean REE by only $25 \%$. According to the criteria of the World Health Organization (WHO) energy requirement of a healthy, retired elderly man equals 1.51 times REE (29).

It is difficult to obtain reliable food intake data, especially concerning the predisease period. Bakkum et al found in healthy elderly people an overstimation of the past food intake (30). Whether newly detected cancer patients also overestimate their pre-disease EI is unknown. Another problem may be that patients deny changes in food intake, but nonetheless have a decreased EI. It is difficult to demonstrate, that anorexia has a role during the early phase of weight loss, because of the wide intra- and interindividual variation in food intake. Small differences in EI may therefore be obscured. However, von Meyenfeldt et al found in almost all gastric and approximately one third of colorectal cancer patients with newly detected tumors an El of less than $80 \%$ of their pre-illness intake (31).

There was some evidence in GCR cancer patients of increased oxidation of fat and ketone body production, because of moderately increased fasting blood levels for free fatty acids and $\beta$-hydroxybutyrate compared to normal levels. Preferential fat oxidation was also noted by a low RQ of $0.76 \pm 0.04$. However, an RQ value in this range has to be considered as normal for subjects who are in the fasting state for at least 10 hours, because healthy controls and lung cancer patients showed the same low value. Serum albumin is moderately decreased in GCR cancer patients as a result of metabolic stress.

A decreased food intake in eight GCR cancer patients was accompanied by a significant weight loss of almost $9 \%$. The degree of undernutrition in these weightlosing GCR cancer patients could be estimated as follows. Mean weight loss in this group was $5.5 \pm 4.5 \mathrm{~kg}$. Assuming that $1 \mathrm{~kg}$ of weight loss equals $4000 \mathrm{kcal}$, the 
total deficit in $\mathrm{EI}$ in these patients was approximately $22000 \mathrm{kcal}$. Taken into account a $30 \%$ lower EI for the semi-starving patients compared to the nonstarving patients, a deficit in EI of this order can account for a starvation period of cal one month. RQ tended to be lower in these semi-starving cancer patients. $\beta$ Hydroxybutyrate was significantly higher and pre-albumin significantly lower in this group. These changes in biochemical and physiological parameters are characteristic for a normal metabolic response during a period of (semi-) starvation. Glycogen stores are emptied and fat oxidation and consequently ketone body production are increased.

However, a comparison of REE in semi-starving GCR cancer patients compared with $\mathrm{H}$ controls, who reported no change in $\mathrm{EI}$ and in weight loss, revealed no difference, even when changes in body composition were considered. This is in contrast with the reduction in EE which normally occurs with underfeeding $(32,33)$. It seems that GCR cancer patients lose the ability to adapt their energy metabolism to the (semi-) starving state. Therefore, these cancer patients appear to be in a relative state of hypermeta-bolism. In a recent study we demonstrated that REE of weight-losing patients with diseases of the gastrointestinal tract was not different from REE of weight-losing GCR cancer patients (16). This finding suggests that relative hypermetabolism may not be a cancer-specific phenomenon, but may be a general phenomenon of weight loss as a consequence of disease.

The results of this study suggest that weight loss in gastric cancer patients (mean weight loss $11.0 \%$ ) is the result of a decreased food intake and of no adaptation in energy metabolism. Mean weight loss in colorectal cancer patients is less than $5 \%$. Most colorectal cancer patients report no change in EI and have a normal REE. In a small group of colorectal cancer patients weight loss may be explained by a reduced food intake not accompanied by a reduction in REE. Lung cancer patients (mean weight loss $8.7 \%$ ) report no decreased EI. However, REE is elevated and results in a relatively low EI. This suggests that weight loss in lung cancer represents a combination of hypermetabolism and a relative anorexia.

The small number of patients in the current study precludes definite conclusions on the contribution of anorexia to the development of weight loss. Especially the validity of El of the pre-disease period has to be considered. The results on energy metabolism confirm our previous findings that lung cancer patients have an elevated REE and that GCR cancer patients display normal REE values $(16,17)$.

We conclude that the current study suggests that tumor type is an important determinant of the development of weight loss. It seems that weight loss occurring in GCR cancer patients is initiated by decreased food intake, whereas increased REE is the primary event in the initiation of weight loss in lung cancer patients. Semi-starvation in GCR cancer leads to metabolic adaptation comparable to 
uncomplicated starvation, implying that the body switches to the utilization of fat as a fuel source. This is not accompanied by an adaptational decrease in REE.

\section{REFERENCES}

1. Theologides A, Ehlert J, Kennedy BJ. The calorie intake of patients with advanced cancer. Minn Med 1976;59:526-529.

2. Costa $G$. Lyles $K$, Ullrich $L$. Effects of human and experimental cancer on the conversion of ${ }^{14} \mathrm{C}$ tripalmitin to ${ }^{14} \mathrm{CO}_{2}$. Cancer 1976;38:1259-1265.

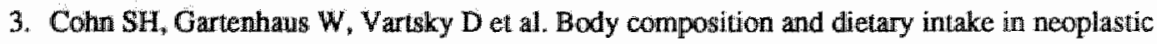
disease. Am J Clin Nutr 1981;34:1997-2004.

4. Walsh TD, Bowman KB, Jackson GP. Dietary intake of advanced cancer patients. Hum. Nutr:Appl Nutr 1983;37A:41-45.

5. Burke M, Bryson EI, Kark AE. Dietary intakes, resting metabolic rates, and body composition in benign and malignant gastrointestinal disease. Br Med J 1980;1:211-215.

6. Hansell DT, Davies JWL, Burns HJG. The relationship between resting energy expenditure and weight loss in benign and malignant disease. Ann Surg 1986;203;240-245.

7. Warnold 1 , Lundholm $K$, Schersten $T$. Energy balance and body composition in cancer patients. Cancer Res 1978;38:1801-1807.

8. Russell DMCR, Shike M, Marliss EB et al. Effects of total parenteral nutrition and chemotherapy on the metabolic derangements in small cell lung cancer. Cancer Res 1984:44:1706-1711.

9. DeWys WD. Anorexia in cancer patients. Cancer Res 1977;37:2354-2358.

10. Arbeit, JM, Lees DE, Brennan MF. Resting energy expenditure in controls and cancer patients with localized and diffuse disease. Ann Surg 1984;199:292-298.

11. Bozzetti F, Pagnoni AM, Del Vecchio M. Excessive caloric expenditure as a cause of malnutrition in patients with cancer. Surg Gyn \& Obstet 1980;150:229-234.

12. Lindmark L, Bennegard $K$, Eden $E$ et al. Resting energy expenditure in malnourished patients with and without cancer. Gastroenterology 1984;87:402-408.

13. Macfie I, Burkinshaw $L_{8}$ Oxby $C$, Holmfield JHM, Hill GL. The effect of gastrointestinal malignancy on resting metabolic expenditure $\mathrm{Br}$ J Surg 1982;69:443-446.

14. Hansell DT, Davies JWL, Burns FUG. The effects on resting energy expenditure of different uumor types. Cancer 1986; 58:1739-1744.

15. Nixon DW, Kutner M, Heymsfield S et al. Resting energy expenditure in lung and colon cancer. Metabolism 1988;37:1059-1064.

16. Fredrix EWHM, Soeters PB, Rouflart MMJ, Meyenfeldt MF von, Saris WHM. Resting energy expenditure in patients with newly detected gastric and colorectal cancer (twis thesis chapter 8).

17. Fredrix EWHM, Wouters EFM, Soeters PB et al, Resting energy expenditure in non-small cell lung cancer patients. (this thesis chapter 7)

18. Weir JB. New methods for calculating metabolic rate with special reference to protein metabolism. J Physiol 1949;109:1-12.

19. Fredrix EWHM, Soeters PB, Meyenfeldt MF von, Saris WHM. Resting energy expenditure in a clinical setting (this thesis chapter 4 ). 
20. Lukaski HC, Johnson PE, Bolonchuk WW, Lykken GI. Assessment of fat-free mass using bioelectrical impedance measurements of the human body. Am J Clin Nutr 1985;41:810-817.

21. Segal KR, Van Loan M, Fitzgerald PI, Hodgdon JA, Van Itallie TB. Lean body mass estimation by bioelectrical impedance analysis: a four-site cross-validation study. Am J Clin Nutr 1988;47:7-14.

22. Metropolitan Life Insurance Company. Desirable weights for men: desirable weight for women, Stat Bul. no. 23 and 24. New York: Life Extension Institute of New York City 1943.

23. Williamson DH, Mellanby J, Krebs HA. Enzymatic determination of $\beta$-hydroxybutyric acid. In: Bergmeyer HU, ed. Methods of enzymatic analysis. New York: Academic Press 1974

24. Guttman I, Wahlefeld AW. Lactate determination with lactate dehydrogenase and NAD. In: Bergmeyer HU, ed. Methods of enzymatic analysis. New York: Academic Press 1974.

25. American Joint Committee on Cancer. Manual for Staging of Cancer. Philadelphia: Lippincott Company 1983.

26. UICC. Lung tumour. In: P Hermanek, Sobin LH, eds. TNM classification of malignant tumours. Berlin Heidelberg New York London Paris Tokyo: Springer-Verlag 1987.

27. Quanjer PH ed. Standardized lung function testing. Clin Resp Physiol 1983;19:7-44.

28. Stichting Nederlands Voedingsstoffenbestand. NEVO tabel. 's-Gravenhage: Voorlichtingsbureau voor de Voeding 1986.

29. World Health Organization. Energy and protein requirements, report of a joint FAO/WHO/UNU expert consultation. Geneva:WHO 1985 (Technical report series 724).

30. Bakkum A, Bjoemberg B, Staveren WA van, Verschuren $M$, West CE. The relative validity of a retrospective estimate of food consumption based on a current dietary history and food frequency list. Nutr Cancer 1988;11:41-53.

31. Meyenfeldt MF von, Visser G, Buil-Maassen R, Soeters PB, Wesdorp RIC. Food intake and nutritional status in patients with newly detected gastric or colorectal cancer. Clin Nutr 1988;7:85-91.

32. Brennan MF. Uncomplicated starvation versus cancer cachexia. Cancer Res 1977;37:23592364.

33. Mansell PI, MacDonald IA. The effect of underfeeding on the physiological response to food ingestion in normal weight women. Br J Nutr 1988;60:39-48. 



\section{CHAPTER 11}

\section{GENERAL DISCUSSION AND CONCLUSIONS}

In this thesis results are presented of studies in which the contribution of increased resting energy expenditure (REE) to the development of cancer cachexia is investigated. For this purpose, it was necessary to validate our technique of REE measurement to ensure reliability of the data.

For this study cancer patients were selected with either cancer from the gastrointestinal tract (gastric and colorectal (GCR) cancer) or non-small cell lung cancer. In contrast to other studies only patients in which cancer was recently detected were included. In this way aberrations in energy metabolism could be studied in patients with relatively early stages of cancer. Furthermore, the effects of different types of treatment on tumor medinted thermogenesis were excluded.

The presence of tumor has little or no impact on energy metabolism in GCR cancer patients, while in lung cancer patients the presence of tumor results in an elevated REE which appears to be a primary effect of the tumor. These conclusions were based on the observation that lung cancer patients had an elevated REE compared to GCR cancer patients and to apparently healthy controls (chapter 7, table 2; chapter 9, table 1), while GCR cancer patients had similar REE's as healthy controls and as patients with nonmalignant diseases of the gastrointestinal tract (chapter 8, table 3; chapter 9, table 1). Furthermore, cancer patients functioned as their own controls by measurement of REE before and after surgical resection of the tumor. Lung cancer patients with no evidence of tumor recurrence had a significant decrease in REE to a normal level (chapter 9, table 4; chapter 9, figure 1; chapter 9, table 3). This finding, however, needs to be confirmed in a larger group of patients. GCR cancer patients with or without signs of tumor recurrence showed a small increase in REE, which was still within the normal range, however (chapter 9, table 2; chapter 9, table 3).

As expected, the prevalence of an elevated REE, defined as $115 \%$ or more of the REE value calculated with the Harris Benedict (HB) equation (1), was high in lung cancer patients (chapter 7, table 2). This high prevalence of hypermetabolism in lung cancer patients may be explained to some extent by the presence of other factors that theoretically may have stimulated energy expenditure (EE), like e.g. anaemia, high blood pressure, thyroid dysfunction, heart failure, infectious disease and chronic obstructive pulmonary disease (COPD). When lung cancer patients with such abnormalities were excluded from analysis the prevalence of hypermetabolism was, however, still high. In GCR cancer patients the prevalence of hypermetabolism was higher than expected based on the literature $(2,3)$ and 
remains higher than expected when patients with factors that may have affected their energy metabolism were excluded (chapter 8, table 3 ).

The fact that the HB equation underestimates REE of elderly people (chapter 6 , table 3) may also result in a relatively high number of hypermetabolic patients. Therefore, the HB equation is in our opinion a poor standard, which is in agreement with the literature (4-8).

Our results concerning the GCR cancer patients agree with recent studies of other investigators $(9,10)$, although there are still studies reporting a slight but significant increase in REE (11). The results of studies in lung cancer patients are inconsistent, suggesting increased REE $(6,12,15)$ or no change $(13,14)$.

We cannot explain the elevation of REE in lung cancer patients. A comparison between hypermetabolic and normometabolic lung cancer patients revealed no significant differences in tumor stage, tumor localisation, pulmonary function or smoking behaviour (chapter 7, table 3). However, a significant negative correlation existed between REE per $\mathrm{kg}$ body weight and pulmonary function, estimated by measuring forced expiratory volume in $1 \mathrm{~s}(\mathrm{FEV})_{1}$ ) (chapter 7, table 4). $\mathrm{FEV}_{1}$ is determined by respiratory muscle force and the degree of chronic airway obstruction. In patients with a significantly decreased FEV1 normal ventilation requires increased muscle work and may induce hypermetabolism. Schols et al indeed found an increased REE in $51 \%$ of COPD patients that had a mean $\mathrm{FEV}_{1}$ of $35 \%$ (16). In the hypermetabolic COPD patients mean $\mathrm{FEV}_{1}$ was significantly lower than in the normometabolic patients ( 29 vs $42 \%$; p $<0.001$ ). However, mean $\mathrm{FEV}_{1}$ of the lung cancer patients was within normal limits ( $85 \%$ ) (chapter 7 , table 1). Therefore, it is not likely that increased work of breathing secondary to an airway obstruction has an important influence on energy metabolism in this group.

It is suggested in the literature that cigarette smoking influences energy metabolism. Hofstetter et al reported a significant elevation of 24-h EE to be associated with smoking, but no effects on REE the morning after a day with cigarette smoking (17). Studies on the effect of smoking cessation on energy metabolism are conflicting: some studies reported a decrease in REE after cessation of smoking (18-20), while others found no effect $(21,22)$. All lung cancer patients in the current study were (ex-) smokers. Ex-smokers were defined as patients who stopped smoking at least 6 months before study entry, i.e. at time of diagnosis. A multiple regression analysis in a group of $104 \mathrm{GCR}$ cancer patients, 36 lung cancer patients and 40 healthy controls revealed that lung cancer patients had still an elevated REE compared to GCR cancer patients $(p<0.001)$ and compared to healthy controls $(p<0.01)$ when adjusted for body size, body temperature and smoking behaviour. Therefore, smoking behaviour did not induce the observed 
increase in REE in lung cancer patients.

The results in this study suggested a relation between cessation of smoking and a decrease in REE after curative surgery. Six (out of eight) lung cancer patients in whom no tumor recurrence was detected were smokers before diagnosis of their disease. Five of them stopped smoking after surgery and one reported to smoke fewer cigarettes. However, because of the conflicting evidence concerning the effects of smoking cessation on $\mathrm{EE}$ and because of the finding of an elevated REE in lung cancer patients even after adjustments for smoking behaviour, we conclude that the fall in REE in lung cancer patients was rather the result of succesful removal of the tumor than of cessation of smoking.

In other conditions where the metabolic rate is elevated, such as in injury or sepsis, hypermetabolism is associated with hypercatabolism, glucose intolerance and preferential fat oxidation, together with an altered hormone profile. In the present thesis in only a limited number of cancer patients total $\mathrm{N}$ in urine was determined, but these values were in the normal range. In a study of Axelrod et al the elevated REE in lung cancer patients was accompanied with normal levels of the stress hormones. Therefore, it is suggested that additional important abnormalities are involved (15).

From the fall in REE in lung cancer patients after succesful removal of the tumor, it appears that the increase in REE in lung cancer patients is induced by the tumor itself. It is unlikely that the metabolic demands of the tumor constitute a significant drain on host metabolism. Even a tumor of only $0.1 \%$ of the weight of the host is able to induce metabolic alterations contributing to weight loss (23). An altemative theory is that tumors induce production of substances that are capable of altering the activity of various host enzymes. In recent years, macrophage products capable of inducing metabolic alterations in both infectious and neoplastic diseases (tumor necrosis factor (TNF), cachectin, interleukines) have been identified (24). Although no detectable increments of TNF levels were found in cancer patients (25), other findings provide circumstantial evidence for TNF or cachectin activity in cancer, eg increased release of TNF by monocytes obtained from patients with cancer (26). However, the hypothesis that some of the metabolic abnormalities in cancer cachexia are due to tumorspecific products or to mediators of the immune system remains to be examined in detail. Furthermore, we have no answer to the question why a tumor in the lung would act differently compared to a tumor in the gastrointestinal tract and why it induces an increase in energy metabolism.

REE was higher in weight-losing lung cancer patients compared to weight-stable lung cancer patients, which suggests that increased REE is causally related to weight loss (chapter 7, figure 2). In GCR cancer patients REE in the weight-losing and the weight-stable group were not different (chapter 8 , table 6). This finding is 
in contrast with the decrease in EE which normally occurs during starvation and weight loss in healthy men and women (27). Therefore, even though REE of GCR cancer patients was not higher than in healthy controls, it was probably greater than expected in those who exhibited weight loss. These weight-losing GCR cancer patients may therefore be considered as relatively hypermetabolic, presumably caused by a tumor effect on energy metabolism. That REE of the weight-losing patients with benign gastrointestinal disease was not different from REE of weightlosing GCR cancer patients (and thus from healthy controls) (chapter 8, table 6) suggests that relative hypermetabolism may not be a cancer-specific phenomenon, but rather a general phenomenon related to weight loss as a consequence of disease. Theoretically, one should compare weight-losing cancer patients with weight-losing elderly healthy controls to identify abnormalities in energy metabolism that are the result of an effect of the tumor.

In the recent literature no study has addressed the impact of longterm fasting on energy metabolism in normal volunteers, except studies in obese subjects (28-31). Classical studies on experimental (semi-)starvation for 1 to 6 months have shown reductions in EE per $\mathrm{kg}$ body weight of $10-20 \%(32,33)$. However, the fall in EE is less in moderate fasting. Semi-starvation ( $50 \%$ of usual intake) in healthy volunteers for 1 to 7 days showed a decrease in 24-h EE of 2-6\% (34,35). Garby et al reported no change in 24-h EE in normal subjects after a 12-week period of moderately decreased EI (75\% of usual intake) (36). If and to what extent the patients in the current study are (semi-) starved, remains unclear, because data on EI are available in only a small group of patients (chapter 10). However, the influence of moderate fasting on energy metabolism is small in view of the available data in the literature. Therefore, in weight losing GCR cancer patients the tun:or has probably little impact on energy metabolism.

In a small group of cancer patients ( $22 \mathrm{GCR}$ and 17 lung) the relative contribution of a reduced food intake to the development of weight loss was studied. Energy intake (EI) in GCR cancer patients was not different from EI in lung cancer patients or healthy controls (chapter 10, table 3). Approximately one third of GCR cancer patients reported a reduction in EI compared to pre-disease intake in contrast to only one (out of 17) lung cancer patient. The small number of patients studied precludes definite conclusions concerning the contribution of anorexia to the development of cancer cachexia. It is difficult to obtain reliable data on food intake, especially for the pre-disease period. The patient must be aware that his eating behaviour has changed, which is, especially in the early stages of cancer, not often the case. Another problem may be that patients deny changes in food intake, but nonetheless have a decreased EI. Several studies have assessed the validity of retrospective dietary interviewing (37-40) and have suggested that the past food intake is influenced by current dietary habits. One study reported that healthy elderly people overestimate their past food intake (40). Whether newly 
detected cancer patients overestimate their pre-disease $\mathbb{E I}$ is unknown. That anorexia has a role during the early phase of weight loss is difficult to demonstrate, because of the wide intra- and interindividual variation in food intake. Small differences in EI may therefore be obscured. Our results agree with those of von Meyenfeldt et ai who reported that anorexia occurred more frequently in newly detected gastric cancer patients than in newly detected colorectal cancer patients (41). The role of insufficient food intake as a cause of weight loss must also be considered relative to an increased EE. El of the lung cancer patients was equal to 1.25 times their REE, which was lower, although not significantly, than EI in GCR cancer patients and in healthy controls (1.43 and 1.41 times REE, respectively). In heterogeneous patient groups in which both $\mathrm{EI}$ and $\mathrm{EE}$ were measured, EI was shown to be relatively low compared to EE $(15,42)$.

Weight loss occurs when dietary intake does not balance EE. Total EE consists usually of three components: REE, diet-induced thermogenesis and $\mathrm{EE}$ due to physical activity (43). REE is the major determinant of total EE in elderly patients (65-70\%) and is the only component in this study that is measured. Only a few studies have measured 24 -h EE in malignant disease, again yielding conflicting results $(42,44)$. The possibility that diet-induced and work-induced thermogenesis is stimulated to a greater extent in tumor-bearing man than in healthy individuals was not explored thoroughly in this thesis.

The results of this thesis suggest that weight loss in GCR cancer patients is initiated by decreased food intake, whereas increased REE is the primary event in the initiation of weight loss in lung cancer patients, resulting in a relatively low EI. The cachexia syndrome is a difficult problem in the management of cancer patients. The current study suggests a different approach in patients with different tumor types. Thus, the development of anorexia seems the main problem in GCR cancer patients, inducing a need for research and therapy in this direction. This is in contrast with lung cancer patients who need to increase their apparently normal food intake in order to balance increased energy requirements. The fact that we could not find other causes for increased EE in lung cancer patients than the presence of the tumor itself, strongly suggests that the interaction between tumor and host, and specifically potential modulators that are generated, needs to be further explored.

In conclusion, the most important observations in the studies reported in this thesis are:

- The presence of the tumor in GCR cancer patients has little or no impact on energy metabolism.

- The presence of the tumor in lung cancer patients results in an elevated REE. This appears to be a primary result of the presence of the tumor and not the result of 
secondary tumor effects, like intrapulmonary shunting, intrapulmonary infilurates, etc.

- Weight loss in GCR cancer patients is initiated by decreased food intake. An increased REE is the primary event in the initiation of weight loss in lung cancer patients.

Further conclusions from this thesis are:

- Measurement of bioelectrical impedance seems a quick, easy and reliable mehod to assess body composition in GCR and lung cancer patients.

$-\mathrm{REE}$ measurement is highly reproducible both in hospitalized patients and in outpatients, with no consistent discrepancy between these two procedures of REE measurement.

- REE can not be measured at any time of the day; the REE measurement is influenced by diet-induced thermogenesis for several $(>2)$ hours.

- Energy requirements for patients undergoing uncomplicated major elective surgery are lower than generally presumed

- Commonly used prediction equations (such as the HB equation) underestimate REE of healthy elderly people.

- It is difficult to predict individual energy requirements accurately in elderly people due to large between-subject variation in REE.

\section{REFERENCES}

1. Harris JA, Benedict FG. A biometric study of basal metabolism in man. Publication no 279 . Washington DC: Carnegie Institute of Washington 1919.

2. Boothby WM, Berkson J, Dunn HL. Studies on the energy of metabolism of normall individuals: A standard for basal metabolism with a nomogram for clinical application. Am J Physioll 1936;3:468-483.

3. Dempsey DT, Feurer ID , Knox LS et al " Energy expenditure in mainourished gastrointestinal cancer patients. Cancer 1984;53:1265-1273.

4. Roza AM, Shizgal HM. The Harris Benedict equation reevaluated: resting energy expenditure and the body cell mass. Am J Clin Nulr 1984;40:168-182.

5. Daly JM. Heymsfield $\mathrm{SB}$, Head $\mathrm{A}$ et al. Human energy requirements: overestimation by widely used prediction equation. Am J Clin Nutr 1985;42:1170-1174.

6. Feurer ID, Crosby LO, Mullen JL. Measured and predicted resting energy expenditure in clinically stable patients. Clin Nutr 1984:3:27-34.

7. Owen OE, Kavle E, Owen RS et al. A reappraisal of caloric requirements in thealthy women. Am J Clin Nutr 1986;44:1-19.

8. Owen OE, Holup JL, D'Alessio DA et al. A reappraisal of the caloric requirements of men. Am I Clin Nutr 1987:46:875-885.

9. Hansell DT, Dawies JWL, Burns HJG. The relationship between resting energy expenditure and weight loss in benign and malignant disease. Ann Surg 1986;203:240-245.

10. Nixon DW, Kutner M, Heymsfield S et all. Resting energy expenditure in lung and colon cancer. Metabolism 1988;37:1059-1064. 
11. Lindmark L, Bennegard K, Edén E et al. Resting energy expenditure in malnourished patients with and without cancer. Gastroenterology 1984;87:402-408.

12. Hansell DT, Davies JWL, Burns. HUG. The effects on resting energy expenditure of different tumor types. Cancer 1986:58:1739-1744.

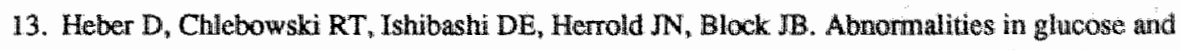
protein metabolism in noncachectic lung cancer patients. Cancer Res 1982;42,48154819.

14. Fearon $\mathrm{KCH}$, Hansell DT, Preston $\mathrm{T}$ et al. Influence of whole body protein tumover rate on resting energy expenditure in patients with cancer. Cancer Res 1988;48:2590-2595.

15. Axelrod L, Halter JB, Cooper DS, Aoki TT, Roussell AM, Bagshaw SL. Hormone levels and fuel now in patients with weight loss and lung cancer. Evidence for excessive metabolic expenditure and for an adaptive response mediated by a reduced level of 3,5,3-triodothyronine. Metabolism 1983;32:924-937.

16. Schols AMWJ, Mostert R, Soeters PB, Greve LH, Wouters EFM. Resting energy expenditure in COPD. Eur Respir $\int 1989 ; 2 ; 359 S$

17. Hofstefter $A$, Schutz $Y$, Jequier $E$ el al. Increased 24-hour energy expenditure in cigarette smokers. N Engl J Med 1986;314:79-82.

18. Glauser SC, Glauser EM, Reidenberg MM, Rusy BF, Tallarida RJ. Metabolic changes associated with the cessation of cigarette smoking. Archs Environ Hith 1970;20:377-381.

19. Dallosso HM, James WPT. The role of smoking in the regulation of energy balance. Int I: Obes 1984;8:365-375.

20. Boekholt HA, Beek A van der, Zegwaard M, Schreurs VVAM. De invloed van roken op het energieverbruilk. Voeding 1988,49:288-289.

21. Burse RL, Bynum GD, Pandolf KB, Goldman RF, Sims EAH, Danforth ER. Increased appetite and unchanged metabolism upon cessation of smoking with diet held constant. Physiologist 1975;18:157.

22. Stamford BA, Matter S, Fell RD, Papanek P. Effects of smoking cessation on weight gain, metabolic rate, caloric consumption, and blood lipids. Am J Clin Nutr 1986;43:486-494.

23. Morrison SD. Control of food intake in cancer cachexia: A challenge and a tool. Physiol Behavior 1976;17:705-714.

24. Beutler B, Cerami A. Cachectin: more than a tumor necrosis factor. N Engl I Med $1987: 316: 379-385$.

25. Scuderi P, Lam KS, Ryan KJ et al. Raised serum levels of tumour necrosis factor in parasitic infections. Lancet 1986;ii:1364-1365.

26. Aderka D, Fisher S, Levo $X$, Holtomann H, Hahn T, Wallach D. Cachectin/tumour-necrosisfactor production by cancer patients. Lancet 1985;il:1190.

27. Brennan MF. Uncomplicated starvation versus cancer cachexia. Cancer Res $1977 ; 37: 2359$ 2364.

28. Apfelbaum M, Bostsarron J, Lacatis D. Effect of caloric restriction and excessive calloric intake on energy expenditure. Am J Clin Nutr 1971;24:1405-1409.

29. Webb P. Abrams T. Loss of fat stores and reduction in sedentary energy expenditure from undereating. Hum Nutr:Clin Nutr 1983;37C:271-282. 
30. Boer 30 de, Es AJH valn Roovers CA, Radil JMA van, Hautwast JGAJ. Adaptation of energy metabolism of overweight women to low-energy intake, studied with whole-body calorimeters. Am J Cln Nutr 1986:44:585-595.

31. Dale D wan. Diet and exercise in the treatment of obesity. Thesis. Meppel: Krips Repro 1989.

32. Benedict FG. A study of prolonged fasting. Publication no 203. Washington DC: Carnegie Institute of Washington $19 \rrbracket 5$.

33. Keys A, Brozek, Henschel A et al. The biology of hunan starvation. Minneapolis: The University of Minnesota Press 1950.

34. Dauncey MJ. Metabolic effects of altering the 24-h energy intake in man, using direct and indirect calorimetry. Br J Nutr 1980;43:257-269.

35. Es AJH van, Vogt JE, Niessen C et al. Human energy metabolism below, near and abowe energy equilibrium. Br J Nutr 1984;52:429-442.

36. Garby L, Kurzer MS, Lammert O, Nielsen E. Effect of 12 weeks" light-moderate underfeeding on 24-hour energy expenditure in normal male and female subjects. Eur $\mathrm{J}$ Clin Nutr $1988 ; 42 ; 295-300$.

37. Jain $\mathrm{M}$, Howe $\mathrm{GR}$, Johnson $\mathrm{KC}_{\mathrm{p}}$ Miller $\mathrm{AB}$. Evaluation of a diet history questionnaire for epidemiologic studies. Am J Epidemiol 1980;111:212-219.

38. Byers TE, Rosenthal RI, Marshall JR, Rzepka TF, Cummings KM, Graham S. Dietary history from the distant past: A methodological study. Nutr Cancer 1983;5:69-77.

39. Leeuwen FE van, Vet HCW de, Hayes RB, Staveren WA van, West CE, Hautvast JGAJ. An assessment of the relative validity of retrospective interviewing for measuring dietary intake. Am J Epidemiol 1983;118:752-758.

40. Bakkum A, Bloemberg B, Staveren WA, Verschuren M, West CE. The relative validity of a retrospective estimate of food consumption based on a current dietary history and food frequency list. Nutr Cancer 1988;11:41-53.

41. Meyenfeldt MF won, Visser G, Buil-Maassen R, Soeters PB, Wesdorp RIIC. Food intake and nutritional status in patients with newly detected gastric or colorectal cancer. Clin Nutr $1988 ; 7: 85-91$.

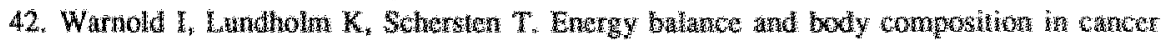

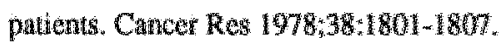

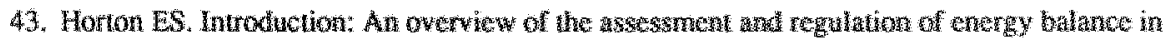
lumans. Am I Cin Nut 1983,38,972977.

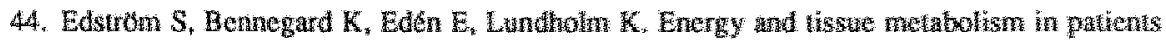
with cancer diring nutritional support. Arch Ote 


\section{SUMMARY}

Cancer is second to cardiovascular disease as the most important cause of death in Western industrialized countries. Weight loss occurs frequently in patients with cancer. It may be one of the presenting symptoms or it may occur with advancing disease. Patients with cancer and no weight loss have a longer survival than patients with weight loss. The condition of extreme weight loss is known as cancer cachexia. Weight loss is caused by a negative energy balance, resulting from decreased energy intake or increased energy expenditure. In this thesis most attention was given to the hypothesis of an increased resting energy expenditure (REE) as contributing factor in the development of weight loss in cancer cachexia.

In chapter 2 a description of the ventilated hood system was given, constructed to assess REE in patients.

It is generally accepted that REE is normalized for fat free mass because adipose tissue contributes little to energy expenditure in humans. The bioelectrical impedance method is a promising new technique for assessing body composition in patients. This method was validated in cancer patients using deuterium dilution as a reference method. A good correlation between total body water as measured by deuterium dilution and height squared divided by resistance was demonstrated, which indicates that bioelectrical impedance seems a useful measure of body composition in these patients (chapter 3).

The availability of equipment for measuring energy expenditure in patients emphasizes the question when and how such measurements should be made. In this thesis REE was measured in the morning after an overnight fast. The reproducibility of the measurement was high. Several factors that are known to influence energy metabolism, such as nutritional support, food intake, physical activity, and recent operation were studied. REE measured in the afternoon was $15 \%$ higher than REE measured in the morning. REE measured at mid-moming was not different from that measured early in the morning, except for patients who had breakfast between the two measurements. Limited physical activities had no influence on REE measurement, including a short travel from home to the hospital. This implies that REE can be measured on an outpatient basis. The effect of total parenteral nutrition (1.5 times REE) on energy metabolism was a $12 \%$ increase. while nine days of discontinuous enteral feeding did not increase REE substantially. However, respiratory quotient rose to almost 1.0 on the parenteral nutrition regimen and increased from 0.78 to 0.87 after enteral feeding support (chapter 4). 
To assess the impact of surgical trauma on energy metabolism REE was determined before and one week after surgery in patients with gastric and colorectal cancer. Postoperative REE was significantly higher than preoperative REE, which could be explained by the administration of total parenteral nutrition, by an increased body temperature mainly as a consequence of postoperative complications and by the surgical trauma itself. Postoperative REE in patients who suffered from (minor) complications was increased by $10 \%$. Patients that had undergone uncomplicated surgery showed a slight increase of $3 \%$ in REE after operation. Therefore, energy requirements for patients that underwent major surgery one week previously were lower than generally presumed (chapter 5).

In order to investigate the contribution of elevated energy expenditure to the development of weight loss REE was measured in two groups of cancer patients: patients with newly detected gastric and colorectal cancer and patients with newly detected non-small cell lung cancer. These patients had not been treated previously with chemotherapy, radiotherapy or surgery. Measured REE was compared with predicted REE calculated by the Harris Benedict formula. Patients with a measured REE above $115 \%$ of that predicted by the Harris Benedict formula were considered hypermetabolic. REE in these cancer patients was also compared with REE of a group of apparently healthy elderly controls, which were measured on an outpatient basis. The reproducibility of these REE measurements proved to be high. There was no significant difference in REE in healthy volunteers measured after they had spent the night in the hospital or measured after they had come from home. The results of REE in healthy volunteers revealed that the Harris Benedict equation underestimates REE by $7 \%$. REE in this group was highly correlated with fat free mass and body weight. However, the use of a prediction equation for REE may result in an over- or underestimation of approximately $10-20 \%$ for individuals due to large between-subject variations (chapter 6).

Sixty percent of lung cancer patients had REE's which were higher than $15 \%$ of the Harris Benedict formula. REE of lung cancer patients was also elevated in comparison to REE in gastric and colorectal cancer patients and in healthy controls. Tumor stage, tumor localisation, pulmonary function or smoking behaviour could not explain the observed increase in REE. These metabolic alterations, therefore, appear to be tumor mediated. To investigate this tumor mediated thermogenesis REE was measured once again one year after tumor resection in patients that survived. Patients in which tumor recurrence was not likely had a significant decrease in REE to a normal level, while patients who had evidence of tumor recurrence showed no change in REE or even an increase. Thus, the presence of the tumor itself resulted in an elevated REE in lung cancer patients (chapter 7, chapter 9). 
REE in gastric and colorectal cancer patients was compared with two groups of controls without cancer: healthy controls and patients with nonmalignant diseases of the gastrointestinal tract. REE in gastric and colorectal cancer patients was not significantly different from REE in patients with benign disease of the gastrointestinal tract or healthy controls. In gastric and colorectal cancer patients that survived REE measurement was repeated one-and-a-half year after tumor resection. A small but significant increase in REE was observed in both gastric and colorecatal cancer patients with or without signs of tumor recurrence. Thus in gastric and colorectal cancer patients the presence of a tumor did not have a clear impact on energy metabolism (chapter 8, chapter 9).

REE was higher in weight-losing lung cancer patients compared to weight-stable lung cancer patients (chapter 7). In gastric and colorectal cancer patients there was no difference in REE between the weight-losing and the weight-stable state. The decrease in energy expenditure which normally occurs during starvation and weight loss in healthy men and women was not shown in weight-losing cancer patients. Therefore, weight-losing gastric and colorectal cancer patients probably are relatively hypermetabolic. The fact that both gastric and colorectal cancer patients and patients with benign diseases of the gastrointestinal tract fail to adapt to starvation implies that relative hypermetabolism may not be a cancer-specific phenomenon, but may be a general phenomenon of weight loss as a consequence of disease (chapter 8). No significant differences in REE were found when patients with liver metastases were compared with patients without metastases. There were also no differences in REE between gastric and colorectal cancer patients (chapter 8).

The last study determined both the relative contribution of an increased REE and a decreased energy intake to the development of weight loss in gastric and colorectal and lung cancer patients. REE in lung cancer patients was significantly increased when compared to healthy controls even when corrected for body composition. Gastric and colorectal cancer patients had no elevated REE compared to healthy controls. No significant differences in energy intake were established between the three groups. Approximately one third of gastric and colorectal cancer patients reported a reduction in food intake compared to pre-disease intake, in contrast to only one (out of 17) lung cancer patient. Although these semi-starving gastric and colorectal cancer patients showed some metabolic changes consistent with underfeeding, no adaptational decrease in REE was observed. It was suggested that weight loss occurring in gastric and colorectal cancer patients is initiated by decreased food intake. An increased REE is the primary event in the initiation of weight loss in lung cancer patients (chapter 10). 
From our study it is concluded that different tumor types have differing effects on REE in cancer patients. In gastric and colorectal cancer patients the presence of the tumor has little impact on energy metabolism in contrast to lung cancer patients where the presence of the tumor results in an elevated REE. This increase in REE in lung cancer patients appears to be a primary effect of the tumor and not the result from secondary sequelae of the tumor. The mechanisms underlying this tumor induced hypermetabolism deserve further study. 


\section{SAMENVATTING}

Kanker is na hart- en vaatziekten de belangrijkste doodsoorzak in geïndustrialiseerde landen. Gewichtsverlies komt veelvuldig voor bij patiënten met kanker en is vaak eén van de symptomen waarmee de patiënt zich presenteert. Patiënten met kanker zonder gewichtsverlies leven langer dan patiẻnten met gewichtsverlies. Als een extreem gewichtsverlies is opgetreden wordt wel gesproken van kanker cachexie. Gewichtsverlies wordt waarschijnlijk voornamelijk veroorzaakt door een negatieve energiebalans, die de resultante is van een verminderde energie-opname of/en een verhoogd energiegebruik. Dit proefschrift schenkt de meeste aandacht aan de hypothese van een verhoogde ruststofwisseling als oorzakelijke factor in het ontstaan van gewichtsverlies bij kanker cachexie.

In hoofdstuk 2 wordt het ventilated hood systeem beschreven, dat gemaakt is om de ruststofwisseling van gezonde mensen èn van patiënten te meten.

Het is vrij gebruikelijk om de ruststofwisseling uit te drukken per $\mathrm{kg}$ vet vrije massa, omdat vetweefsel weinig bijdraagt aan het totale energiegebruik van mensen. De bio-electrische impedantie methode lijkt een waardevolle nieuwe techniek om de lichaamssamenstelling van patiënten te schatten. Deze methode werd gevalideerd bij kankerpatiënten, waarbij de deuterium verdunningsmethode als referentie gold. Theoretisch bestaat er een lineair verband tussen vetvrije massa of totaal lichaamswater en lengte $2 /$ resistance. Ook in deze studie correleerde totaal lichaamswater gemeten met de verdunningsmethode goed met lengte $2 /$ resistance. Dit lijkt er op te duiden dat de bio-electrische impedantie methode bruikbaar is om de vetvrije massa van deze patiënten te bepalen (hoofdstuk 3 ).

De beschikking over apparatuur om energiegebruik van patiënten te meten doet vragen ontstaan over de condities waaronder dit soort metingen gedaan moeten worden. In dit onderzoek geschiedde de ruststofwisselingsmeting in de ochtenduren, terwijl de patiènt nog nuchter was. De reproduceerbaarheid van een meting onder dergelijke condities was hoog. Verschillende factoren beïnvloeden het energiemetabolisme. De invloed van voedingsondersteuning, voedselopname, lichamelijke activiteit en een recente operatie op de ruststofwisseling werd bestudeerd. Wanneer de patiënt 's ochtends nuchter bleef was er geen verschil in ruststofwisseling gemeten 's ochtends vroeg of halverwege de ochtend. Lichte lichamelijke activiteit had weinig invloed op de ruststofwisseling. Ook de invloed van activiteiten voorafgaande aan een poliklinische meting van de ruststofwisseling was verwaarloosbaar. Het toedienen van parenterale woeding (1.5 keer ruststofwisseling) resulteerde in een $12 \%$ toename van het energiegebruik; het 
respiratoir quotiènt steeg tot bijna 1.0. Het drinken van enterale voeding deed de ruststofwisseling nauwelijks stijgen; echter het respiratoir quotiênt steeg van 0.78 tot 0.87 (hoofstuk 4).

On de invloed van operatie-trauma op energiemetabolisme te bepalen werd de ruststofwisseling gemeten van patiènten met maag- en dikke darmkanker vóór en één week na operatie. De ruststofwisseling na operatie was significant hoger dan ervoor. Deze stijging was te verklaren door de toediening van parenterale voeding, door een verhoogde lichaamstemperatuur voornamelijk als gevolg van postoperatieve complicaties en door het operatie-trauma zelf. Patiënten met minder ernstige postoperatieve complicaties lieten een stijging van $10 \%$ in ruststofwisseling zien. Patiènten met een ongecompliceerd postoperatief verloop hadden een stijging van slechts $3 \%$. Deze resultaten duiden er op dat de energiébehoefte van patiënten één week na een grote buikoperatie lager is dan algemeen wordt aangenomen (hoofdstuk 5).

Om de bijdrage van een werhoogde ruststofwisseling aan het ontstaan van gewichtsverlies te onderzoeken werd de ruststofwisseling gemeten in twee groepen kankerpatiënten: patiënten met een pas ontdekte maligniteit in de tractus digestivus en patiënten met een pas ontdekt niet-kleincellig longcarcinoom. Geen van deze patiënten had al therapie ondergaan. De gemeten ruststofwisseling werd vergeleken met de normaalwaarde berekend volgens de Harris Benedict formule. Patiënten werden als hypermetabool beschouwd wanneer de gemeten ruststofwisseling $115 \%$ of meer bedroeg van de normaalwaarde. Daarnaast werd de gemeten ruststofwisseling van patiënten vergeleken met de ruststofwisseling van een controle groep bestaande uit ogenschijnlijk gezonde oude mensen. Deze controle groep kwam 's ochtends nuchter naar het ziekenhuis. Er was geen verschil in ruststofwisseling bij gezonde vrijwilligers wanneer men de nacht in het ziekenhuis had doorgebracht of wanneer men 's ochtends van huis kwam. Onderzoek bij deze gezonde vrijwilligers toonde aan dat de Harris Benedict vergelijking de ruststofwisseling met $7 \%$ onderschat. De ruststofwisseling van deze mensen correleerde goed met de vetvrije massa en met het lichaamsgewicht. Echter, een regressievergelijking om de ruststofwisseling van individuen te schatten kan een over- of onderschatting wan ongeveer 10-20\% geven als gevolg van grote tussenpersoons variaties (hoofdstuk 6).

Zestig procent van de longkankerpatiënten was hypermetabool (15\% boven de voorspelde waarde). Ook in vergelijking met de ruststofwisseling van maagdarmkankerpatiënten en van gezonde controle personen hadden de longkankerpatiënten een verhoogde ruststofwisseling. Deze toename in ruststofwisseling kon niet verklaard worden door tumorstadium, tumorlocalisatie (perifeer/centraal), longfunctie of rookgedrag. De metabole veranderingen leken daarom door de tumor te zijn geïnduceerd. Om deze tumor geïnduceerde 
thernogenese te onderzoeken werd de ruststofwisseling opnieuw gemeten cén jaar na het operatief verwijderen wan de tumor bij die patiènten die nog in leven waren. Patiënten die blijkens standaard poliklinische controle tumor vrij waren eén jaar na operatie toonden een significante daling van de ruststofwisseling naar een waarde in het normaalgebied. Dit in tegenstelling tot de patiènten met tekenen van tumor recidief, die geen verandering in ruststofwisseling of zelfs een stijging vertoonden. De verhoogde ruststofwisseling bij longkankerpatiènten was dus het resultaat van de aanwezigheid van de tumor zelf (hoofdstuk 7, hoofdstuk 9).

De ruststofwisseling van maagdarmkankerpatiënten werd behalve met de controle groep van gezonde oude mensen vergeleken met een groep patiënten die een nietkwaadaardige aandoening van de tractus digestivus hadden. De ruststofwisseling van de maagdarmkankerpatiënten verschilde niet van de ruststofwisseling van deze beide controle groepen. Na anderhalf jaar werd de ruststofwisseling opnieuw gemeten in die maagdarmkankerpatiënten die nog in leven waren. Zowel de patiënten met als zonder tekenen van tumorrecidief lieten een kleine significante toename van de ruststofwisseling zien. De aanwezigheid van een tumor had dus geen duidelijke invloed op het energiemetabolisme bij maagdarmkankerpatiënten (hoofdstuk 8, hoofdstuk 9).

Longkankerpatiënten met gewichtsverlies hadden een hogere ruststofwisseling dan longkankerpatiënten zonder gewichtsverlies (hoofdstuk 7). Bij maagdarmkankerpatiënten echter was er geen verschil in ruststofwisseling tussen de gewichtsverliezende en gewichtsstabiele patiënten. Normaliter daalt de ruststofwisseling bij gezonde mensen tijdens hongeren en gewichtsverlies. Deze adaptatie leek niet op te treden bij de kankerpatiënten. Het is dus mogelijk dat maagdarmkankerpatiënten met gewichtsverlies relatief hypermetabool zijjn. Deze adaptatie trad echter ook niet op bij patiënten met een goedaardige aandoening van het maagdarmkanaal. Dit suggereert dat relatief hypermetabolisme geen kankerspecifiek fenomeen is, maar een algemeen fenomeen dat optreedt bij gewichtsverlies als gevolg van ziekte. De ruststofwisseling van patięnten met en zonder lever metastasen was niet verschillend. Eveneens waren er geen verschillen in ruststofwisseling tussen patiènten met maagkanker of dikke darmkanker (hoofdstuk 8).

In de laatste studie werd aandacht besteed aan de relatieve bijdrage van een verhoogde nuststofwisseling en een verminderde energie-opname aan het ontstaan van gewichtsverlies bij maagdarm- en longkankerpatiënten. De longkankerpatiënten hadden een verhoogde ruststofwisseling, terwijl de maagdarmkankerpatiënten een ruststofwisseling hadden die vergelijkbaar was met die van een gezonde controle groep. De energie-opname was niet significant verschillend tussen deze drie groepen. Ongeveer één derde van de maagdarmkankerpatiènten gaf aan minder te zijn gaan eten na klachten van hun ziekte, terwijl slechts éen 
longkankerpatiênt (van de 17) een verminderde voedselopname rapporteerde. Hoewel een aantal maagdarmkankerpatiënten die onvoldoende aten, metabole veranderingen wertoonden die samenhangen met ondervoeding, werd er geen adaptatie van de ruststofwisseling waargenomen. Gewichtsverlies bij maagdarmkankerpatiënten lijkt geïnitieerd te worden door een verminderde voedselopname. Bij longkankerpatienten lijkt het ontstaan van gewichtsverlies primair het gevolg van een toegenomen ruststofwisseling (hoofdstuk 10).

Op basis van de studies beschreven in dit proefschrift moet de conclusie zijn dat verschillende typen maligne tumoren de ruststofwisseling van patiënten verschillend beïnwloeden. Bij maagdarmkankerpatiënten lijkt de aanwezigheid van de tumor slechts geringe invloed op het energiemetabolisme te hebben. Bij longkankerpatiënten echter betekent de aanwezigheid van de tumor een stijging van de ruststofwisseling. Deze verhoogde ruststofwisseling lijkt een primair gevolg van de aanwezigheil van de tumor te zijn en niet het resultaat van secundaire tumoreffecten. Verder onderzoek is nodig naar het mechanisme van tumor geïnduceerd lhypermetabolisme. 


\section{ABBREVIATIONS}

A

AM

BI

BMI

BW

${ }^{\circ} \mathrm{C}$

$\mathrm{cm}$

$\mathrm{CO}_{2}$

COPD

$\mathrm{CV}_{\mathrm{w}}$

$\triangle$

EE

$\mathrm{EF}$

EI

FAO

$\mathrm{FEV}_{1}$

FFM

$\mathrm{g}$

GCR

GI

$\mathrm{h}$

H

$\mathrm{HB}$

${ }^{2} \mathrm{H}_{2} \mathrm{O}$

$\mathrm{kcal}$

$\mathrm{kg}$

L.

m

mg

$\min$

$\mathrm{mL}$

n

N

np

$\mathrm{O}_{2}$

$\%$

PIBW

POST

PRE age

morning (ante meridium)

bioelectrical impedance

body mass index

body weight

degree Celcius

centimeter

carbon dioxide

chronic obstructive pulmonary disease

within-subject coefficient of variation

delta

energy expenditure

enteral feeding

energy intake

Food and Agricultural Organization

forced expiratory volume in $1 \mathrm{~s}$

fat free mass

gram

gastric and colorectal

gastrointestinal

hour

height

Harris Benedict

deuterium dilution technique

kilocalorie

kilogram

liter

meter

milligram

minute

milliliter

number

nitrogen

non-protein

oxygen

percentage

percentage ideal body weight

after tumor resection

before tumor resection 


$\begin{array}{ll}\text { R } & \text { resistance } \\ \text { REE } & \text { resting energy expenditure } \\ \text { RQ } & \text { respiratory quotient } \\ \text { s } & \text { second } \\ \text { SCHO } & \text { Schofield } \\ \text { SD } & \text { standard deviation } \\ \text { SE } & \text { standard error } \\ \text { SEE } & \text { sleeping energy expenditure } \\ \text { SEM } & \text { standard error of mean } \\ \text { STPD } & \text { standard ternperature pressure dry } \\ \text { TBW } & \text { total body water } \\ \text { TIBC } & \text { total iron binding capacity } \\ \text { TNF } & \text { tumor necrosis factor } \\ \text { TPN } & \text { total parenteral nutrition } \\ \text { UNU } & \text { United Nations University } \\ \text { WHO } & \text { World Health Organization } \\ \text { y } & \text { year }\end{array}$




\section{NAWOORD}

Op deze plaats wil ik iedereen bedanken, die mij heeft geholpen bij de verwezenlijking van dit proefschrift. Een aantal mensen wil ik graag met name noemen.

In de eerste plaats wil ik mijn (co)-promotoren bedanken:

prof dr ir Wim Saris, die me de kans gaf op dit onderzoek te promoveren; zijn enthousiaste woorden waren een stimulans om met het onderzoek door te gaan;

prof dr Peter Soeters, die altijd tijd voor me wist vrij te maken, ondanks drukke werkzaamheden in de kliniek; zijn inzichten en ideeën waren van veel waarde bij de totstandkoming van dit proefschrift.

dr Maarten von Meyenfeldt; van hem kwam de suggestie het onderzoek met longkankerpatiënten uit te breiden.

De leden van de beoordelingscommissie, prof dr GH Blijham, prof dr F ten Hoor, prof dr JM Kinney, prof de S de Lange en prof dr RIC Wesdorp dank ik voor de kritische wijze waarop zij het manuscript beoordeelden.

I explicitely wish to express my gratitude to prof dr JM Kinney for being present on the day I will defend this thesis.

Margriet Rouflart was altijd bereid om te helpen. $\mathrm{Zij}$ vormde een niet te missen schakel bij de uitvoering van het onderzoek in de kliniek.

Ing Paul Schoffelen ontwikkelde het ventilated hood systeem. Van hem heb ik veel geleerd over respiratiemetingen.

Dr Miel Wouters wil ik graag bedanken voor de prettige samenwerking met de afdeling longziekten.

Dr Amold Kester ben ik dank verschuldigd voor zijn statistische adviezen.

Dr Klaas Westerterp bedank ik voor de samenwerking op het gebied van lichaamssamenstelling.

Ir Annemie Schols wil ik hartelijk bedanken voor haar waardevolle suggesties en bijdragen aan het onderzoek.

Ir Angelie van der Aalst en Ingeborg Deerenberg waren alls studenten nauw bij het onderzoek betrokken.

Ing Loek Wouters bedank ik, omdat ik bij technische problemen altijd een beroep op hem kon doen.

De ontwikkeling van het ventilated hood systeem geschiedde in prettige samenwerking met de firma Mijnhardt. 
Graag wil ik nog bedanken:

drs Resi Buil-Maassen voor de samenwerking ten tijde wan de periop-studie, dr Djoeke van Dale woor het vervangen tjjens vakantieperiodes,

drs Jeroen Meyerink voor het uitvoeren van medische keuringen,

Mieke Janssen voor het analyseren van bloedmonsters,

ing Erik Ulrichts voor de hulp bij de computer,

Gerrie van Wunnik voor een tekening op het laatste moment,

Yolande van de Berghe en Liesbeth van der Ploeg voor het afnemen van dieetanamneses.

De verpleegkundigen van de afdelingen algemene heelkunde, interne geneeskunde en longziekten dank ik voor hun vlotte medewerking.

Tot slot dank ik de patiènten en proefpersonen, die mij in staat hebben gesteld dit onderzoek te verrichten. 


\section{CURRICULUM VITAE}

De auteur werd op 12 januari 1960 in Elsloo geboren. In 1978 behaalde zij het gymnasium- $\beta$ diploma aan het St. Michiel Lyceum te Geleen. In datzelfde jaar begon zij haar studie aan de Landbouwuriversiteit te Wageningen, om in september 1985 het doctoraal-examen te behalen, met Voedingsleer en Inspanningsfysiologie ais hoofdvakken en Gezondheidsleer en Pedagogiek \& Didactiek als bijvakken. Per 1 november 1985 trad zij in dienst als assistent in opleiding (A.I.O.) bij de vakgroep Humane Biologie aan de Rijksuniversiteit Limburg te Maastricht. In nauwe samenwerking met de vakgroep Algemene Heelkunde van het Academisch Ziekenhuis Maastricht werd gedurende vier jaar het in dit proefschrift beschreven onderzoek verricht. 